University of Louisville

ThinkIR: The University of Louisville's Institutional Repository

Electronic Theses and Dissertations

$5-2014$

\title{
Investigation of thiol derivatized gold nanoparticle sensors for gas analysis.
}

Jared S. Stephens 1990-

University of Louisville

Follow this and additional works at: https://ir.library.louisville.edu/etd

\section{Recommended Citation}

Stephens, Jared S. 1990-, "Investigation of thiol derivatized gold nanoparticle sensors for gas analysis." (2014). Electronic Theses and Dissertations. Paper 1383.

https://doi.org/10.18297/etd/1383

This Master's Thesis is brought to you for free and open access by ThinkIR: The University of Louisville's Institutional Repository. It has been accepted for inclusion in Electronic Theses and Dissertations by an authorized administrator of ThinkIR: The University of Louisville's Institutional Repository. This title appears here courtesy of the author, who has retained all other copyrights. For more information, please contact thinkir@louisville.edu. 


\title{
INVESTIGATION OF THIOL DERIVATIZED GOLD NANOPARTICLE SENSORS FOR GAS ANALYSIS
}

\author{
By
}

Jared S. Stephens

B.S., University of Louisville, May 2013

\author{
A Thesis \\ Submitted to the Faculty of the \\ University of Louisville \\ J. B. Speed School of Engineering \\ as Partial Fulfillment of the Requirements \\ for the Professional Degree
}

MASTER OF ENGINEERING

Department of Chemical Engineering

May 2014 

INVESTIGATION OF THIOL DERIVATIZED GOLD

NANOPARTICLE SENSORS FOR GAS ANALYSIS

Submitted by:

Jared Stuart Stephens

A Thesis Approved On

(Date)

by the Following Reading and Examination Committee:

Xiao-An Fu, Thesis Director

James C. Watters

Gamini Sumanasekera 


\section{ACKNOWLEDGEMENTS}

I would like to express my greatest appreciation to everyone who helped me with my thesis especially my advisor, Dr. Xiao-An Fu. He allowed me to explore gas analysis and gain a deeper understanding of higher level research. His guidance and encouragement is unparalleled.

I would like to thank Minh Tran and Zhenzhen Xie for all their help in understanding laboratory equipment and assisting in data collection. They helped create a very positive work environment. Thank you to my classmates and friends whom I discussed my work with. They motivated me to reach my goals.

I am very honored for Dr. James Watters and Dr. Gamini Sumanasekera as my thesis committee members and am thankful for their advice.

I am very grateful to my family for their loving and continued support. It is always encouraging and inspiring. 


\begin{abstract}
Analysis of volatile organic compounds (VOCs) in air and exhaled breath by sensor array is a very useful testing technique. It can provide non-invasive, fast, inexpensive testing for many diseases. Breath analysis has been very successful in identifying cancer and other diseases by using a chemiresistor sensor or array with gold nanoparticles to detect biomarkers. Acetone is a biomarker for diabetes and having a portable testing device could help to monitor diabetic and therapeutic progress. An advantage to this testing method is it is conducted at room temperature instead of 200 degrees Celsius. ${ }^{3}$
\end{abstract}

The objective of this research is to determine the effect of thiol derivatized gold nanoparticles based on sensor(s) detection of VOCs. The VOCs to be tested are acetone, ethanol, and a mixture of acetone and ethanol. Each chip is tested under all three VOCs and three concentration levels $(0.1,1$, and $5.0 \mathrm{ppm})$. VOC samples are used to test the sensors' ability to detect and differentiate VOCs. Sensors (also referred to as a chip) are prepared using several types of thiol derivatized gold nanoparticles. The factors are: thiol compound and molar volume loading of the thiol in synthesis.

The average resistance results are used to determine the VOC selectivity of the sensors tested. The results show a trend of increasing resistance as VOC concentration is increased relative to dry air; which is used as baseline for VOCs. Several sensors show a high selectivity to one or more VOCs. Overall the $57 \mu$ moles of 4-methoxy-toluenethiol sensor shows the strongest selectivity for VOCs tested. 


\section{TABLE OF CONTENTS}

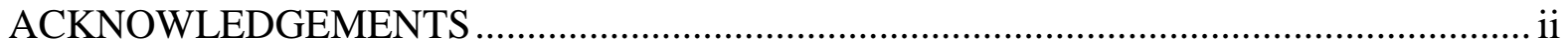

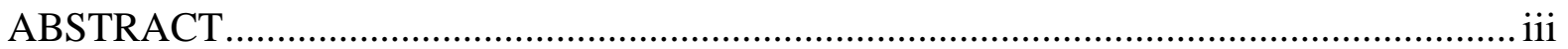

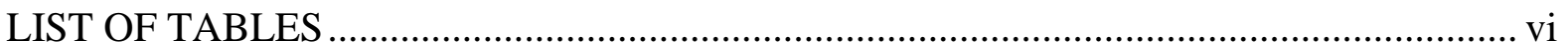

LIST OF FIGURES .................................................................................................. vii

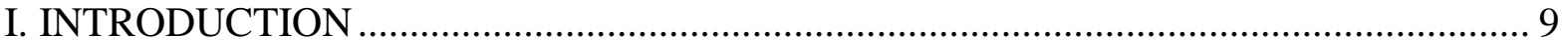

1.1 Motivation to Use Thiol Derivatized Gold Nanoparticles for Breath Analysis ......... 9

1.2 Thiol Derivatized Gold Nanoparticles for Breath Analysis ........................................ 9

1.3 Objectives................................................................................................ 10

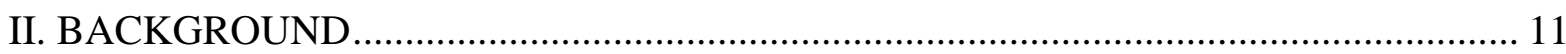

2.1 Introduction to Colloidal Gold Solutions and Chemiresistor Sensors ...................... 11

2.2 Gold Colloidal Redox Reaction .................................................................... 12

2.3 Gibbs Free Energy …………………………………………………………... 13

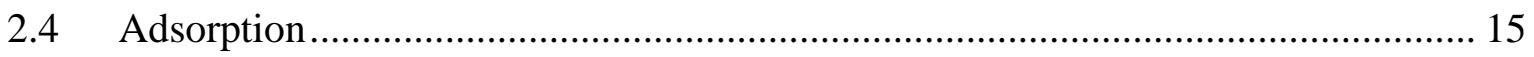

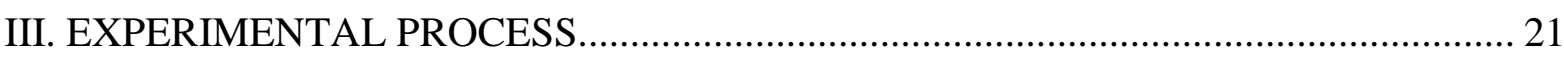

3.1 Synthesis of thiol derivatized gold nanoparticles................................................... 21

3.2 Preparation of thiol derivatized gold nanoparticles electrode sensor chip ............... 26

3.3 Preparation of Gas samples ............................................................................... 26

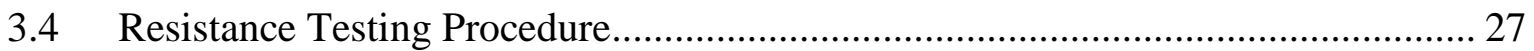

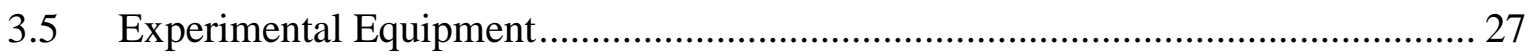

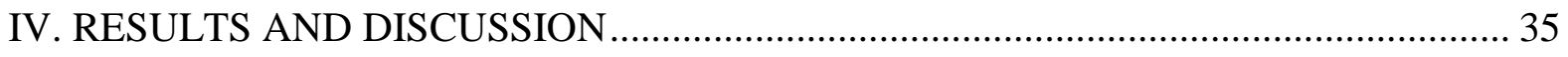

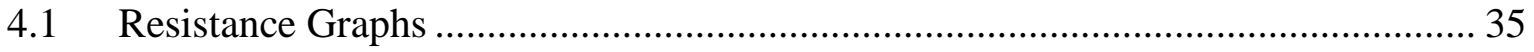

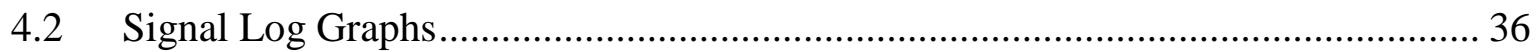

4.3.1 Chip 1A (1-Dodecanethiol and 35 rmoles) Results ........................................... 37

4.3.2 Chip 1B (1-Dodecanethiol and $71 \mu$ moles) Results .............................................. 41

4.3.3 Chip 1C (1-Dodecanethiol and $142 \mu$ moles) Results ........................................... 45

4.3.4 Chip 2A (MATT and 57 pmoles) Results ....................................................... 49

4.3.5 Chip 2B (MATT and 114 pmoles) Results ....................................................... 52

4.3.6 Chip 2C (MATT and 228 mmoles) Results ...................................................... 56

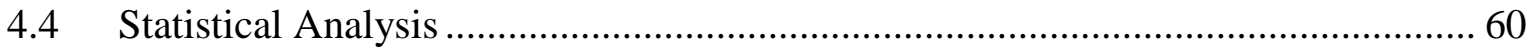

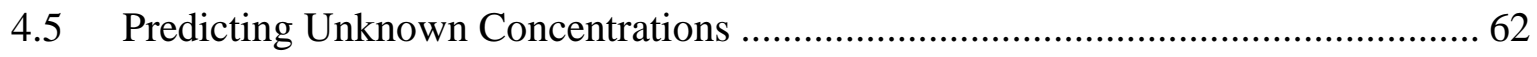

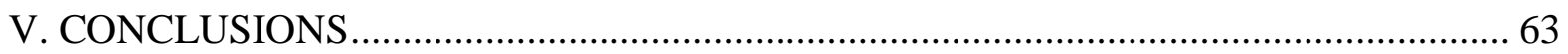




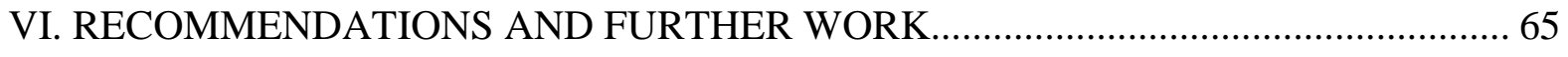

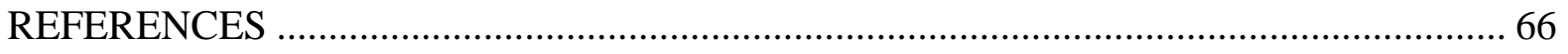

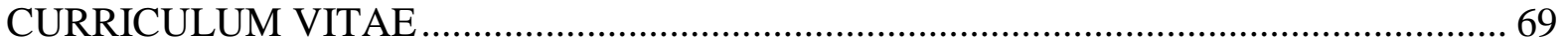




\section{LIST OF TABLES}

Table I: Synthesis Reactants....................................................... 12

Table II: Chip Factor Levels................................................26

Table III: ANOVA Minitab Results...............................................51 


\section{LIST OF FIGURES}

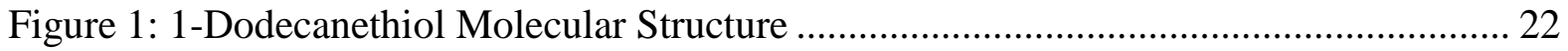

Figure 2: MATT Molecular Structure............................................................................. 22

Figure 3: Monolayer Thiol Derviatized Gold Nanoparticles Diagram ${ }^{24}$............................. 22

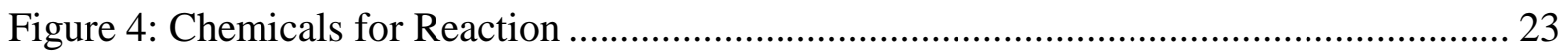

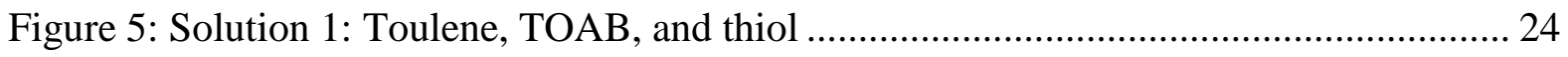

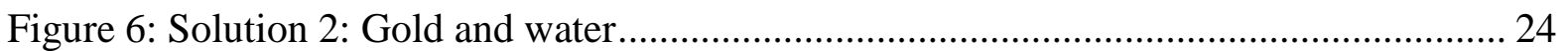

Figure 7: Mixture of Solution 1 and 2: Toluene, TOAB, thiol, gold, and water .................. 25

Figure 8: Mixture of Solution 1, 2, and 3: All reactants mixed ......................................... 25

Figure 9: Container for Nanoparticles in Toluene Dispersion ............................................ 28

Figure 10: Fisher Scientific Vortex Mixer................................................................... 28

Figure 11: Hamilton Microliter Syringe ....................................................................... 29

Figure 12: Keithley Multimeter Model 2400 ............................................................... 29

Figure 13: Vacuum Chamber.......................................................................................... 30

Figure 14: Blank Sensor Chip 10x Magnification: Diameter of $0.1 \mu \mathrm{m}$............................ 31

Figure 15: Sensor Chip with Gold Nanoparticles ............................................................. 31

Figure 16: Supelco Analytical 10 L Bag....................................................................... 32

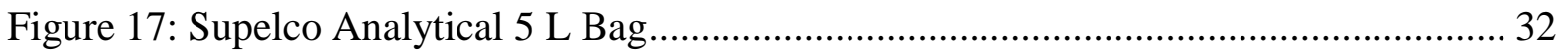

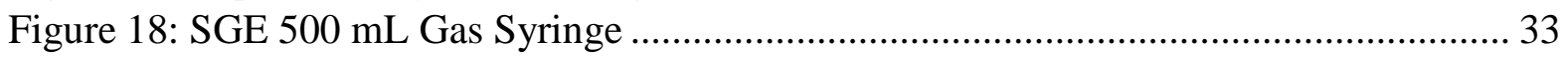

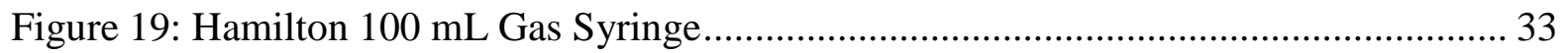

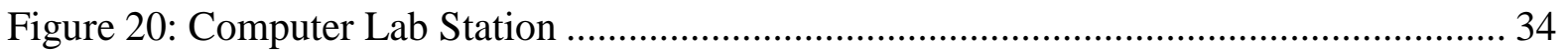

Figure 21: Scanning Electron Microscope of Chip 2A.................................................. 36

Figure 22: Chip 1A (1-Dodecanethiol 35 umoles: 0.049 grams Gold) Acetone Resistance.. 37

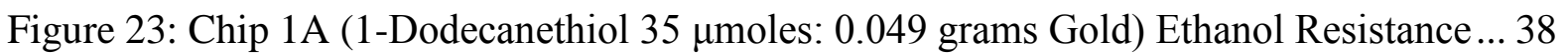

Figure 24: Chip 1A (1-Dodecanethiol 35 umoles: 0.049 grams Gold) Acetone-Ethanol Mix

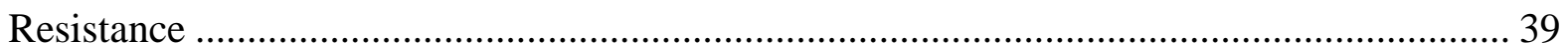

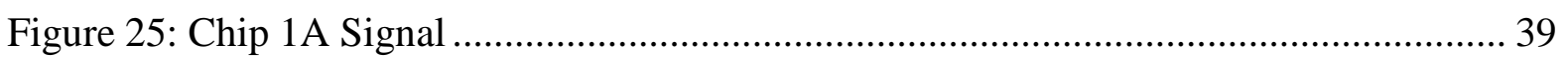

Figure 26: Chip 1A Gold Nanoparticles under 50x magnification.................................... 40

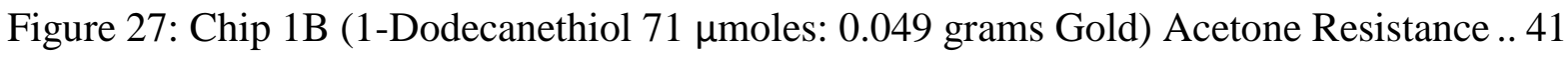

Figure 28: Chip 1B (1-Dodecanethiol 71 umoles: 0.049 grams Gold) Ethanol Resistance ... 42

Figure 29: Chip 1B (1-Dodecanethiol 71 mmoles: 0.049 grams Gold) Acetone-Ethanol Mix

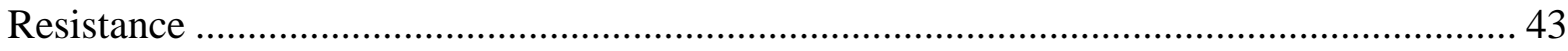

Figure 30: Chip 1B Signal .......................................................................................... 44

Figure 31: Chip 1B Gold Nanoparticles under 50x Magnification...................................... 44

Figure 32: Chip 1C (1-Dodecanethiol 142 umoles: 0.049 grams Gold) Acetone Resistance 45

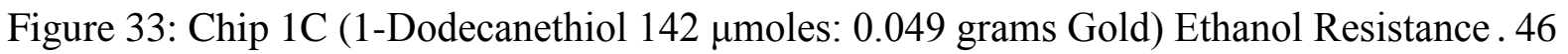
Figure 34: Chip 1C (1-Dodecanethiol 142 umoles: 0.049 grams Gold) Acetone-Ethanol Mix

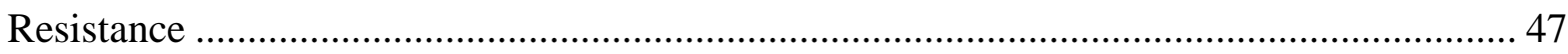

Figure 35: Chip 1C Signal ......................................................................................... 48

Figure 36: Chip 1C Gold Nanoparticles under 50x Magnification...................................... 48

Figure 37: Chip 2A (MATT 57 mmoles: 0.049 grams Gold) Acetone Resistance ................ 49

Figure 38: Chip 2A (MATT 57 moles: 0.049 grams Gold) Ethanol Resistance ................. 50 
Figure 39: Chip 2A (MATT $57 \mu$ moles: 0.049 grams Gold) Acetone-Ethanol Mix Resistance

Figure 40: Chip 2A Signal

Figure 41: Chip 2A Gold Nanoparticles under 50x Magnification ......................................... 51

Figure 42: Chip 2B (MATT 114 umoles: 0.049 grams Gold) Acetone Resistance ................ 52

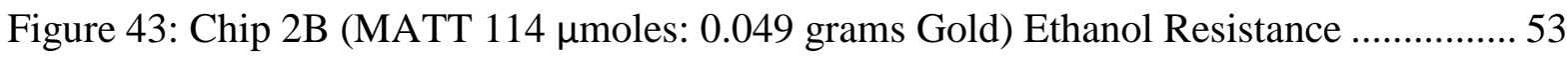

Figure 44: Chip 2B (MATT 114 umoles: 0.049 grams Gold) Acetone-Ethanol Mix

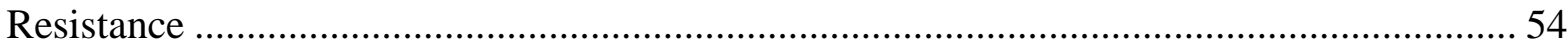

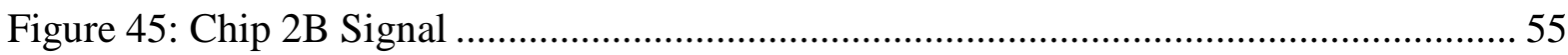

Figure 46: Chip 2B Gold Nanoparticles under 50x Magnification....................................... 55

Figure 47: 2C (MATT 228 4moles: 0.049 grams Gold) Acetone Resistance ......................... 56

Figure 48: Chip 2C (MATT 228 umoles: 0.049 grams Gold) Ethanol Resistance ................. 57

Figure 49: Chip 2C (MATT 228 umoles: 0.049 grams Gold) Acetone-Ethanol Mix

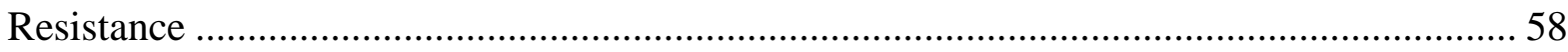

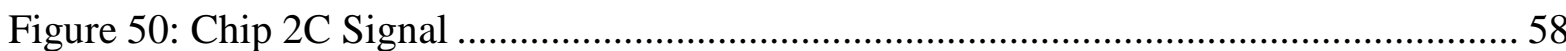

Figure 51: Chip 2C Gold Nanoparticles under 50x Magnification......................................... 59

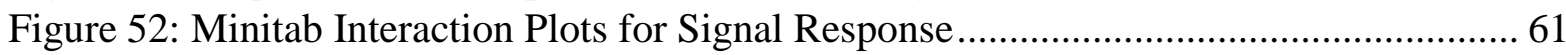




\section{INTRODUCTION}

\subsection{Motivation to Use Thiol Derivatized Gold Nanoparticles for Breath Analysis}

The motivation for using thiol derivatized gold nanoparticles is to be able to conveniently and non-invasively test breath samples of people or air quality for target volatile organic compounds (VOCs). For example, lung cancer screenings are expensive and not very accessible. Gas chromatography and mass spectrometry techniques are used to identify VOC markers for lung cancer and others. ${ }^{12}$ Other breath/gas sensors exist using metal oxides like Tin Oxide and Zinc Oxide as the sensing element and run at 200 degrees Celsius or higher; however the thiol derivatized gold nanoparticles provide a significant advantage of being run at room temperature. Investigating the detection of acetone, ethanol, and a mixture of the two provides insight for diabetes research. The average acetone concentration in a diabetic is 0.8 to $1.8 \mathrm{ppm} .{ }^{23}$ The sensor can provide a portable testing device to monitor disease and therapeutic progress. The low cost and ease of use of the thiol derivatized gold nanoparticle sensors are excellent advantages over invasive and costly tests.

\subsection{Thiol Derivatized Gold Nanoparticles for Breath Analysis}

Thiol derivatized gold nanoparticles are synthesized using a two phase reaction to form stable particles with varying size (diameter of $2-50 \mathrm{~nm}$ ). The particles are used to produce a sensor chip to detect VOCs in gas samples. Certain VOC species have a strong 
correlation to diseases like some cancers and diabetes. Testing the sensors with varying concentrations of VOCs is an excellent way to explore the potential use of this simple device to detect VOCs in gas or breath samples.

\subsection{Objectives}

The objectives of this research project are:

1) Synthesize thiol derivatized gold nanoparticles.

a. Observe the effect of varying the thiol on particles.

b. Observe the effect of varying the thiol molar volume loading to gold weight on particles.

2) Prepare gas sensors with thiol derivatized gold nanoparticles.

3) Study the thiol derivatized gold nanoparticles sensor chips with VOC gas samples of acetone, ethanol, and acetone-ethanol mix.

4) Compare testing results to explore selectivity of VOCs of the sensors.

The experimental factors are thiol compound, ratio of thiol molar volume to gold mass, VOCs, and the concentrations of VOC samples. The measured response is electrical resistance from LabVIEW. 


\section{BACKGROUND}

\subsection{Introduction to Colloidal Gold Solutions and Chemiresistor Sensors}

Faraday prepared colloidal gold solutions by using a two phase system in the $1850 \mathrm{~s}$ by reducing a gold salt solution with phosphorous. ${ }^{2}$ The colloidal gold solutions Faraday synthesized had aggregation issues. The nanoparticles would aggregate, reducing the functionality. ${ }^{1}$ Since Faraday's work, the use of two phase liquid - liquid systems to produce a colloidal gold solution has been improved by various techniques. One important variation used to prepare gold nanoparticles is using a thiol coating by self-assembly. The product is very simple and safe to handle. ${ }^{1}$

The method uses an oxidation reduction (redox) reaction to transfer electrons (potential) from the gold salt solution to allow the thiol compound to self-assemble to the gold. The successful synthesis of the thiol derivatized gold nanoparticles is important to provide a mono-layer of thiol molecules on the surfaces of gold nanoparticles to a sensor. The sensor can be used to test the adsorption and desorption of VOCs in gas or breath samples. The adsorption and desorption can be correlated with a change in electrical resistance across the sensor.

The sensor is a solid-state device that experiences electrical resistance changes due to adsorption or desorption of VOCs or other chemical species. The device consists of an interdigitated electrode (IDE) and two contact pads. The thin film is the monolayers of thiol 
derivatized gold nanoparticles. It is believed that the resistance change is caused by electron tunneling between the gold molecules and the thiol. ${ }^{25}$ The importance of the experiment is its potential use as a sensor to detect certain VOCs based on the thiol attached to the gold nanoparticles. The device is unique because it operates at room temperature where other current VOC sensors require much higher temperatures $\left(200^{\circ} \mathrm{C}\right)$ because current sensors use metal oxides such as Tin Oxide with catalytic doping. ${ }^{5}$

\subsection{Gold Colloidal Redox Reaction}

The following two equations represent the redox reaction to synthesize the thiol derivatized gold nanoparticles. The thiol used in this reaction is 1-Dodecanethiol. The $\mathrm{n}$ to $\mathrm{m}$ ratio is the thiol moles to gold mass and affects the reaction conditions. ${ }^{1}$ This is why one of the testing factors is changing the ratio.

$$
\begin{gathered}
A u C l_{4}^{-}(a q)+n\left(C_{8} H_{17}\right)_{4}+C_{7} H_{8} \rightarrow n\left(C_{8} H_{17}\right)_{4}+A u C l_{4}^{-}\left(C_{7} H_{8}\right) \\
m A u C l_{4}^{-}\left(C_{7} H_{8}\right)+n C_{12} H_{25} S H\left(C_{7} H_{8}\right)+3 m e^{-} \\
\rightarrow 4 m C l^{-}(a q)+\left(A u_{m}\right)\left(C_{12} H_{25} S H\right)_{n}\left(C_{7} H_{8}\right)
\end{gathered}
$$

To show the thermodynamic favorability of the redox reaction, the reduction potentials must be calculated to determine how far away from equilibrium the system is. Nernst developed the following equation to adjust potentials for the redox reaction. ${ }^{17}$

$$
E=E^{0}-\left(\frac{R T}{n F}\right) \ln Q
$$

Where $\mathrm{R}$ is the gas constant, $\mathrm{T}$ is temperature of reaction in Kelvin, $\mathrm{n}$ is the number of electrons transferred, $\mathrm{Q}$ is the stoichiometric concentration ratio of products to reactants, $\mathrm{F}$ is the Faraday constant, $\mathrm{E}^{0}$ is standard potential, and $\mathrm{E}$ is the corrected potential. ${ }^{16}$ The half reactions for reduction and oxidation respectively are shown in equations 4 and 5. 


$$
\begin{gathered}
A u^{3+}(a q)+3 e^{-} \rightarrow A u^{0}(s) \\
3 B H_{4}^{-}(a q) \rightarrow 3 B H_{4}^{0}(a q)+3 e^{-}
\end{gathered}
$$

The potential value determines if the reactants or products are thermodynamically favored. For this experiment the $\mathrm{AuCl}_{4}{ }^{-}$contains the oxidizing agent $\left(\mathrm{Au}^{3+}\right)$, that is reduced to a neutral charge by the $\mathrm{NaBH}_{4}\left(\mathrm{BH}_{4}{ }^{-}\right)$reducing agent. E is calculated to be $0.264 \mathrm{~V}$ at standard pressure and temperature. The greater $\mathrm{E}$ is than $\mathrm{E}^{0}$ means the more products will form more products and vice versa if $\mathrm{E}$ is less than $\mathrm{E}^{0}$. If the reaction was run at a higher temperature it would increase the potential slightly. A temperature increase can result in evaporating the toluene; which could reduce the amount of usable product. The smaller the $\mathrm{Q}$ value the larger $\mathrm{E}$ is, because of the natural logarithm term in equation 3 . The $\mathrm{E}$ is important to show that the products are favored for the reaction. When the synthesis solutions are mixed to conduct the redox reaction a sharp color occurs only in a few seconds

after the reaction is started. A color change is a basic indicator of a chemical reaction taking place and shows the process is thermodynamically favored. Understanding the fundamental thermodynamics of redox reactions helps to recognize what is occurring during synthesis of thiol derivatized gold nanoparticles.

\subsection{Gibbs Free Energy}

The Gibbs free energy is an important parameter to any reaction or system because it determines how spontaneous or favored it is. Also the equilibrium concentration of the redox reaction can be determined from Gibbs as well. The equilibrium concentration uses the changes of Gibbs Free Energy, enthalpy, and entropy because all three are state functions. State functions are properties that are not affected by the path taken from the initial condition 
to the final condition. Gibbs Free Energy (G) does not have any physical reality like enthalpy $(\mathrm{H})$ and entropy $(\mathrm{S})$; it serves as a mathematical idea to simplify calculations of the energy in a system. The fundamental equation is below.

$$
\Delta G=\Delta H-T \Delta S
$$

Equation 7 is the Gibbs relation at equilibrium with $\mathrm{K}$ being the equilibrium constant.

$$
\Delta G=-R T \ln K
$$

Gibbs Free Energy can be defined in term of the system's reduction potential. The derivation is accomplished by relating equation 3 and Gibbs Energy at equilibrium equation 7 because at equilibrium $\mathrm{Q}=\mathrm{K}$ thus producing equation $8 .{ }^{17}$

$$
\Delta G=-n F E
$$

$\mathrm{G}$ is the Gibbs free energy and $\mathrm{n}$ is the number of moles in the redox stoichiometry. In equation 8 it makes sense that an increase in reduction potential will increase the change in Gibbs Free Energy because the higher the reduction potential the more favored the products are. The same holds true for $\mathrm{n}$, the number of moles, because as the moles increase so will the amount of energy available.

The process to produce thiol functionalized gold nanoparticles is conducted at constant temperature and pressure. Gibbs Free Energy is the fundamental variable to determine if a chemical reaction is thermodynamically possible; however kinetics dictates the reaction rate. ${ }^{9}$ It is important to confirm the experimental conditions are favorable for the desired products using the fundamental ideas of Gibbs energy and redox potentials. Understanding the importance of Gibbs Free Energy leads to a better understanding of the experimental synthesis and thermodynamics. 


\subsection{Adsorption}

The adsorption of VOCs to the thiol derivatized gold nanoparticles causes a change in resistance as current travels across the sensor. This is an interesting application of adsorption because normal applications are more industrial like scrubbing flue gas of a particular pollutant. Thermodynamics can connect multiple properties of materials or a process. This is true for adsorption because the temperature coefficient of adsorption is directly related to the heat of immersion of the solid adsorbent. ${ }^{11}$

The adsorption isotherm is the amount of gas adsorbed in the solid as a function of external pressure. Thermodynamics plays an important role in the equilibrium adsorption isotherms. Equilibrium of the system will be reached by either raising or lowering the pressure. For this research the vacuum chamber is filled with the sample, the pressure increases and adsorption will occur. When the sample is evacuated from the vacuum chamber the pressure decreases and desorption occurs. Desorption of VOCs occurs best at a high vacuum and good pump efficiency. Removing the VOCs is important to prepare the sensor for the next sample resistance test. The adsorption and desorption isotherms will match up at equilibrium. A hysteresis occurs if equilibrium is not reached; it can occur in some micro-porous materials. ${ }^{9}$

Equation 9 is a modified virial equation where $\mathrm{P}$ is the pressure in the gas phase, $\mathrm{n}$ is the mole of gas per kilogram of solid, $\mathrm{K}$ is Henry's constant, $\mathrm{m}$ is the saturation capacity, and $\mathrm{C}_{\mathrm{i}}$ are virial coefficients. ${ }^{11}$ The virial equation applies to pure gases and must be modified to fit the mixtures for the breath analysis. 


$$
P(n)=\frac{n}{K} *\left[\frac{m}{m}-n\right] * \exp \left(C_{1} n+C_{2} n^{2}+C_{3} n^{3}\right)
$$

The isotherms are still useful to find $\bar{h}$, the enthalpy of adsorption. The simplified equation to find $\bar{h}$ is below. $\mathrm{R}$ is the gas constant. It is important to note that enthalpy of adsorption is negative because adsorption is exothermic. ${ }^{11}$

$$
\bar{h}=R\left[\frac{\partial \ln P}{\partial\left(\frac{1}{T}\right)}\right]_{n}
$$

Another important equation to the thermodynamics of adsorption is the grand potential.

$$
\Omega=F-\sum_{i} n_{i} \mu_{i}=-P V
$$

Where $\Omega$ is the grand potential, $\mathrm{F}$ is is the Helmholtz free energy, $\mathrm{n}$ is moles, $\mu$ is the chemical potential. This equation is useful because the independent variables: chemical potential, temperature, and volume are needed to describe the adsorption process at constant volume.

The extensive thermodynamic properties (free energy, enthalpy, and entropy) of a system can be derived from equation 11 using three terms. The first term is the value of the property for the adsorbate molecules at equilibrium and the value of the property for the clean solid adsorbent in vacuum. Lastly, the change in the property associated with the immersion of the clean adsorbent in the gas. All the terms are at constant temperature. ${ }^{11}$ The clean adsorbent is important for this research because it provides the clearest resistance results when testing different gas samples for each sensor. 
To apply the grand potential to mixtures the components are set up individually for the amount adsorbed. The experimental gas samples will all be mixtures of air and a VOCs and dry air. The mixtures will be assumed to be tertiary mixtures of a volatile organic compound, $\mathrm{N}_{2}$, and $\mathrm{O}_{2}$. The simplest case will be for dry air which is assumed to be only oxygen and nitrogen.

$$
\begin{gathered}
P y_{1}=P_{1}^{0}\left(n_{1}^{0}, T\right) x_{1} \\
P y_{2}=P_{2}^{0}\left(n_{2}^{0}, T\right) x_{2} \\
P y_{3}=P_{3}^{0}\left(n_{3}^{0}, T\right) x_{3} \\
\Omega_{1}\left(n_{1}^{0}, T\right)=\Omega_{2}\left(n_{2}^{0}, T\right) \\
\Omega_{1}\left(n_{1}^{0}, T\right)=\Omega_{3}\left(n_{3}^{0}, T\right)
\end{gathered}
$$

Equations 12 to 16 are used to solve for the potentials of each component in the mixture to determine how much of a specific component is adsorbed. $\mathrm{P}$ is pressure, $\mathrm{P}^{0}$ is the partial pressure of each component, $\mathrm{T}$ is temperature in Kelvin, $\mathrm{y}$ and $\mathrm{x}$ are the component phase fractions, now $\Omega$ is the energy of immersion, and $\mathrm{n}^{0}$ is the amount adsorbed. For this research the assumption of ideality for the sample gases is sound at standard conditions, thus the fugacity is reduces to the pressure of the system. The ability of the sensors to work at standard temperature and pressure is an excellent benefit too. The above equations are solved to yield enthalpy and entropy values for the system in equations 17 and $18 .{ }^{11}$ And then evaluated on the amount adsorbed, $\mathrm{n}^{0}$, for each component. The exact amount of VOCs adsorbed for each sample was not calculated and the entropy and enthalpy values are used to better understand what is occurring during the sensor testing. 


$$
\begin{aligned}
& H=\sum_{i} n_{i} H_{i}^{0}\left(n_{i}^{0}\right) \\
& S=\sum_{i} n_{i} S_{i}^{0}\left(n_{i}^{0}\right)
\end{aligned}
$$

In fundamental thermodynamics, the chemical potential is a form of potential energy which can be used during many chemical processes. It is an abstract concept; like Gibbs Free Energy, the change in the chemical potential is more important than calculating an absolute chemical potential value.

$$
\mu_{i}=\left(\frac{\partial G}{\partial n_{i}}\right)_{P, T, n_{j}}
$$

Equation 19 is the partial molar Gibbs energy because the independent variables are temperature and pressure. Where $\mu$ is the chemical potential, $\mathrm{G}$ is Gibbs Free Energy, and $\mathrm{n}$ is moles of each component. The independent variables are based on molar quantities. ${ }^{13}$ Also the Gibbs-Duhem equation can be used to characterize the intensive state of the heterogeneous system at equilibrium by the temperature, pressure, and chemical potential.

$$
S d T-V d P+\sum_{i} n_{i} d \mu_{i}=0
$$

The Gibbs-Duhem relates the variables through derivation to solve for the values in a single phase. ${ }^{13}$ The gas samples used in the experiment are single phase with no liquid phase of the VOCs present during the adsorption. The change in pressure will be atmospheric to a partial vacuum. To deal with the abstract nature of chemical potential an auxiliary equation can be used with fugacity. Prausnitz shows this relation in equation 21 and is defined for ideal, pure gas components. The standard state of the chemical potential will fix the standard 
state of fugacity, f. Each cannot be set without affecting the other. ${ }^{13}$ At constant temperature fugacity and chemical potential can be related by the following equation where "a" and "b" are liquid and gas standard state phases, respectively.

$$
\mu_{i}^{0 a}-\mu_{i}^{0 b}=R T \ln \left(\frac{f_{i}^{0 a}}{f_{i}^{0 b}}\right)
$$

Fugacity, f, and chemical potential, $\mu$, are used to provide a conceptual aid in conducting the transition from thermodynamic to physical variables. The thermodynamics of the experimental process can be abstracted and solved with fundamental equations then brought back to the real system conditions. ${ }^{13}$

At equilibrium the VOCs in the adsorption space have the same chemical potential value and is defined by the bulk phase; thus the change in chemical potential at equilibrium is zero. ${ }^{19}$ The chemical potential can be defined for adsorption as a function of the macro or micro surroundings. As a solid adsorbs a gas, the chemical potentials of the surface lattice elements (in the solid) change and the solid will swell to maintain the chemical potential homogeneity in the internal lattice. Electron hopping shows a solid in an external electric field changes in volume because of the changes in the electric field. ${ }^{19}$ Electron hopping could correspond to the VOCs adsorbed to the sensor; thus altering the resistance. The response of the thiol derivatized gold nanoparticle film on the sensor obtains the resistance measurements by electron tunneling between the gold cores. The conductivity of the film is dependent on the core spacing of the gold cores. ${ }^{25}$ For this experiment the solid film on the sensor electron hopping occurs as the VOCs are adsorbed and then desorbed by changing the pressure of the system. The adsorption mechanics are not completely known. Zamborini and other authors 
work provides a strong insight in predicting and hypothesizing the results of the resistances tests due to adsorption. 


\section{EXPERIMENTAL PROCESS}

\subsection{Synthesis of thiol derivatized gold nanoparticles}

Thiol derivatized gold nanoparticles are synthesized by using a similar two phase liquid-liquid system developed by Brust. ${ }^{1}$ The general synthesis materials are the same, except for varying the thiol compound and thiol volume. The reactants in each solution are in Table I.

TABLE I

SYNTHESIS REACTANTS

\begin{tabular}{|l|l|l|}
\hline Solution 1 & Solution 2 & Solution 3 \\
\hline $\begin{array}{l}40 \mathrm{~mL} \text { of toluene }(99.8 \%, \\
\text { Sigma-Aldrich) }\end{array}$ & $\begin{array}{l}\text { 0.1 g of Gold(III) chloride } \\
\text { trihydrate }(99 \%, \text { Sigma-Aldrich) }\end{array}$ & $\begin{array}{l}\text { 0.1 g of sodium borohydride } \\
\text { (NaBH })(99 \%, \text { Fluka } \\
\text { Analytical })\end{array}$ \\
\hline $\begin{array}{l}\text { 1.14 g tetraoctylammonium } \\
\text { bromide (TOAB) }(98 \%, \text { Sigma- } \\
\text { Aldrich) }\end{array}$ & 8 mL Deionized Water & 8 mL Deionized Water \\
\hline Thiol Compound & \\
\hline
\end{tabular}

The thiol compound for synthesis uses a volume of $8.5,17$, or $34 \mu \mathrm{L} .1$-dodecanethiol,

Figure 1, (98\%, Sigma-Aldrich) with a density of $0.845 \mathrm{~g} / \mathrm{mL}$ and molecular weight of 202.4 
g/mole or 4-methoxy-alpha-toluenethiol, Figure 2, (MATT) (90\%, Sigma-Aldrich) with a density of $1.107 \mathrm{~g} / \mathrm{mL}$ and molecular weight of $165.44 \mathrm{~g} / \mathrm{mole}$ are used in synthesis.

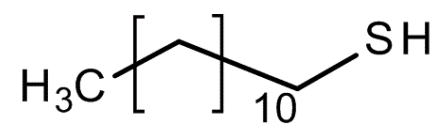

Figure 1: 1-Dodecanethiol Molecular Structure

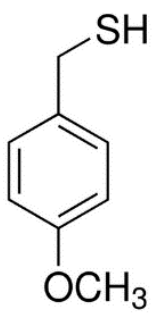

Figure 2: MATT Molecular Structure

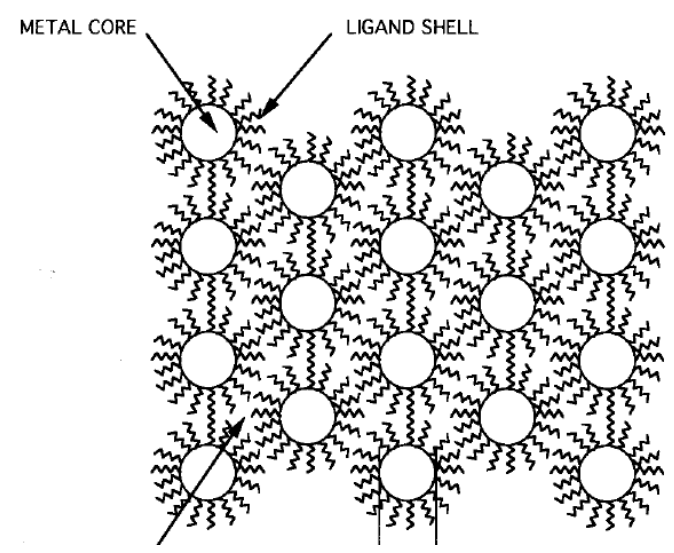

Figure 3: Monolayer Thiol Derviatized Gold Nanoparticles Diagram ${ }^{24}$

Figure 3 is a diagram of what the self-assembly of thiol derivatized gold nanoparticles look like after synthesis. 


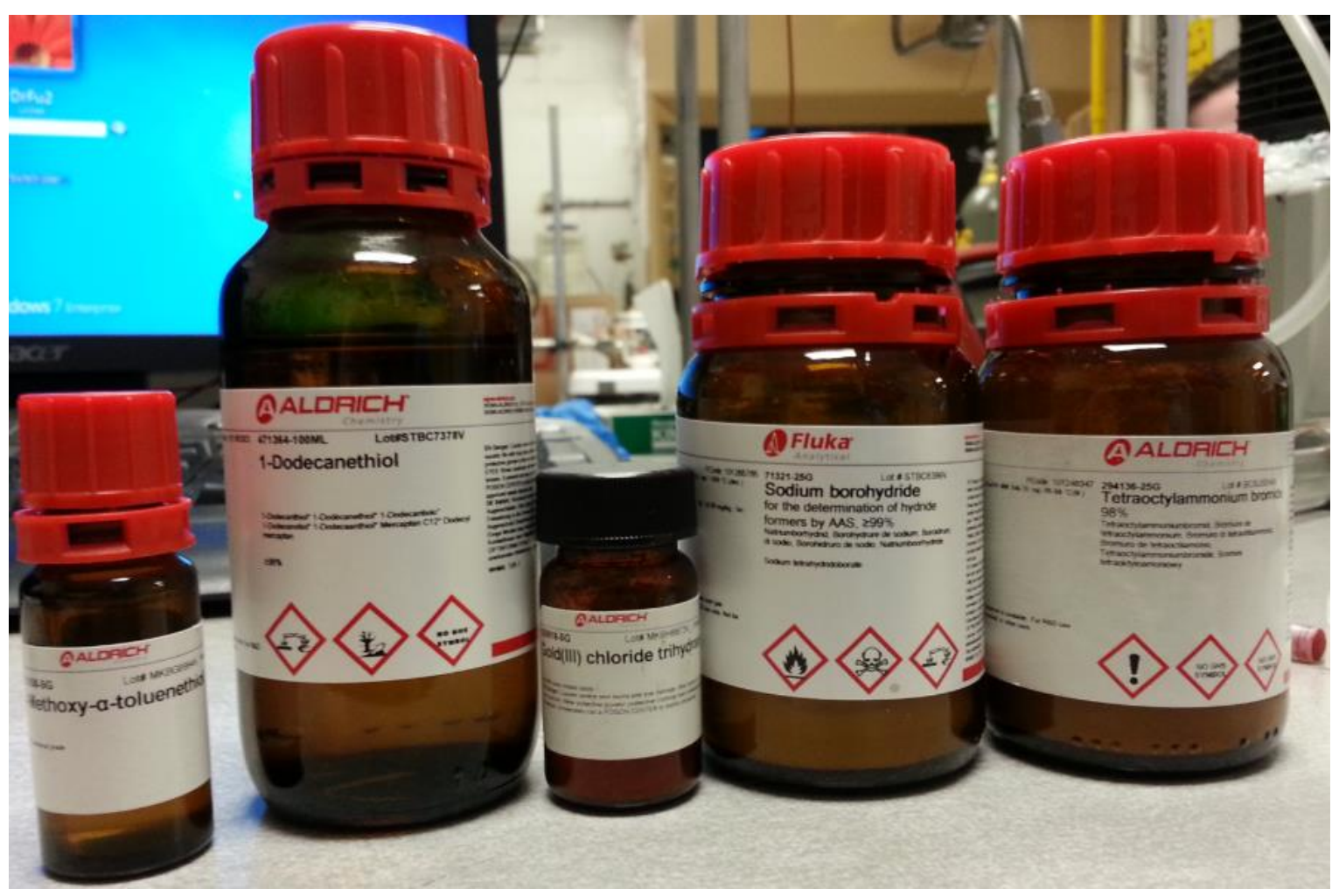

Figure 4: Chemicals for Reaction

First, solutions 1 (Figure 5) and 2 (Figure 6) are mixed well separately then combined to react for 15 minutes. Solution 3 is prepared and then added to the mixture of solutions 1 and 2 (Figure 7) for one hour. The resulting product solution (Figure 8) is composed of organic and inorganic layers. The thiol derivatized gold nanoparticles are present in the organic layer. The organic layer is decanted off the top and then any remaining organic layer is removed by pipetting. ${ }^{1}$

Next the organic layer is purified by casting drop-wise into a solution of ethanol (stirred at about $600 \mathrm{rpm}$ at room temperature). The gold nanoparticles in ethanol are left for about 12 hours to settle out before use. 


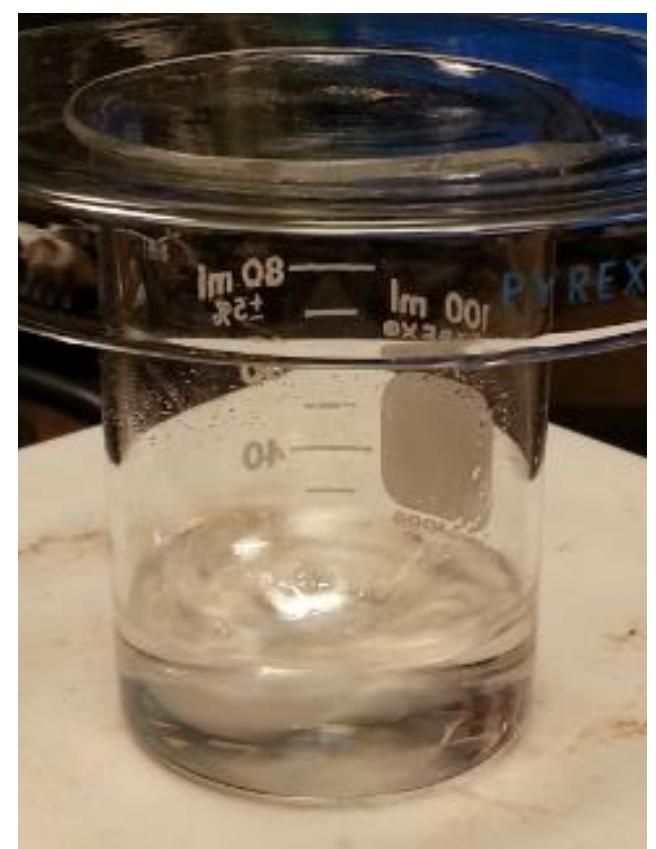

Figure 5: Solution 1: Toulene, TOAB, and thiol

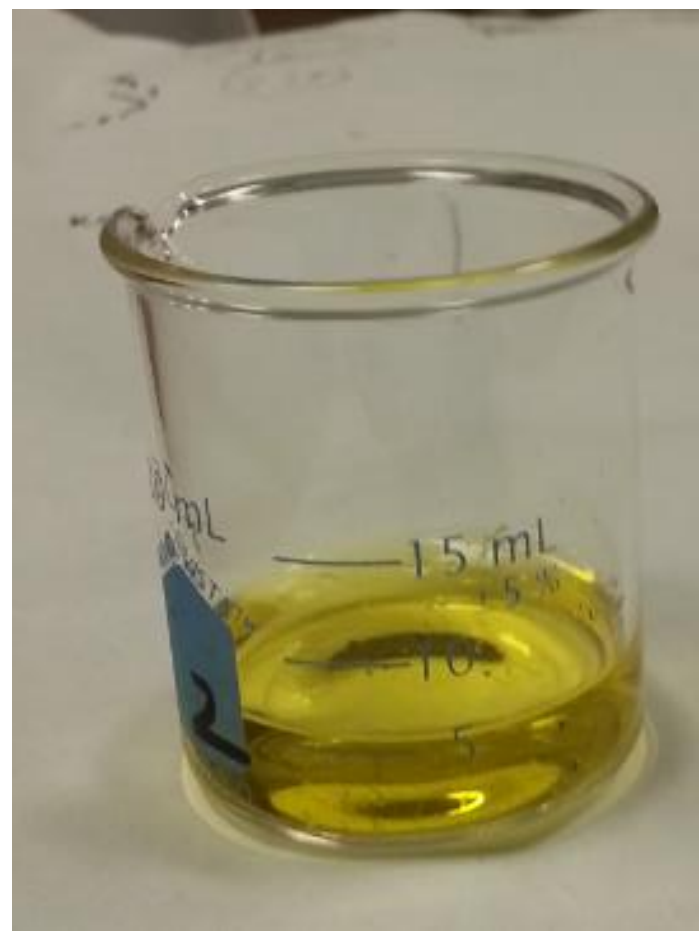

Figure 6: Solution 2: Gold and water 


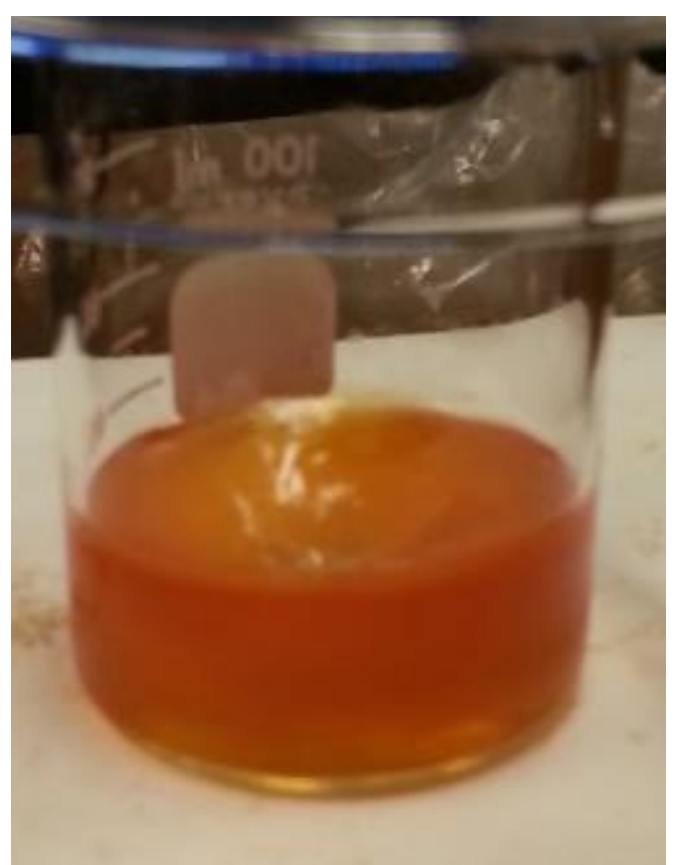

Figure 7: Mixture of Solution 1 and 2: Toluene, TOAB, thiol, gold, and water

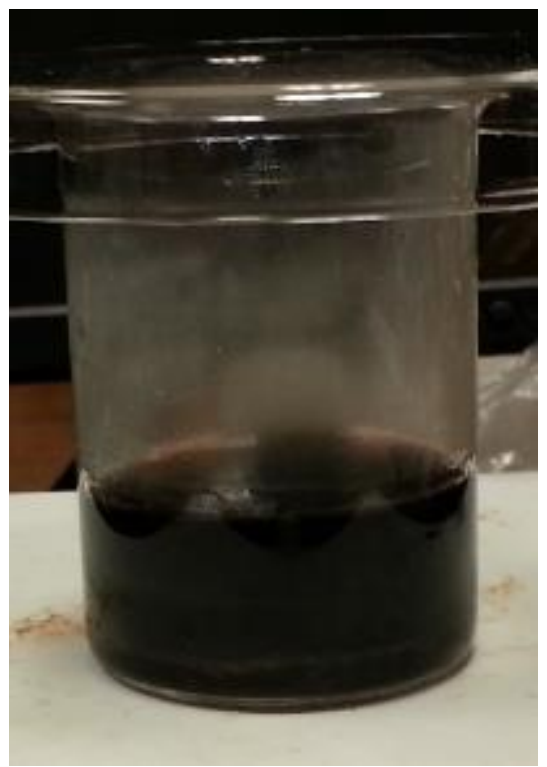

Figure 8: Mixture of Solution 1,2, and 3: All reactants mixed 


\subsection{Preparation of thiol derivatized gold nanoparticles electrode sensor chip}

To prepare the thiol derivatized gold nanoparticles for use in gas analysis, the particles must be placed on an electrode chip. A dispersion is prepared with an approximate ratio of $1 \mathrm{mg}$ gold particles to $100 \mu \mathrm{L}$ of toluene. The dispersion is placed in a small container for storage, Figure 9. The dispersion is mixed with a vortex mixer, Figure 10, to assure it is well mixed before applying to a sensor. In the fume hood a $\mu \mathrm{L}$ syringe, Figure 14 , is used to apply the dispersion to a chip. The dispersion is added one drop at a time letting the toluene evaporate, leaving the gold nanoparticles on the sensor. Drops are added until the gold particles have full coverage of the interdigitated fingers of the electrode. Coverage confirmed under a standard microscope.

\subsection{Preparation of Gas samples}

Gas samples are prepared using source concentration of acetone and ethanol mixtures of 100 or 1000 parts per million (ppm) volume based (Figure 16). Figures 16-19 show the sample bags and syringes to prepare samples. The volume of the source bags are 10 or $5 \mathrm{~L}$. The testing sample bags are $5 \mathrm{~L}$. The source concentration bags use the ideal gas law to assure the correct concentration. For example, the density and molecular weight of acetone at standard conditions is used to calculate the liquid volume of acetone needed to evaporate in 5 or $10 \mathrm{~L}$ bags to get 100 or $1000 \mathrm{ppm}$. The dilution of each sample is calculated by a dilution ratio and the volume of the sample bag. The source concentration is divided by the desired concentration. That value is then divided by the volume of the sample bag to give the needed volume of source gas to prepare the sample. A fresh gas sample was prepared for each test. The mixture of acetone and ethanol was prepared to total concentrations of $0.1,1$, and $5 \mathrm{ppm}$. 


\subsection{Resistance Testing Procedure}

The resistance testing procedure followed that of Gerfen's procedure. ${ }^{3}$ The vacuum chamber, Figure 13, is used to hold the sensor chip with an electric circuit connecting the chip to the Keithley multimeter (Figure 12). To conduct a test, first turn on the Keithley multimeter and open the LabVIEW program to record resistance versus time. The resistance changes because of the adsorption and desorption of VOCs to the thiol derivatized gold nanoparticles.

Next, attach the gas sample to the chamber and ensuring the valve from the sample to the chamber is closed. Turn on the vacuum pump and open the gas chamber to the pump valve to allow the vacuum to reach 25 to $30 \mathrm{in} \mathrm{Hg}$ (the max for the vacuum pump). Press start button in LabVIEW to collect data. After 300 seconds (five minutes) of data is recorded open the chamber to the gas sample and close the vacuum pump valve. Collect data on the gas sample for 300 seconds. Repeat vacuum and sample steps two more times for a total of three vacuum followed by three sample data readings. The 300 second time frame allows the chamber to reach a steady state for the vacuum or gas sample. The LabVIEW data is exported to Microsoft EXCEL for analysis. The computer setup to run resistance tests is shown in Figure 20.

\subsection{Experimental Equipment}

The experimental setup to produce thiol derivatized gold nanoparticles and test gas samples requires various pieces of equipment show in Figures 9-20. 


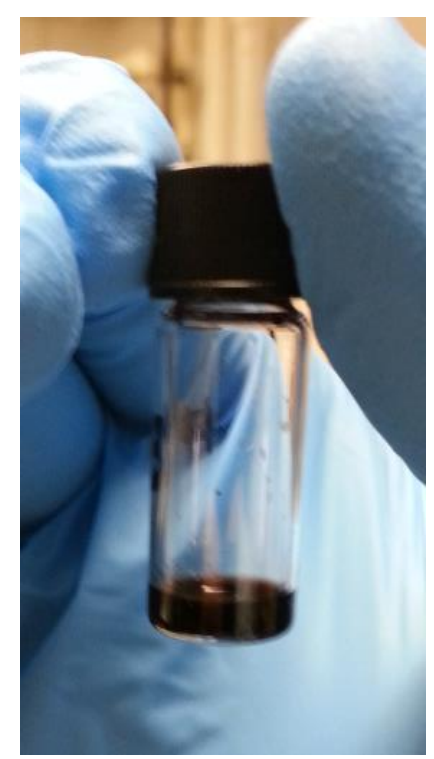

Figure 9: Container for Nanoparticles in Toluene Dispersion

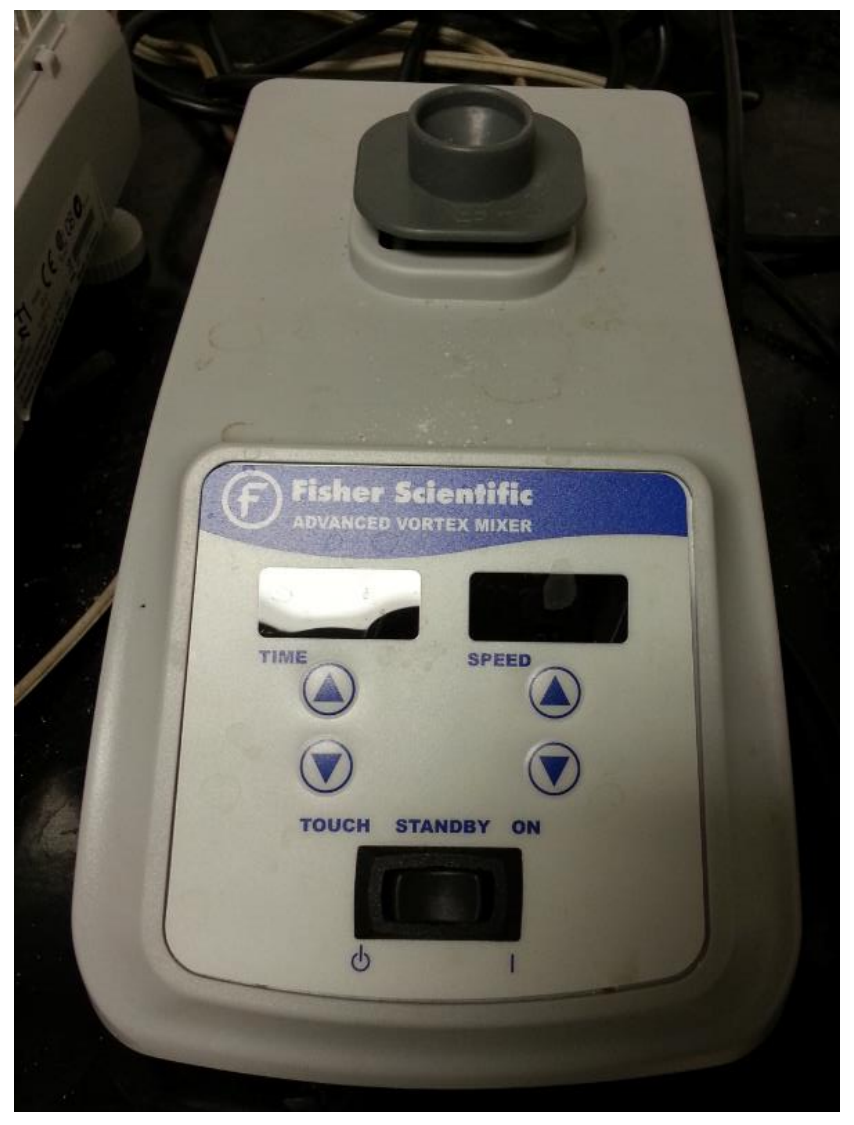

Figure 10: Fisher Scientific Vortex Mixer 


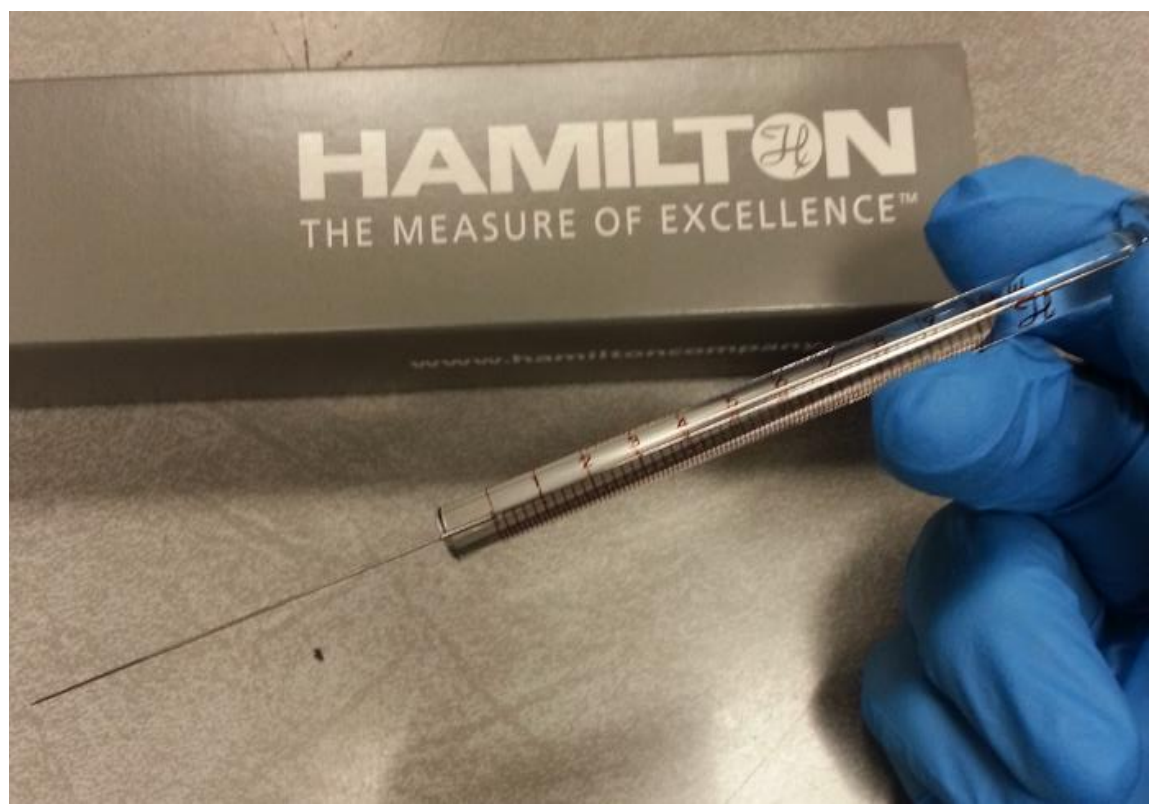

Figure 11: Hamilton Microliter Syringe

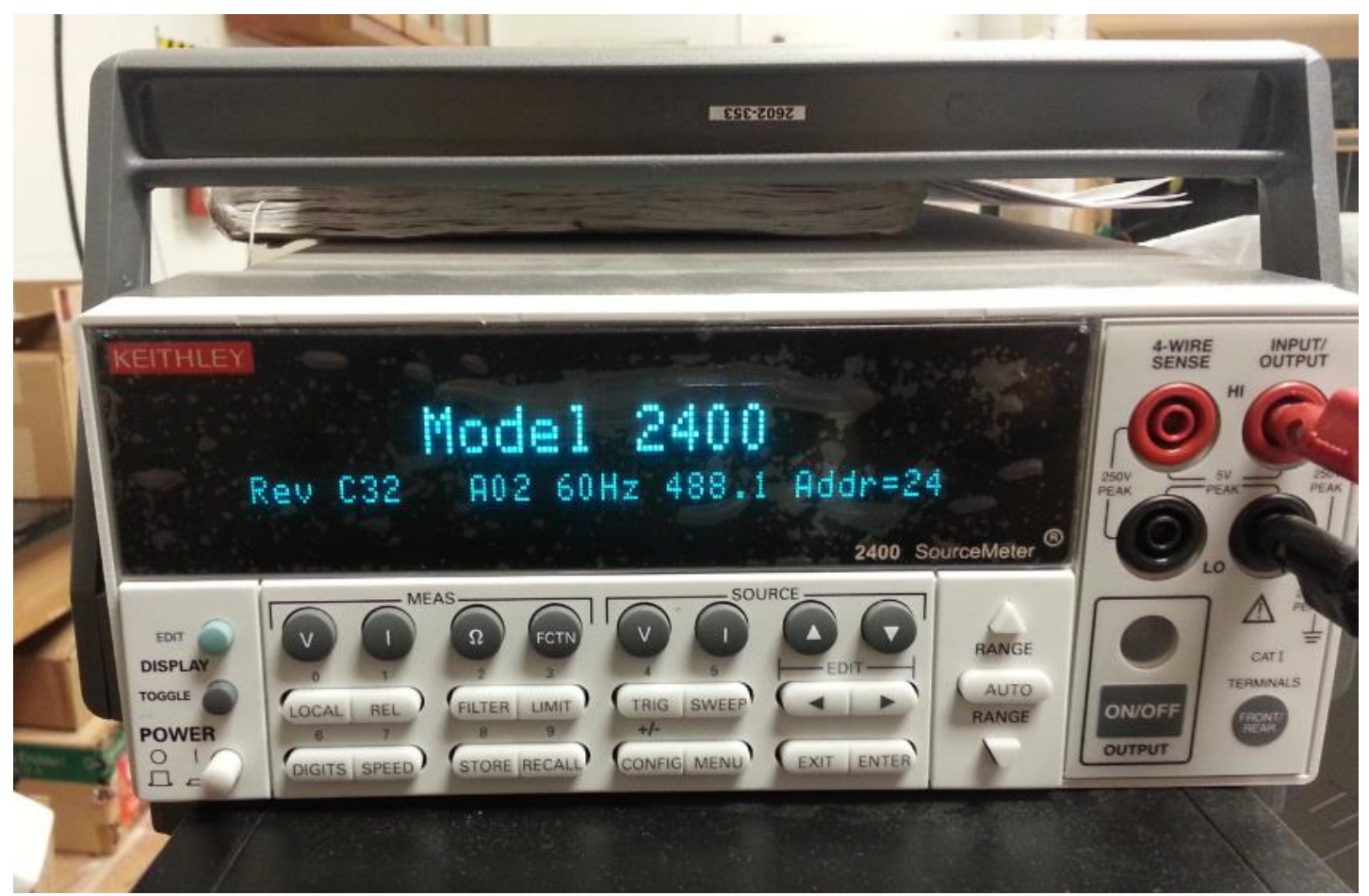

Figure 12: Keithley Multimeter Model 2400 


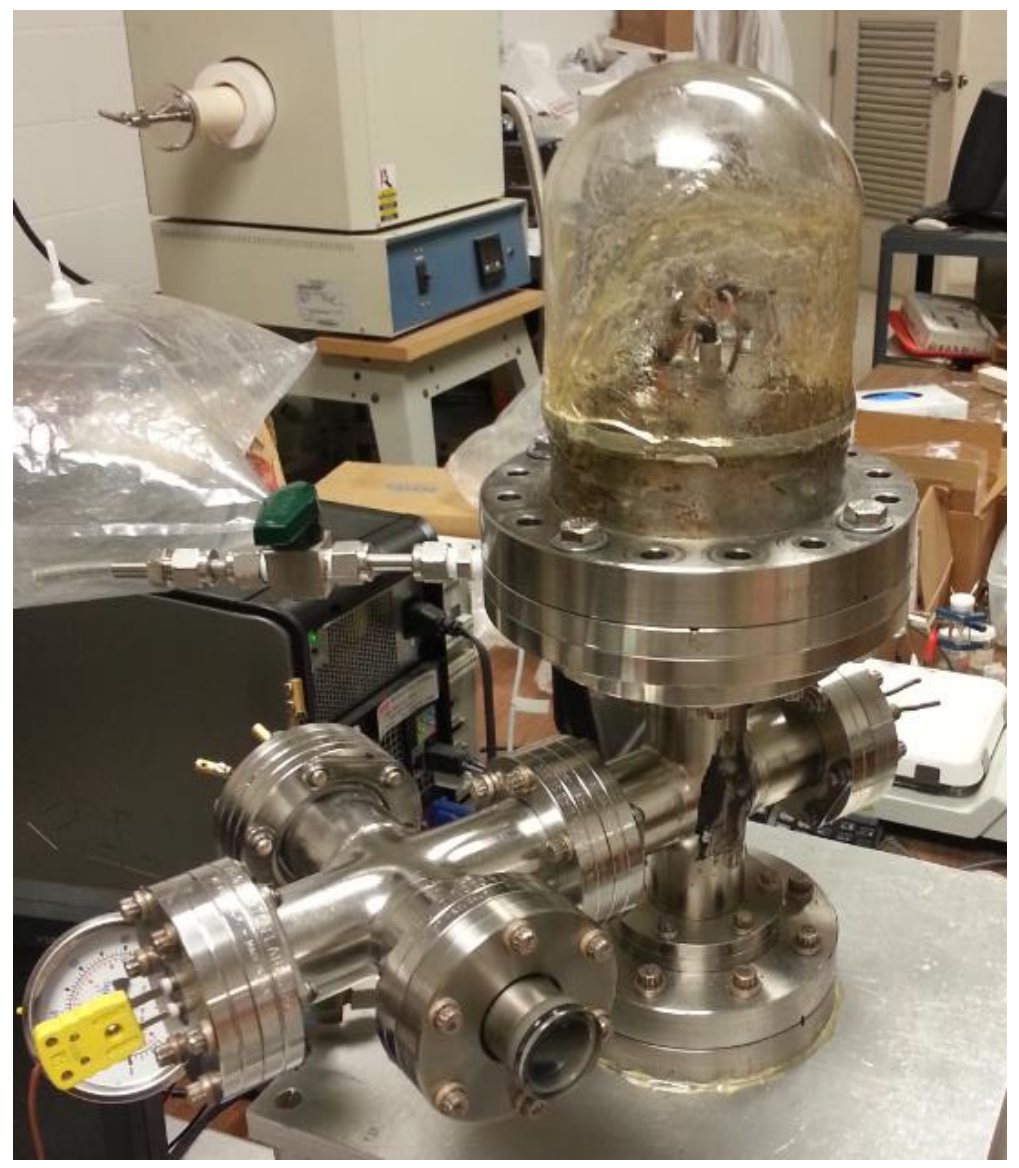

Figure 13: Vacuum Chamber 


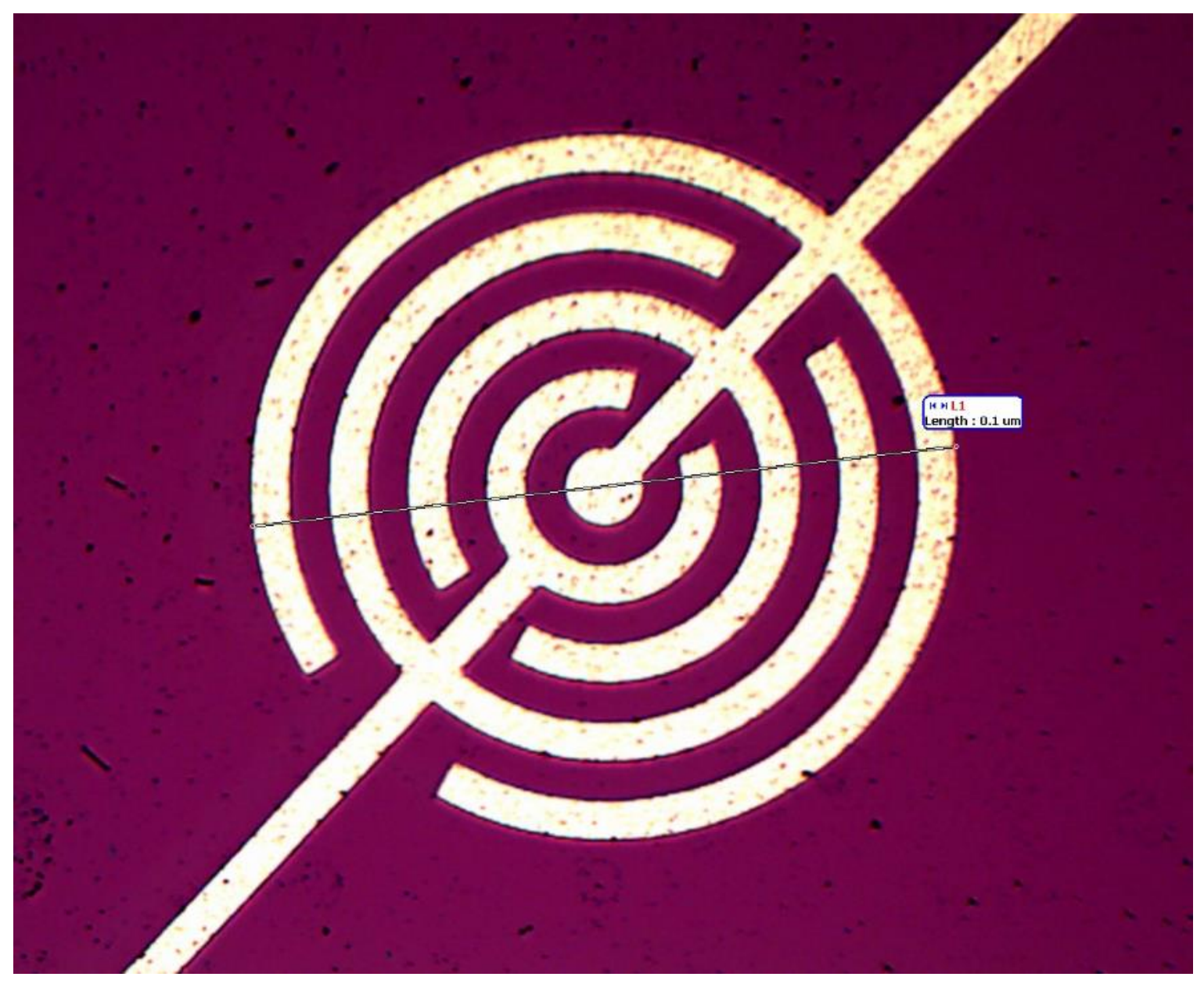

Figure 14: Blank Sensor Chip 10x Magnification: Diameter of 0.1 $\mu \mathrm{m}$

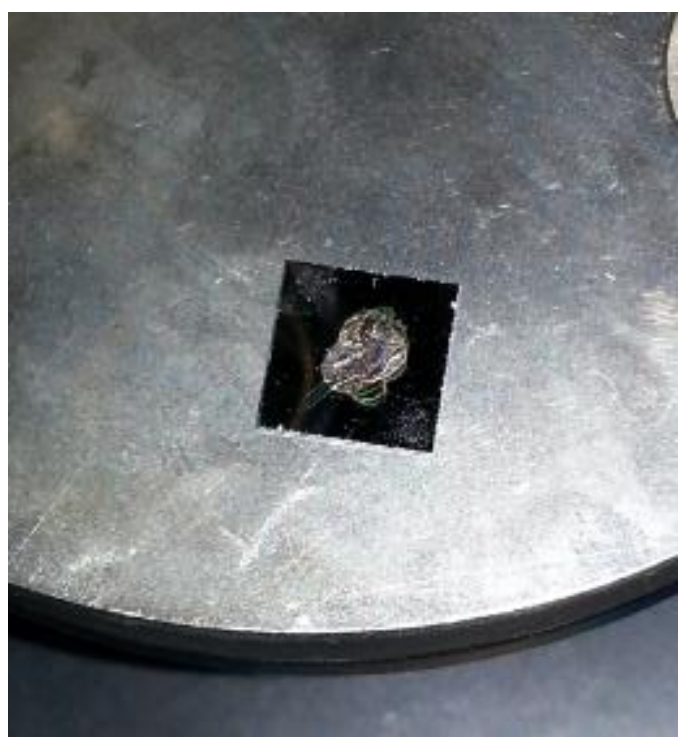

Figure 15: Sensor Chip with Gold Nanoparticles 


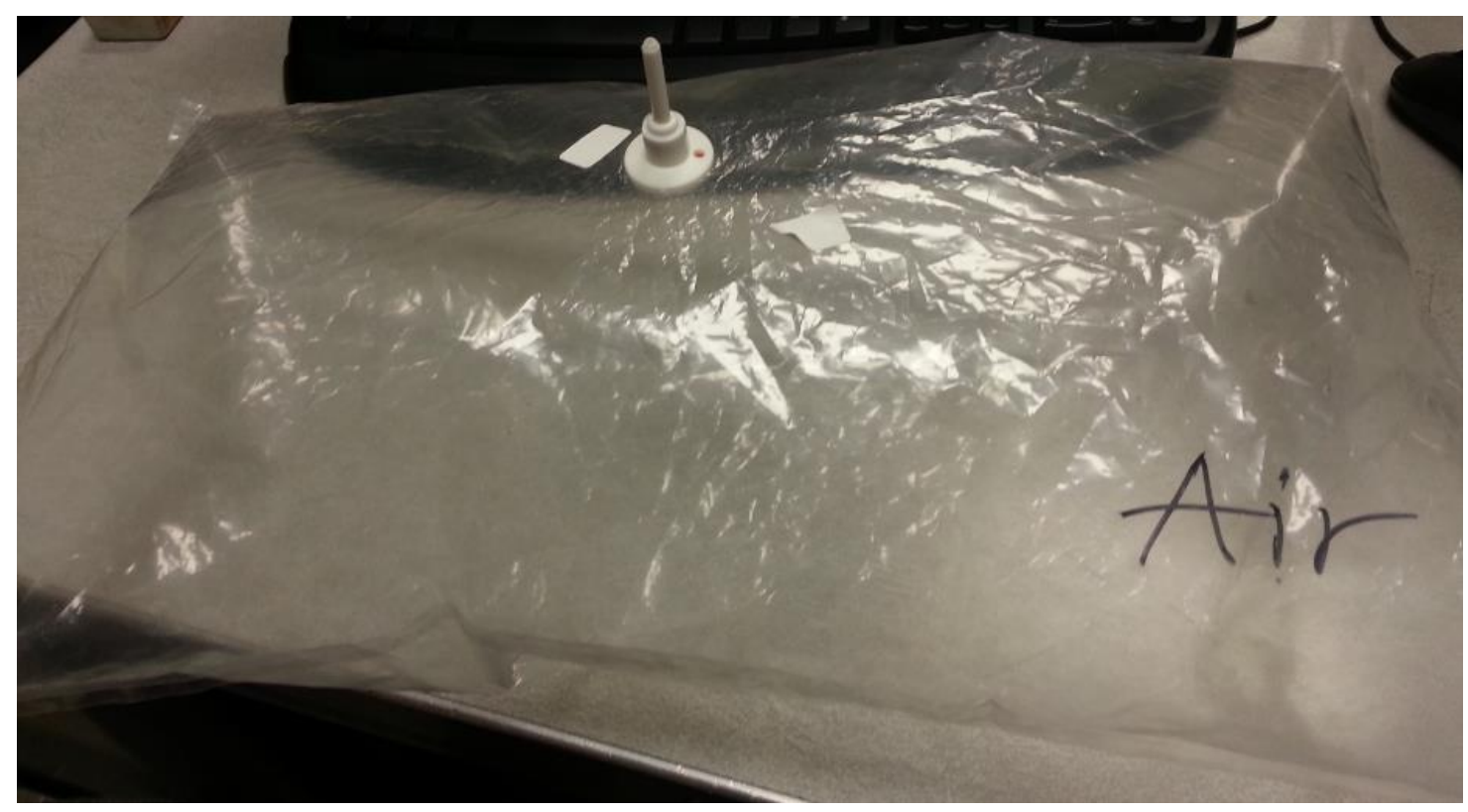

Figure 16: Supelco Analytical 10 L Bag

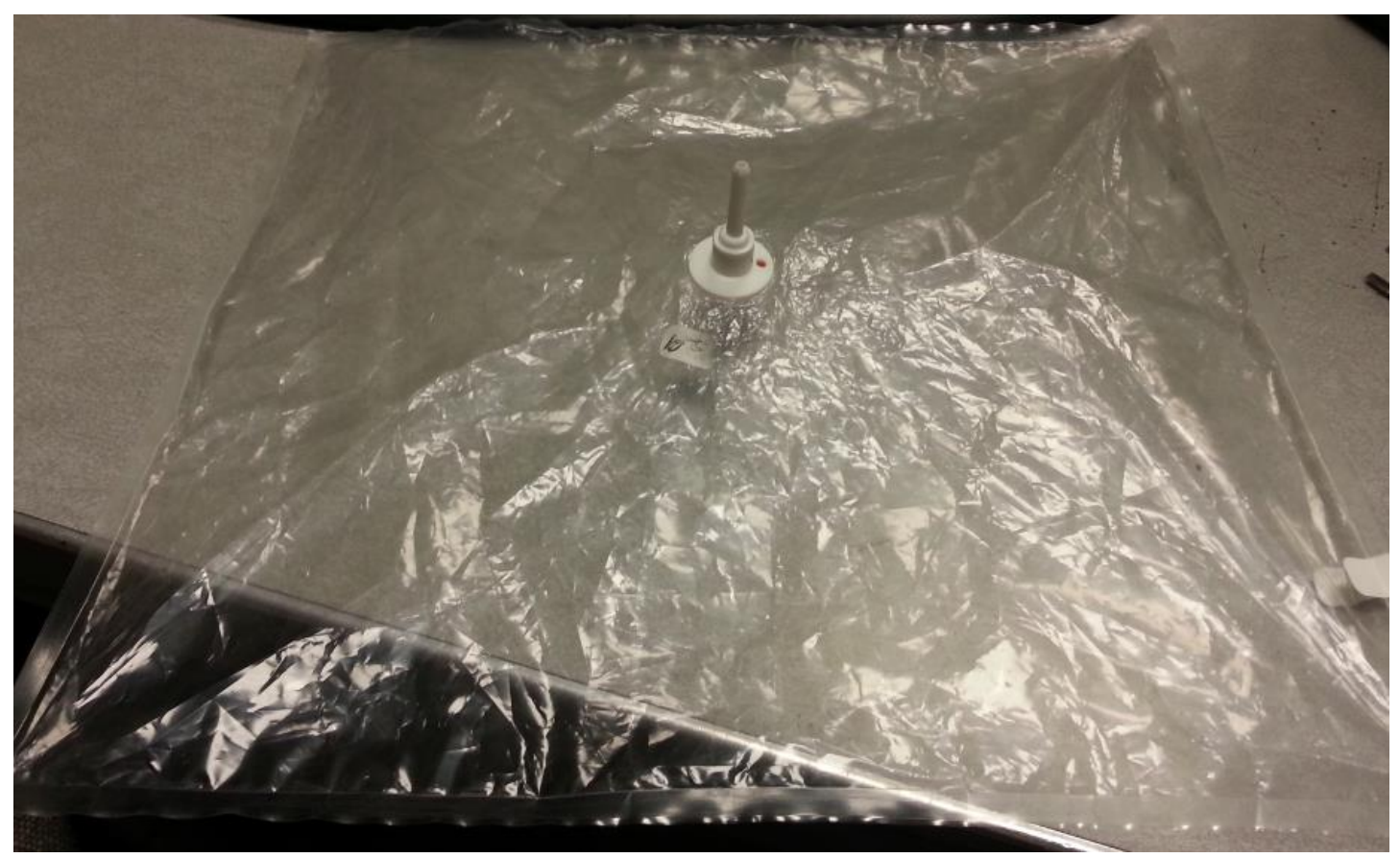

Figure 17: Supelco Analytical 5 L Bag 


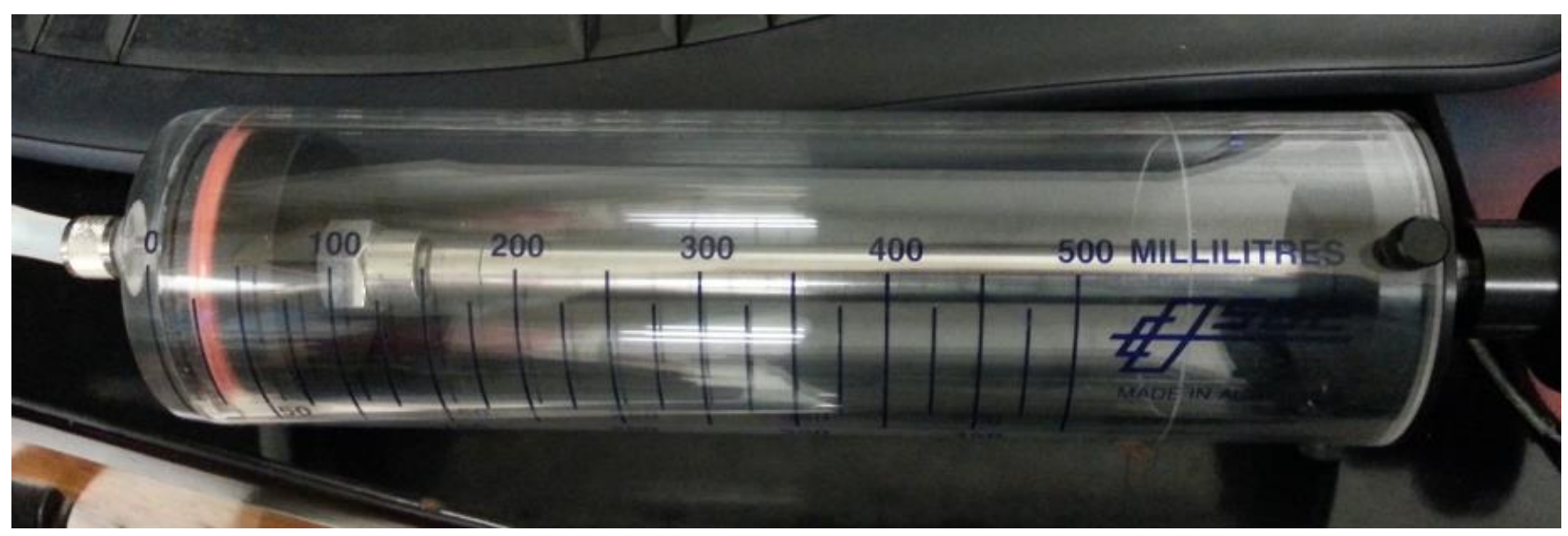

Figure 18: SGE 500 mL Gas Syringe

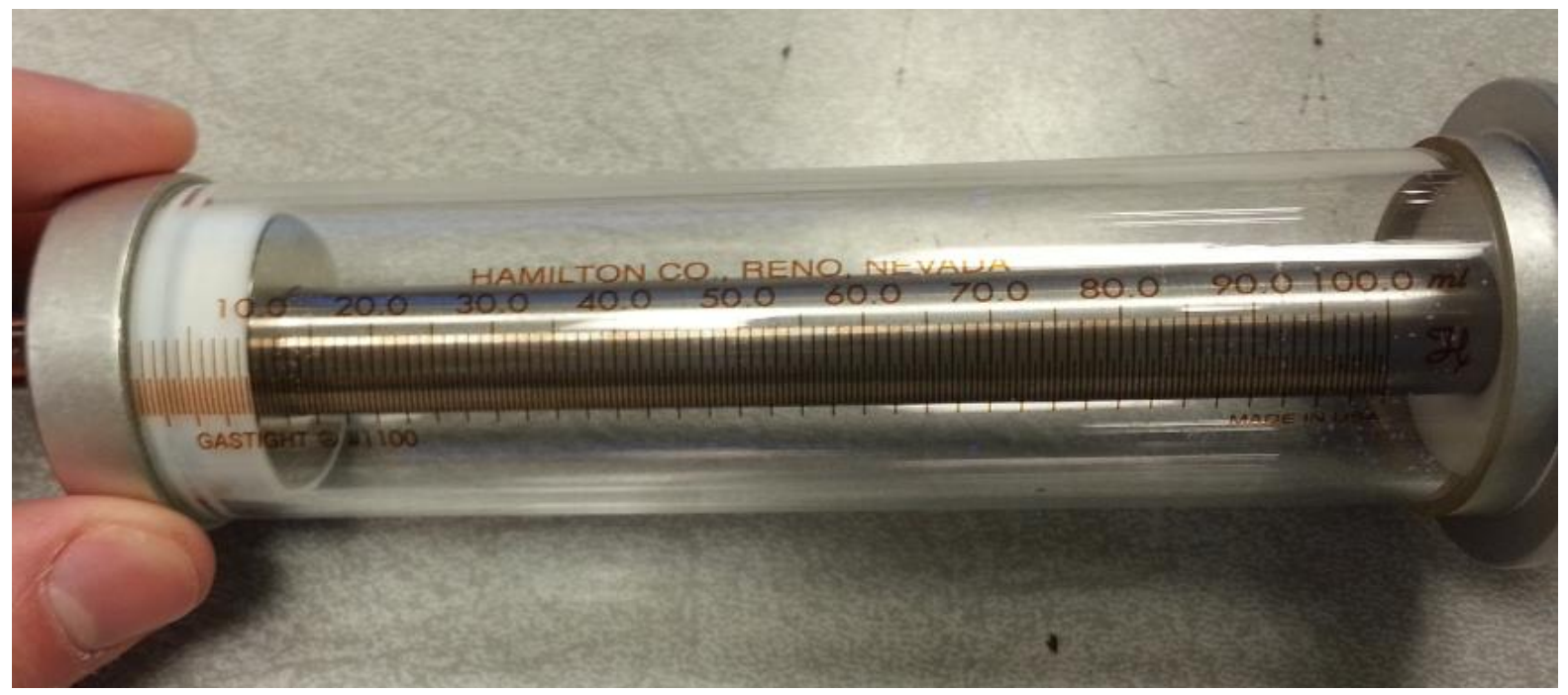

Figure 19: Hamilton 100 mL Gas Syringe 


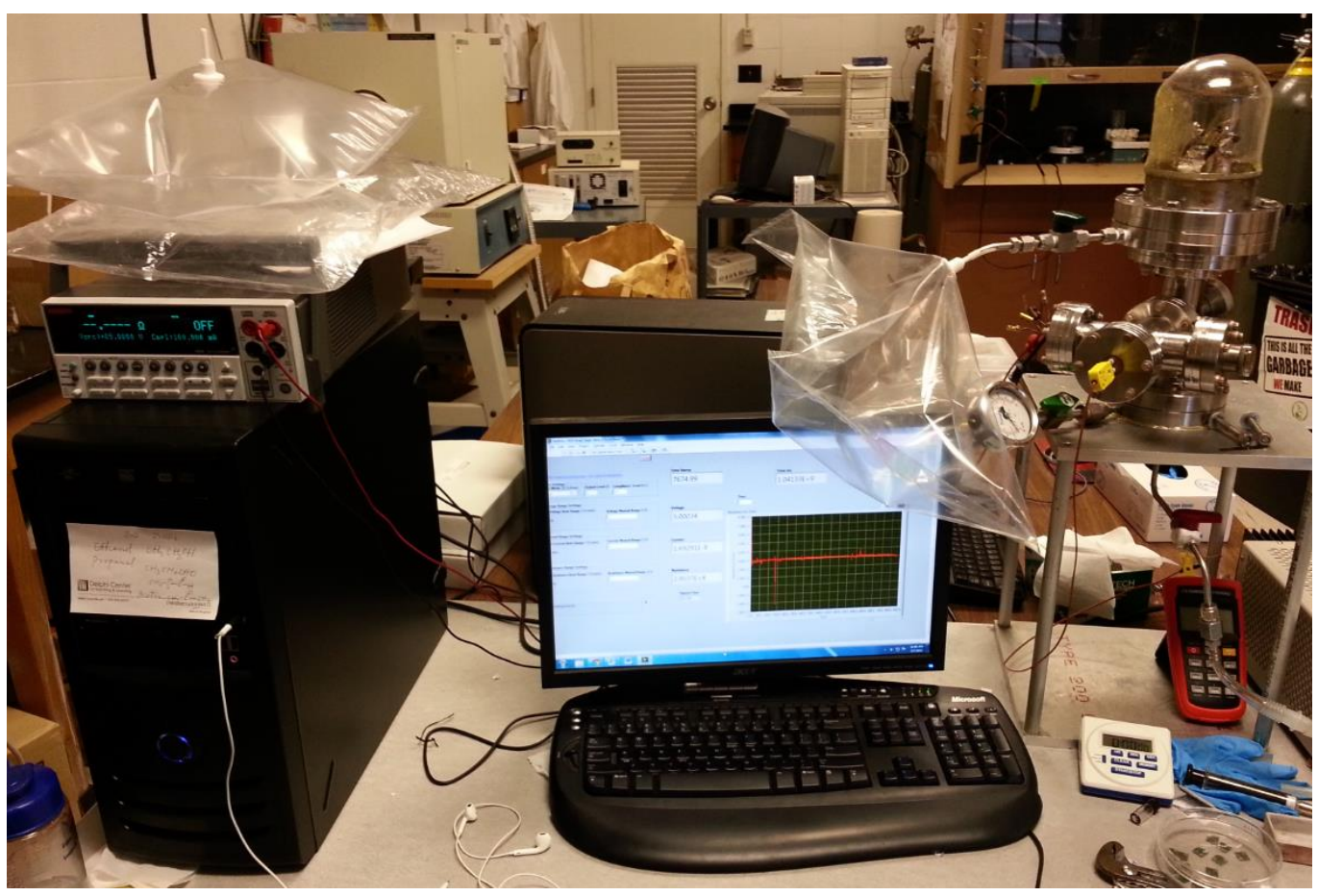

Figure 20: Computer Lab Station 


\section{RESULTS AND DISCUSSION}

\subsection{Resistance Graphs}

The resistance test results are shown in Figures 22-51. The data is exported from LabVIEW and plotted in Microsoft Excel. The resistance results figure like Figure 22 the vacuum portion of the tests are at $0-300,600-900$, and $1200-1500$ seconds. The gas sample resistances occur during the $300-600,900-1200$, and 1500-1800 second periods. The sharp drop in resistance is easily seen on each resistance test. The change in resistance is confirmation of adsorption of the VOCs in the gas sample to the thiol derivatized gold nanoparticles. TABLE II represents the factor levels of each different sensor. The factor levels are listed with each resistance figure title. Figure 21 shows the thiol derivatized gold nanoparticles from a scanning electron microscope.

\section{TABLE II}

CHIP FACTOR LEVELS

\begin{tabular}{|c|c|c|c|}
\hline Thiol & Chip & $\begin{array}{r}\text { Thiol Loading Volume ( } \mu \text { moles): Gold (grams) } \\
\text { Ratio }\end{array}$ & $\begin{array}{r}\text { Loading } \\
\text { Ratio Code }\end{array}$ \\
\hline \multirow{3}{*}{ 1-Dodecanethiol } & $1 \mathrm{~A}$ & $35: 0.049$ & 0.5 \\
\hline & 1B & 71: 0.049 & 1 \\
\hline & $1 \mathrm{C}$ & 142: 0.049 & 2 \\
\hline \multirow{3}{*}{$\begin{array}{l}\text { 4-methoxy-alpha } \\
\text { toluenethiol }\end{array}$} & $2 \mathrm{~A}$ & 57: 0.049 & 0.5 \\
\hline & $2 \mathrm{~B}$ & 114: 0.049 & 1 \\
\hline & $2 \mathrm{C}$ & 228: 0.049 & 2 \\
\hline
\end{tabular}




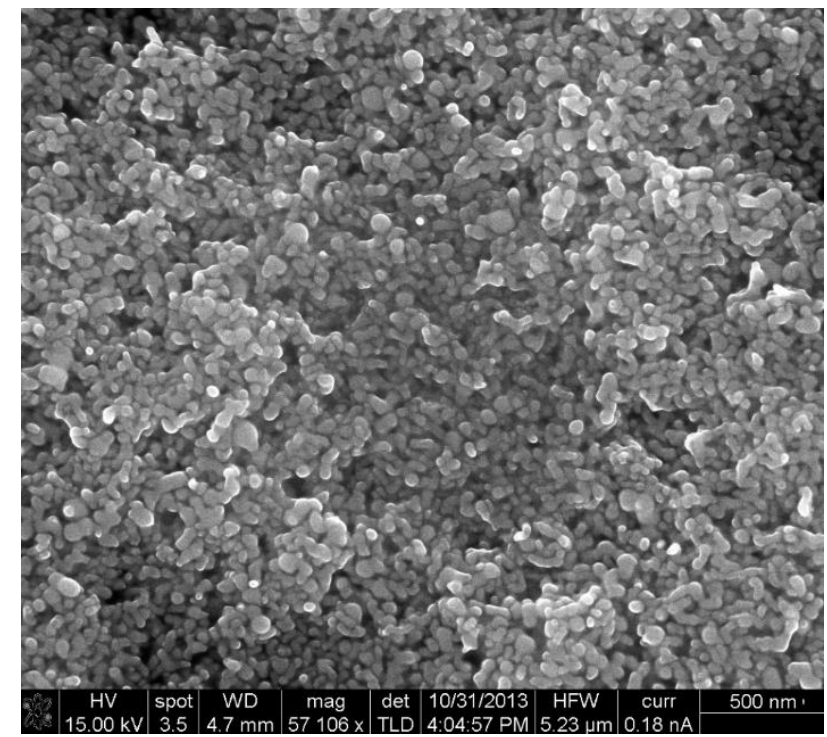

Figure 21: Scanning Electron Microscope of Chip 2A

\subsection{Signal Log Graphs}

The chip signal is calculated by equation $22 . \mathrm{R}_{\text {sample }}$ is the average resistance of the gas sample over 300 seconds and $\mathrm{R}_{\text {air }}$ is the average resistance of dry air for each chip.

$$
\text { Signal }=a b s\left[\frac{\left(R_{\text {sample }}-R_{\text {air }}\right)}{R_{\text {air }}}\right]
$$

The signal determines the range of resistance values of each VOC concentration relative to dry air. The signal values of each sensor are plotted for each VOC versus concentration like in Figure 26. The log values of .1, 1, and 5 are $-1,0$, and 0.69 respectively. 


\subsubsection{Chip 1A (1-Dodecanethiol and 35 moles) Results}

The first chip to discuss is chip 1A. Figure 22 clearly shows the acetone resistance increases significantly as the VOC concentrations increases. The biggest increase is between $1 \mathrm{ppm}$ and $5 \mathrm{ppm}$. Figure 23 is labeled with sample and vacuum arrows to indicate which part of the test is which. As the air sample comes into the test chamber, the resistance immediately decreases and reaches a fairly stable value in about twenty seconds. The change in resistance is evidence of the adsorption occurring as related to pressure of the system. The decrease in pressure by the vacuum will desorb the VOCs; thus increasing the resistance of the sensor. The same pattern is seen in the majority of resistance graphs. The vacuum sections of the test usually have very similar resistances, but some tests show shifting of vacuum resistance. This could be caused by residual VOCs on the chip. Residual VOCs could be from testing the same chip on different days. The vacuum is applied for two to three minutes to remove residual VOCs before collecting data; however some curves still show a shift in vacuum and dry air resistances.

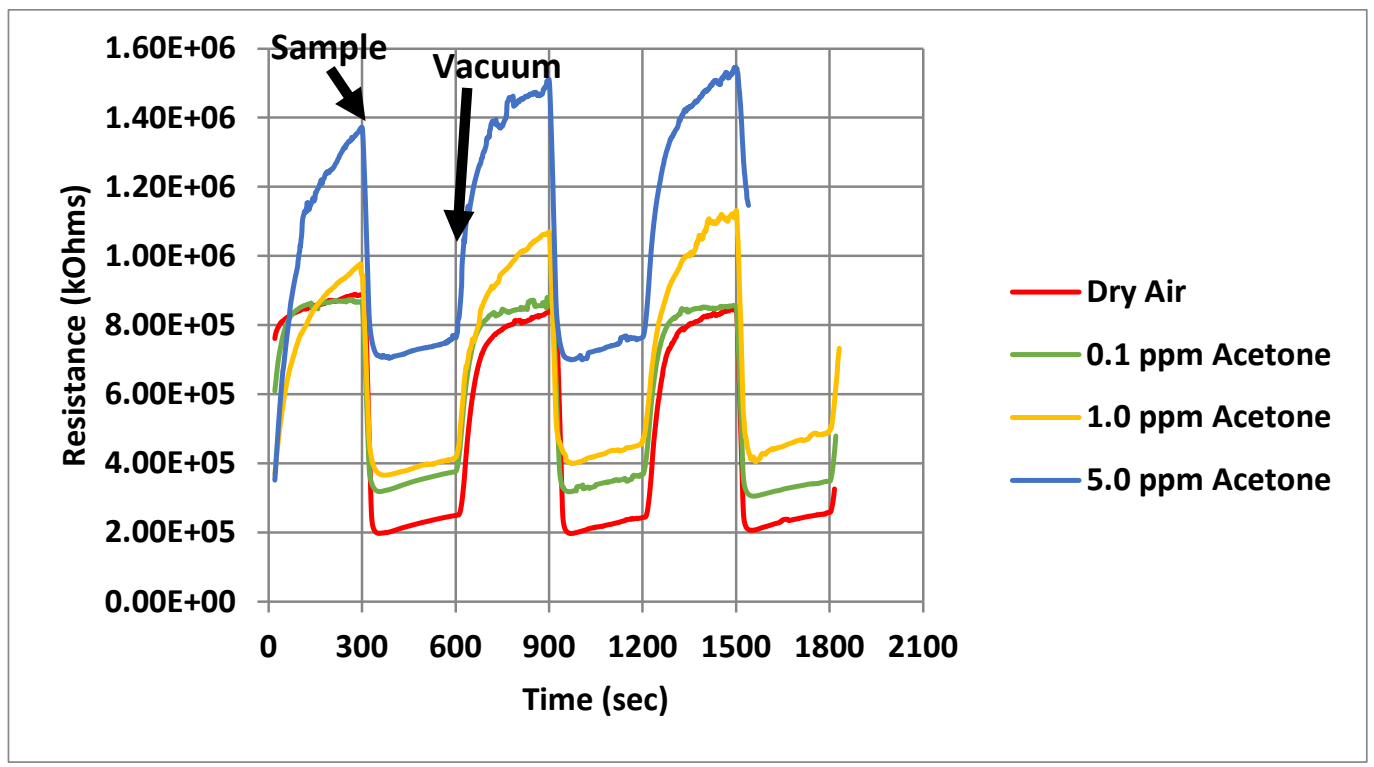

Figure 22: Chip 1A (1-Dodecanethiol 35 mmoles: 0.049 grams Gold) Acetone Resistance 
Figure 23 is the ethanol test for chip 1A. The results show the same trend of increasing resistance as VOC concentration increases, but the values are much closer together than acetone. The resistance changes seen for ethanol are small; however the trend is good and could be used to determine ethanol concentrations.

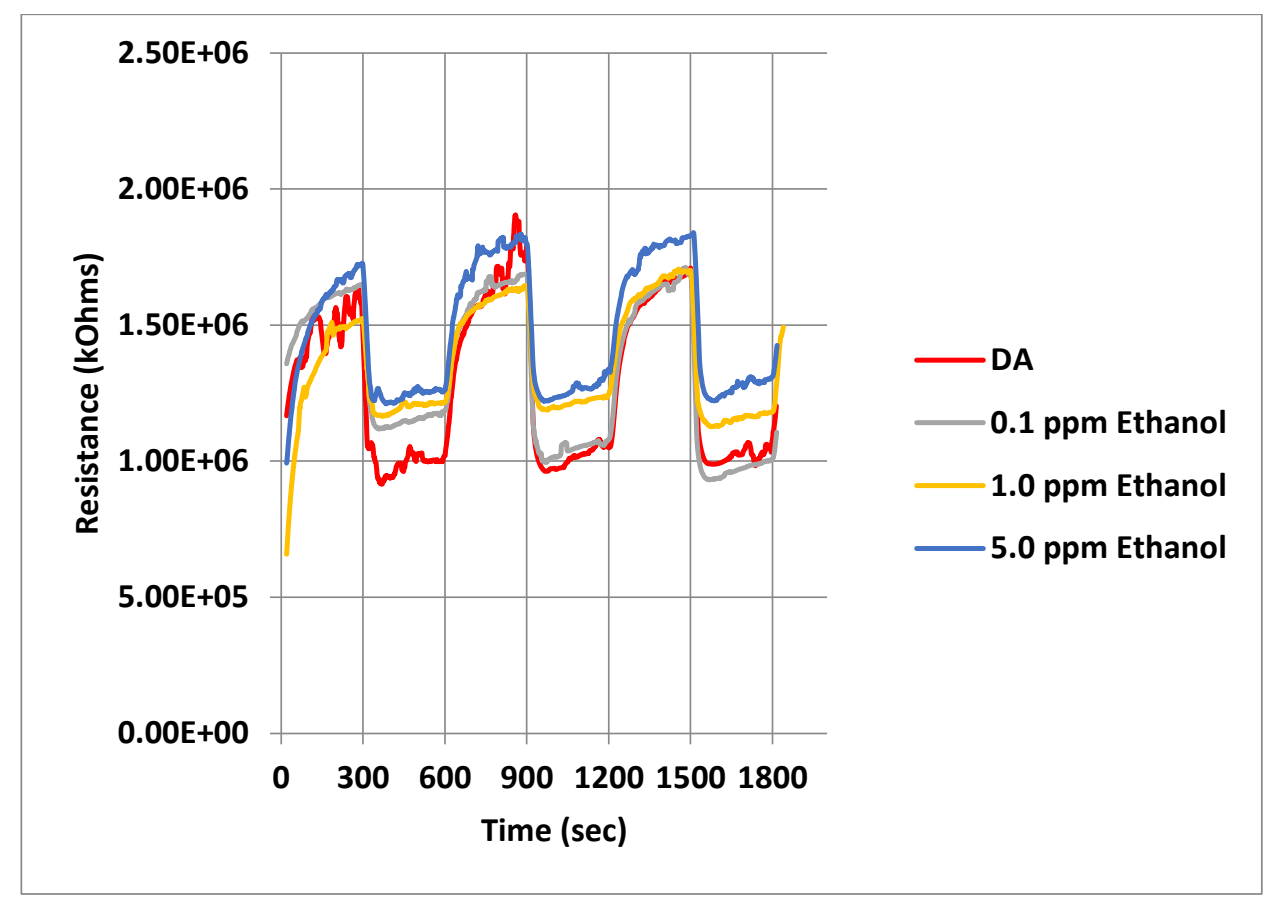

Figure 23: Chip 1A (1-Dodecanethiol 35 moles: 0.049 grams Gold) Ethanol Resistance

The results of the acetone - ethanol mix show that chip 1A does not distinguish well for this VOC. The trend of increasing resistance with increasing concentration is not seen. 


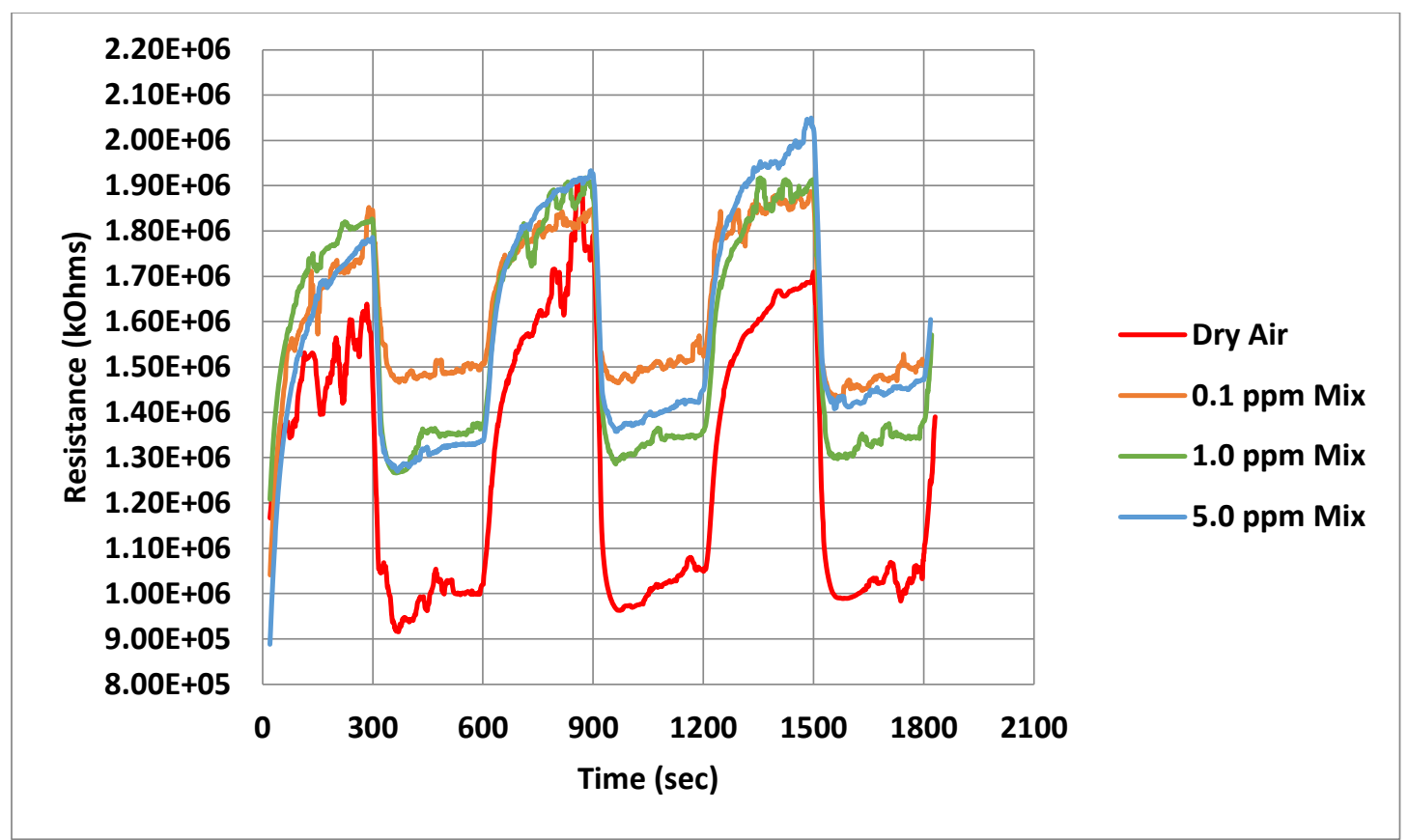

Figure 24: Chip 1A (1-Dodecanethiol 35 umoles: 0.049 grams Gold) Acetone-Ethanol Mix Resistance

Figure 25 is a $\log$ plot for the signal response of chip $1 \mathrm{~A}$. The log plot shows that the acetone signal is sensitive, but a low linear trend. Ethanol has a much stronger linear trend even with the lower signal.

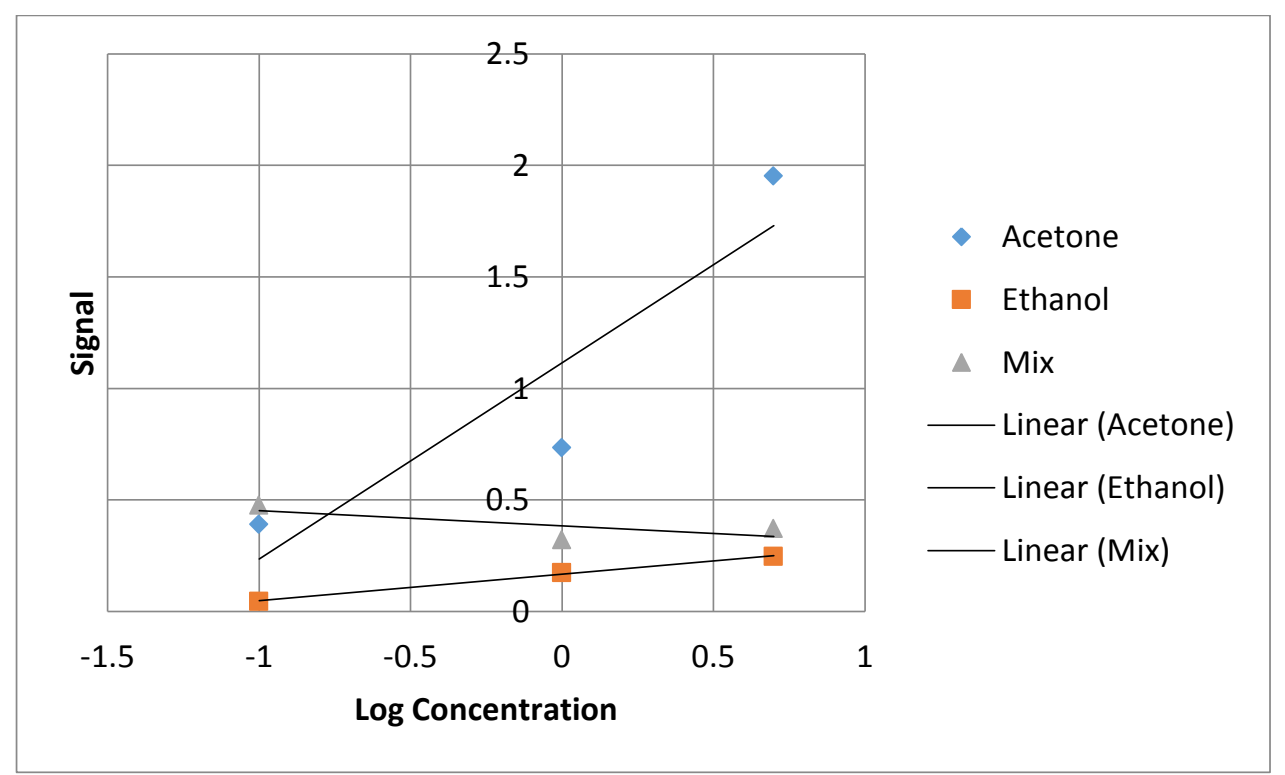

Figure 25: Chip 1A Signal 


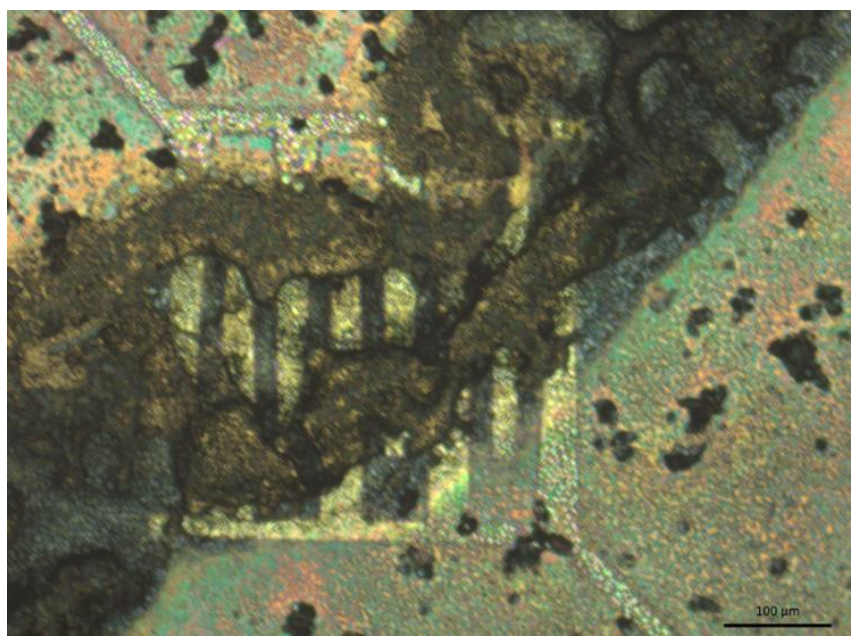

Figure 26: Chip 1A Gold Nanoparticles under 50x magnification 


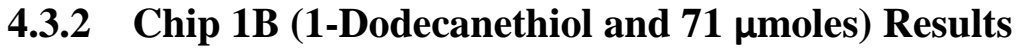

Chip 1B for acetone in Figure 27 shows a large increase from dry air in resistance. The $5 \mathrm{ppm}$ test does not follow the trend of increasing resistance with concentration. The samples for this test also have a sharp increase in resistance before leveling out at equilibrium. The previous tests show a rounded decrease to equilibrium resistance. The difference in resistance response could be the chip factor levels (the thiol compound and molar loading).

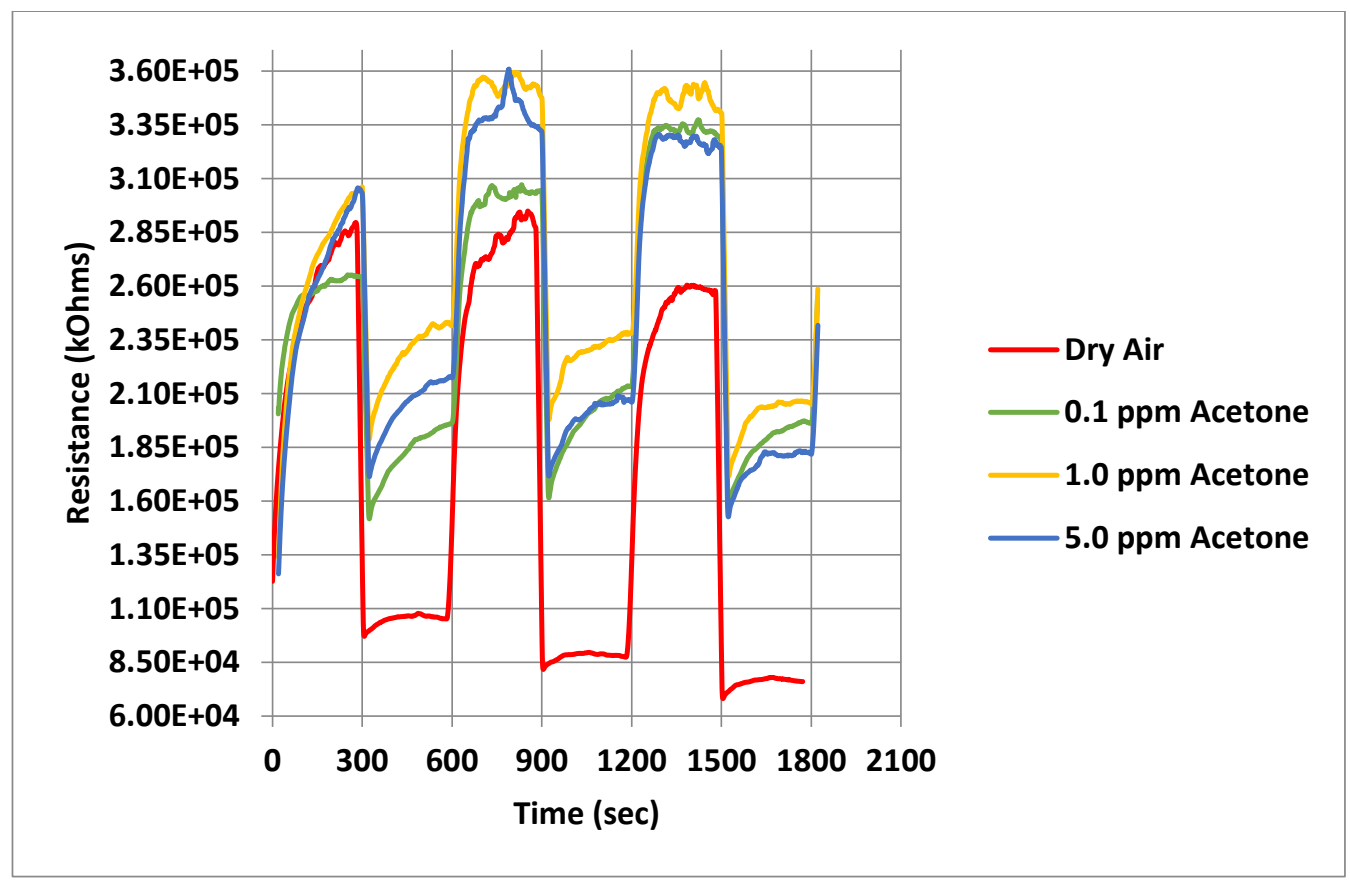

Figure 27: Chip 1B (1-Dodecanethiol 71 umoles: 0.049 grams Gold) Acetone Resistance 


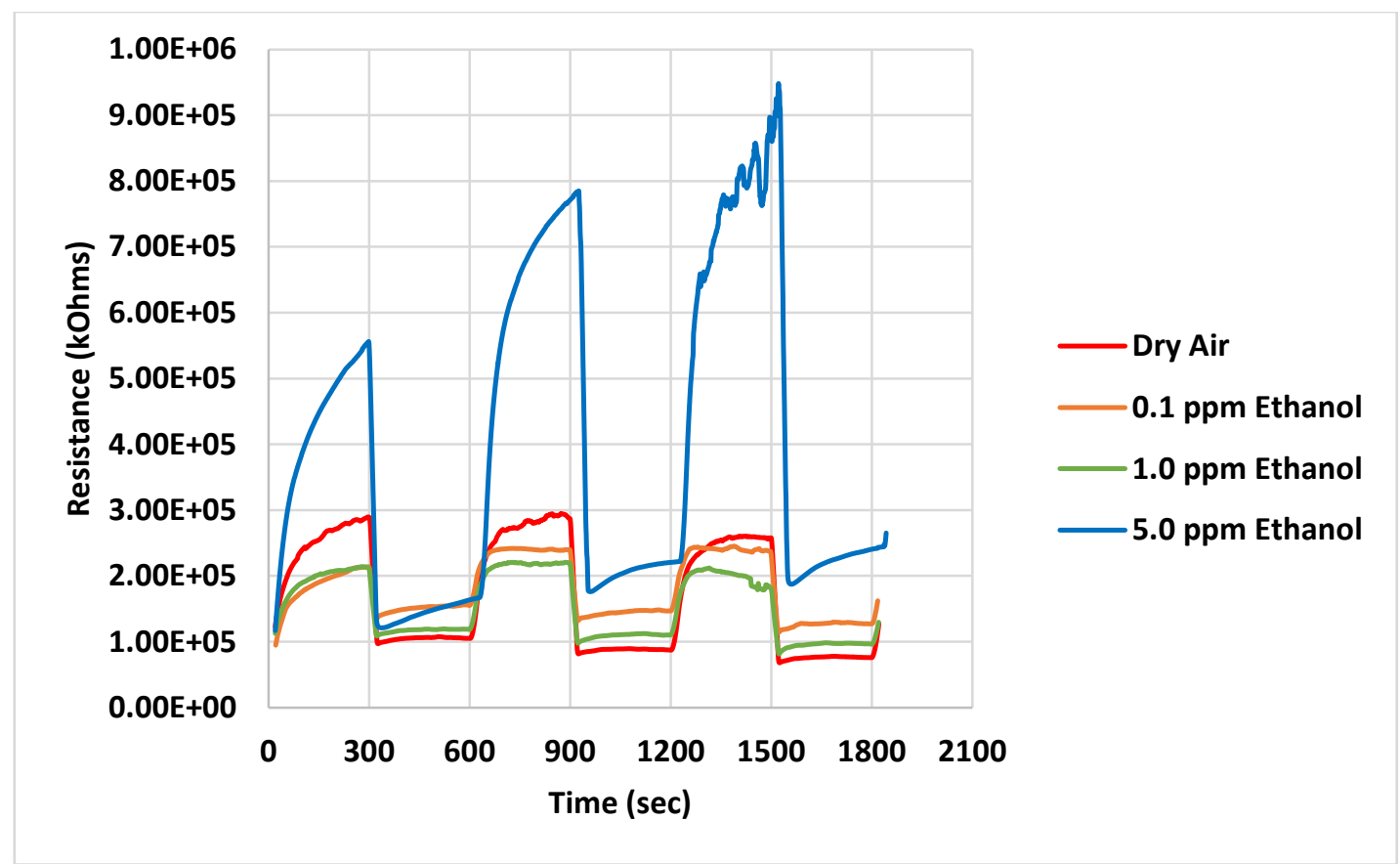

Figure 28: Chip 1B (1-Dodecanethiol 71 umoles: 0.049 grams Gold) Ethanol Resistance

Chip 1B for ethanol has a very high vacuum resistance for the $5 \mathrm{ppm}$ test. The resistance samples are close together. Chip 1B for the acetone - ethanol mix provides good results. Each concentration shows about a 50,000 kOhms increase in average resistance; this trend is better seen in Figure 30. The air resistance is much lower than the samples. The results mean that a potential source of error is in the vacuum desorbing the acetone and ethanol molecules from the sensor. This relates back to the thermodynamics of the adsorption and what is expected to happen to the resistance. 


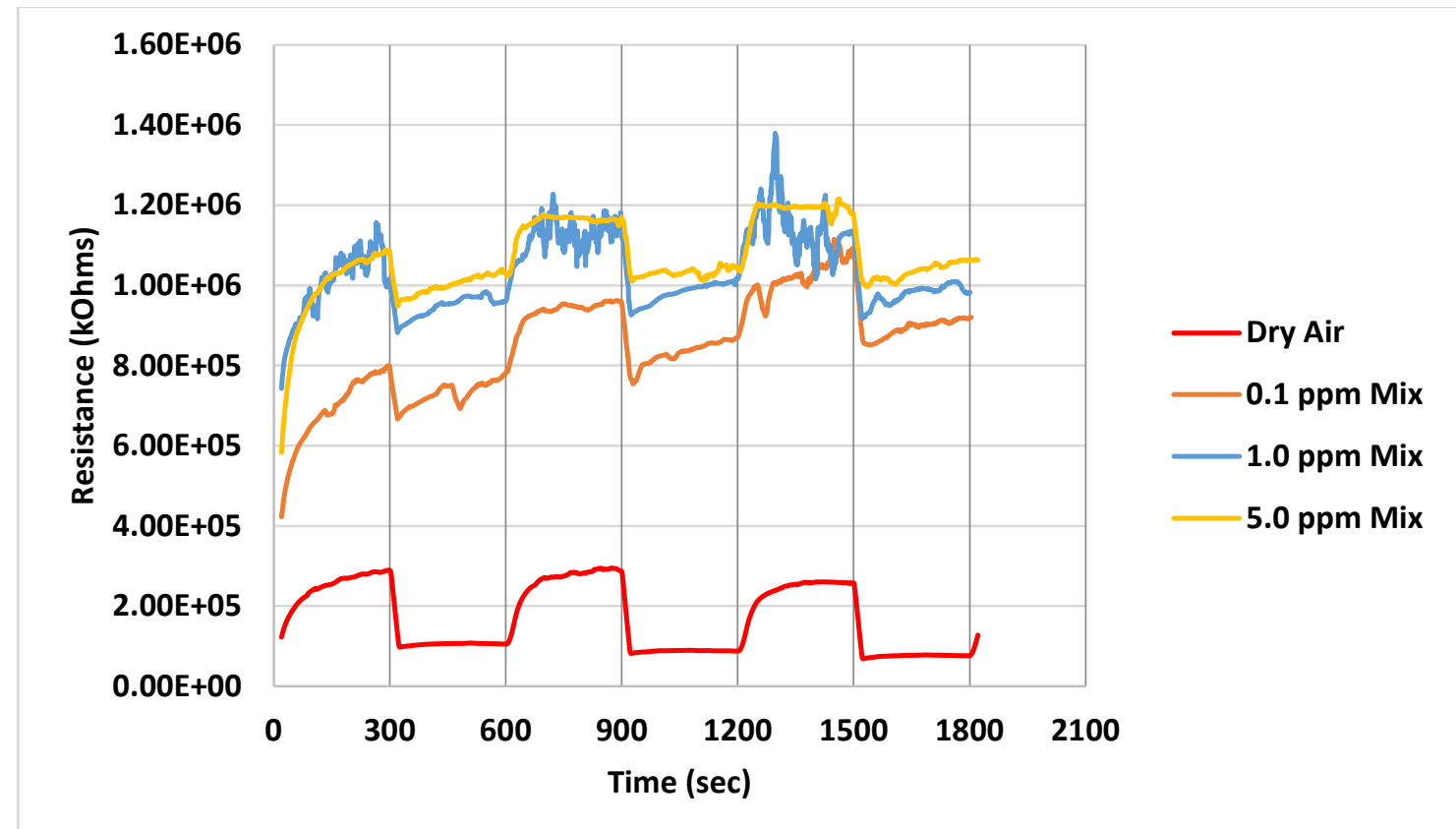

Figure 29: Chip 1B (1-Dodecanethiol 71 mmoles: 0.049 grams Gold) Acetone-Ethanol Mix Resistance

The log plot for chip 1B show the weak slopes for acetone and ethanol; which corresponds to the low trends in resistance differences between the concentrations. The chip could still be potentially successful in detecting a mixture of acetone and ethanol over just acetone or ethanol. For example if an unknown sample has a similar resistance; it could determine concentration of a sample of acetone and ethanol mixture. 


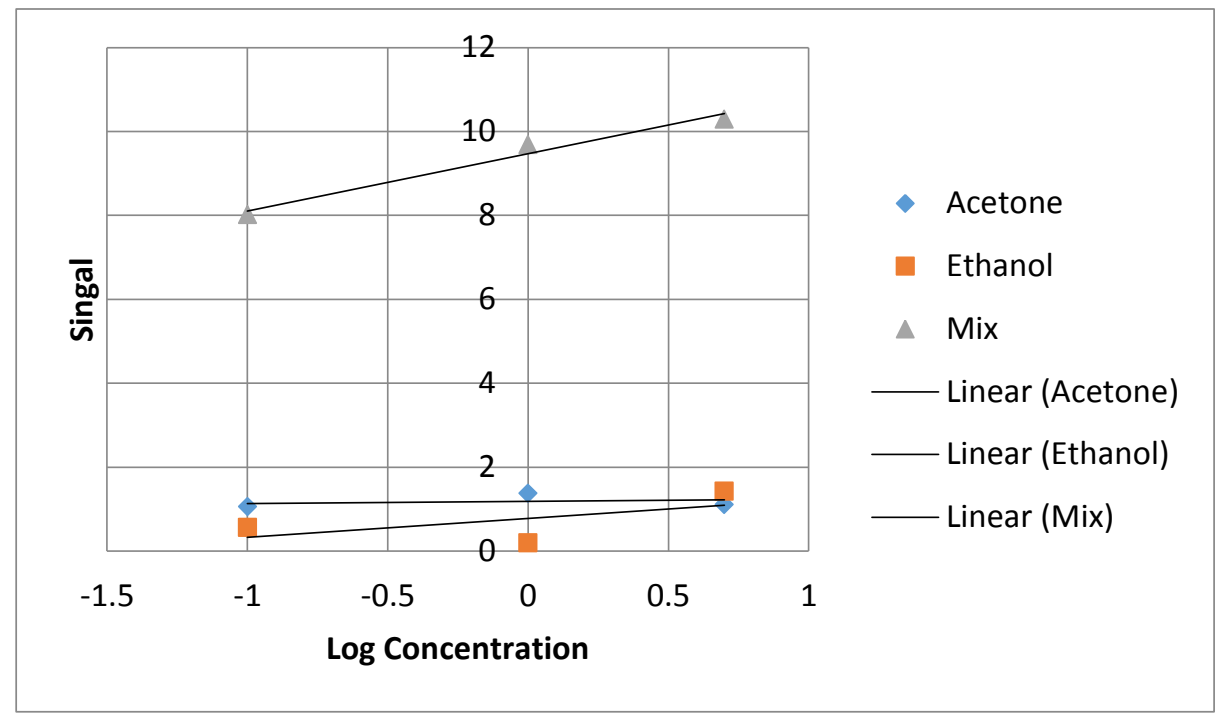

Figure 30: Chip 1B Signal

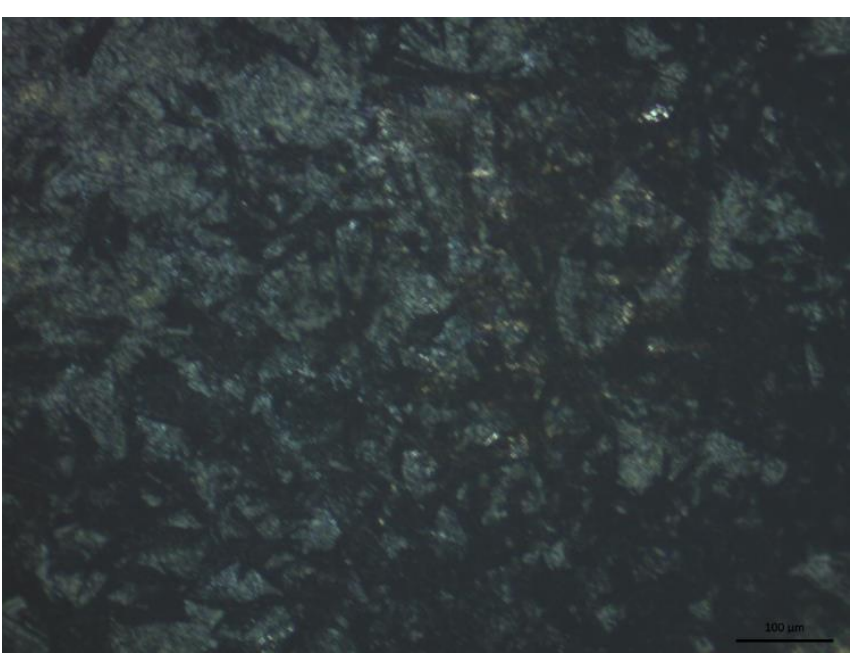

Figure 31: Chip 1B Gold Nanoparticles under 50x Magnification 


\subsubsection{Chip 1C (1-Dodecanethiol and $142 \mu$ moles) Results}

Chip 1C shows an interesting change in the trends of increasing concentration versus resistance. The resistance is inversely proportional to the concentration. Chip $1 \mathrm{C}$ has a very strong trend of acetone resistances with about 75,000 kOhms between each average resistance. This trend is easier to see on Figure 35 in the slope of the acetone plot.

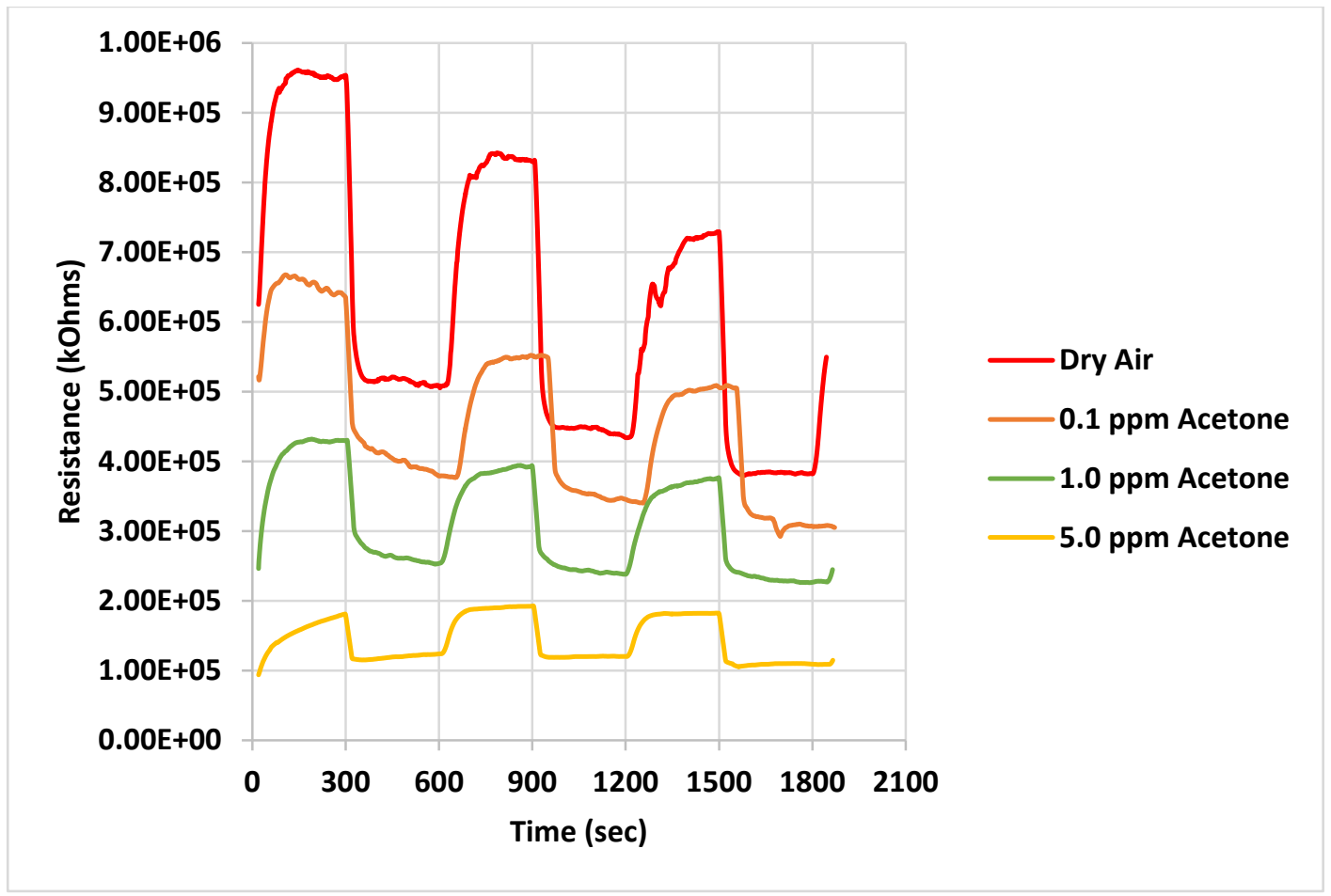

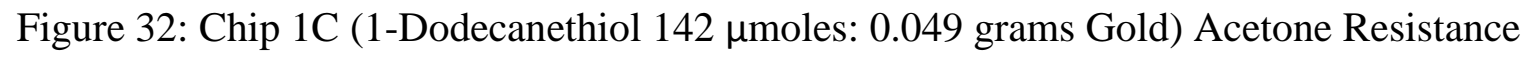




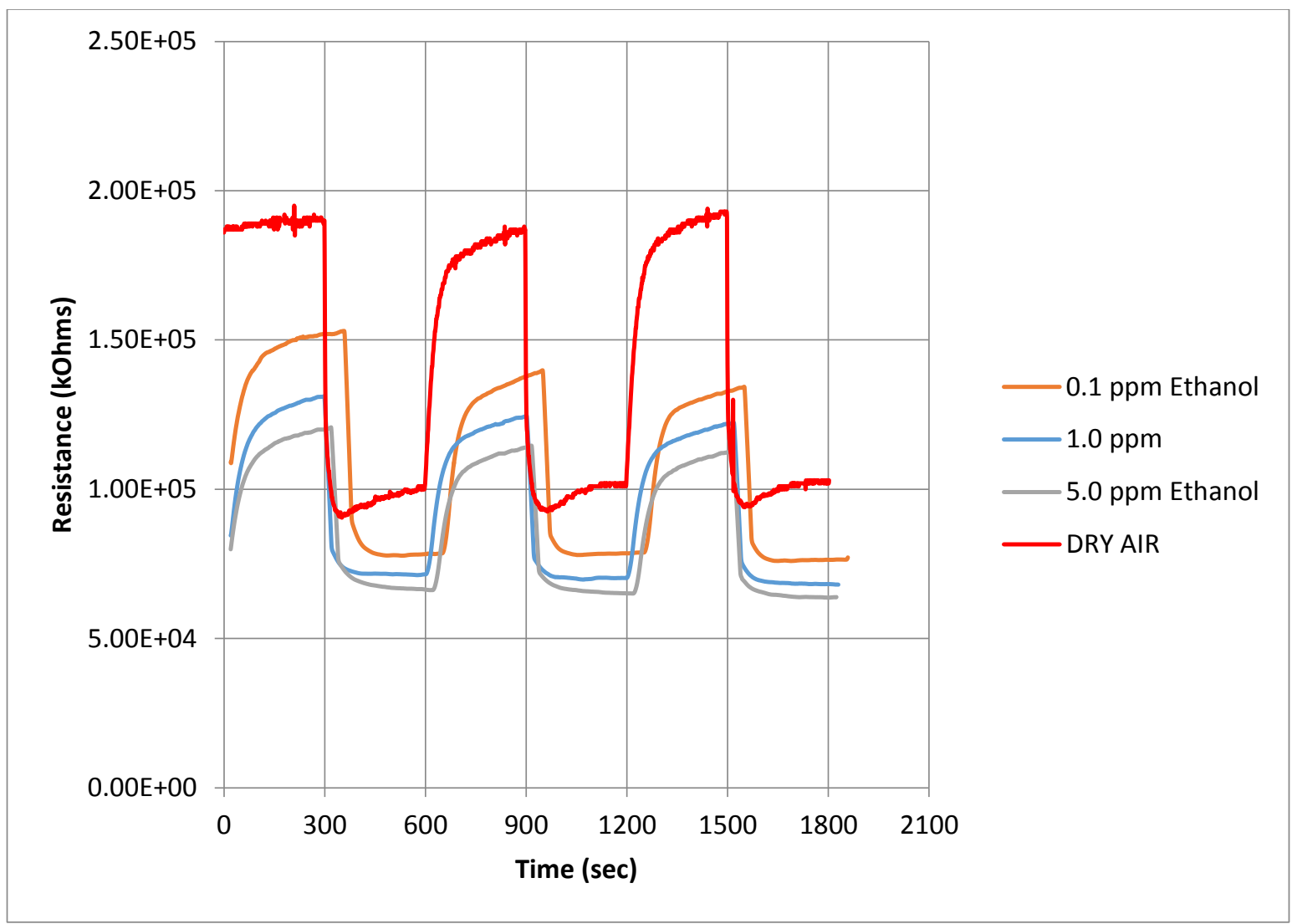

Figure 33: Chip 1C (1-Dodecanethiol $142 \mu$ moles: 0.049 grams Gold) Ethanol Resistance

Chip 1C has a very small variation of resistance between each concentration of ethanol. Chip $1 \mathrm{C}$ shows very high potential for acetone detection with the excellent resistance changes between each concentration. 


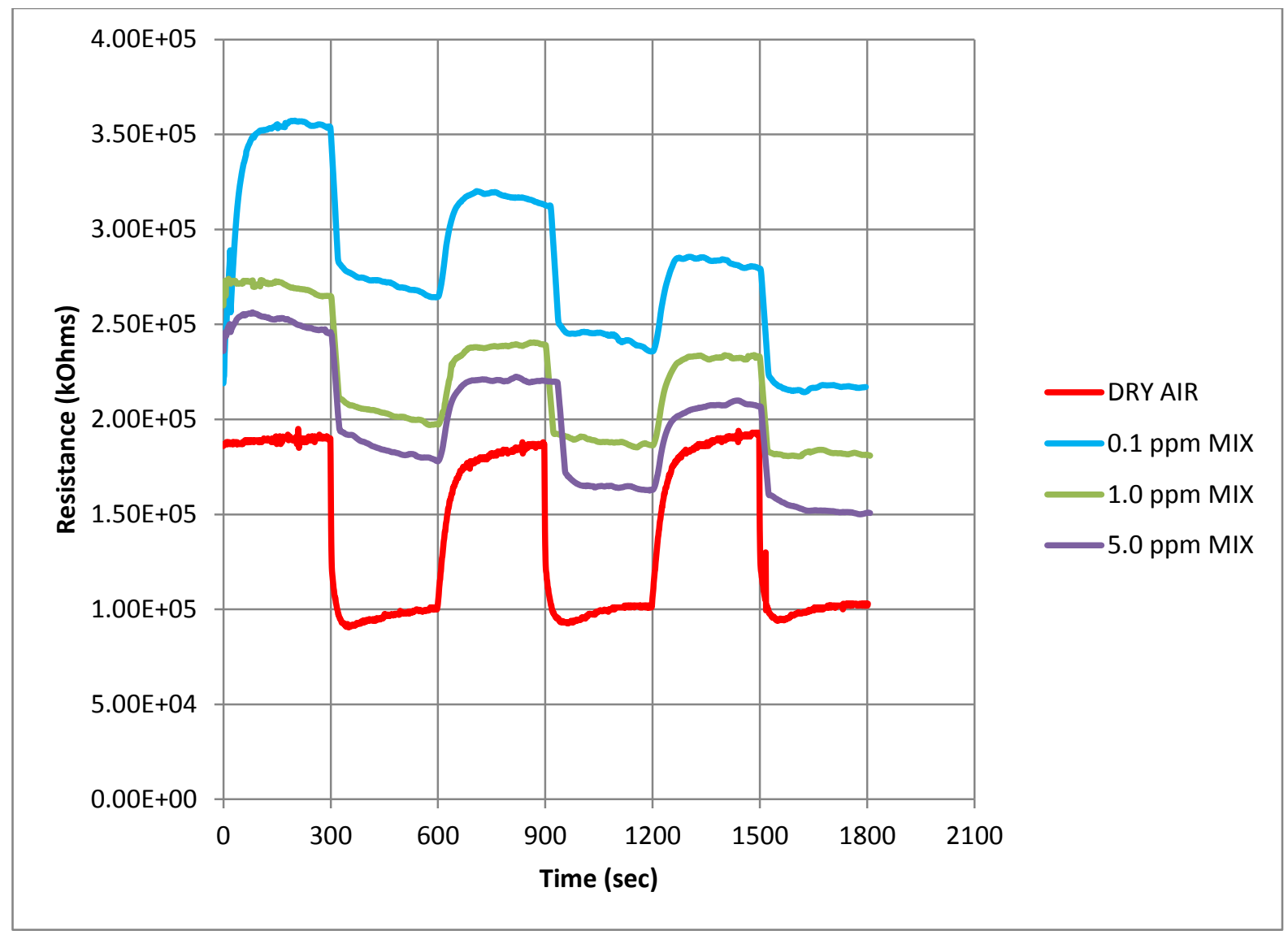

Figure 34: Chip 1C (1-Dodecanethiol $142 \mu$ moles: 0.049 grams Gold) Acetone-Ethanol Mix Resistance

In Figure 34, the trend of increasing VOC concentration increases resistance is not seen. The potential error could be the vacuum desorbing all the VOCs between each test. A component of further work can be to retest the ethanol and acetone-ethanol mix to better understand the phenomenon of resistance from adsorption. Relative to dry air the acetone-ethanol mix does have a good selectivity in Figure 35 despite not following the general trend. 


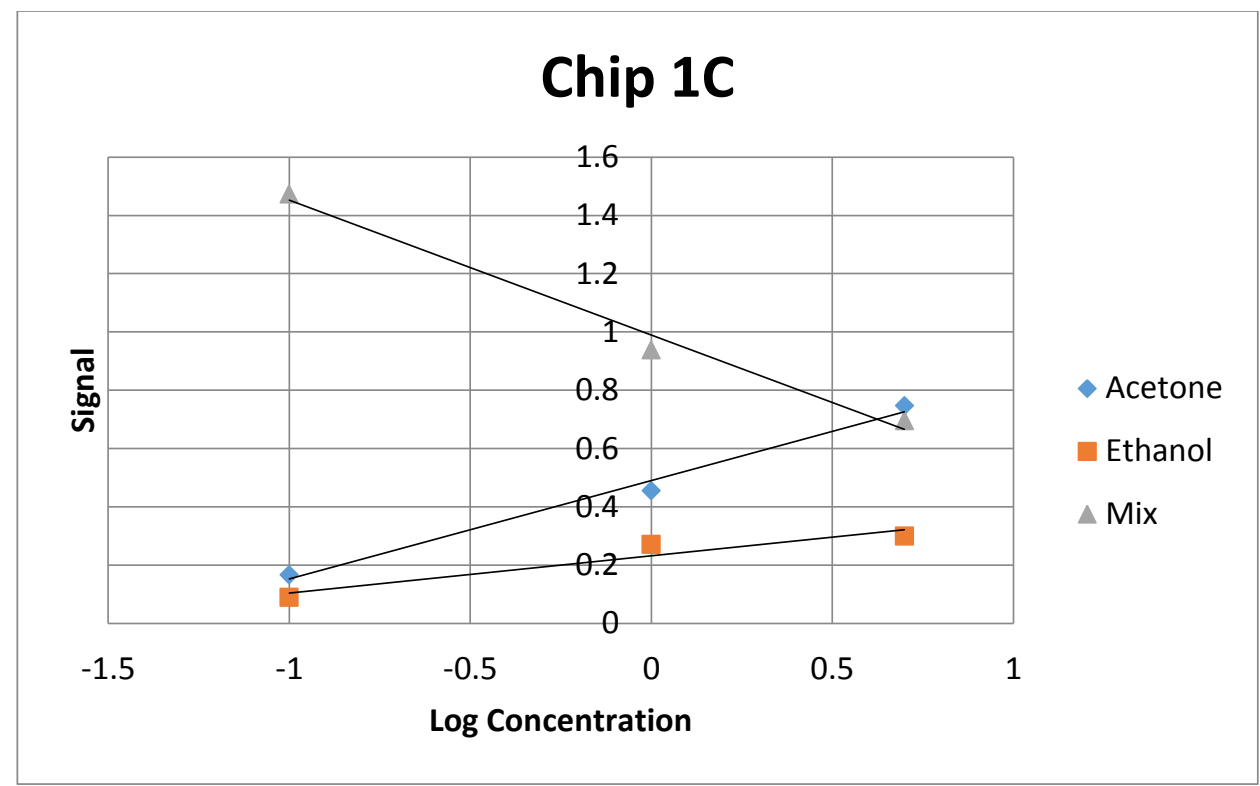

Figure 35: Chip 1C Signal

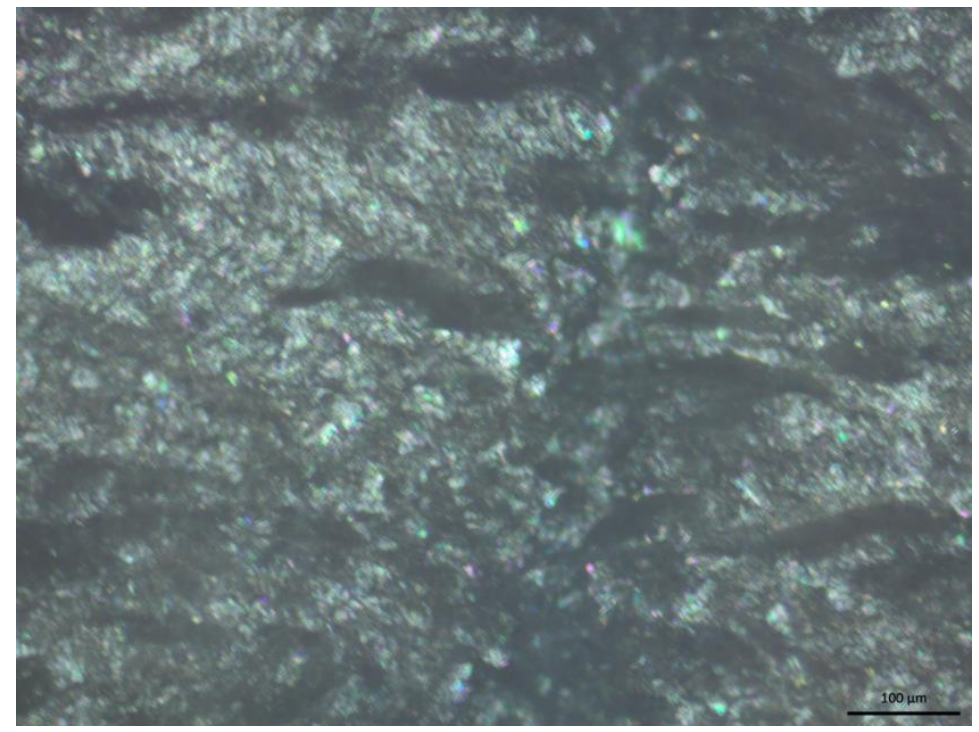

Figure 36: Chip 1C Gold Nanoparticles under 50x Magnification 


\subsubsection{Chip 2A (MATT and $57 \mu$ moles) Results}

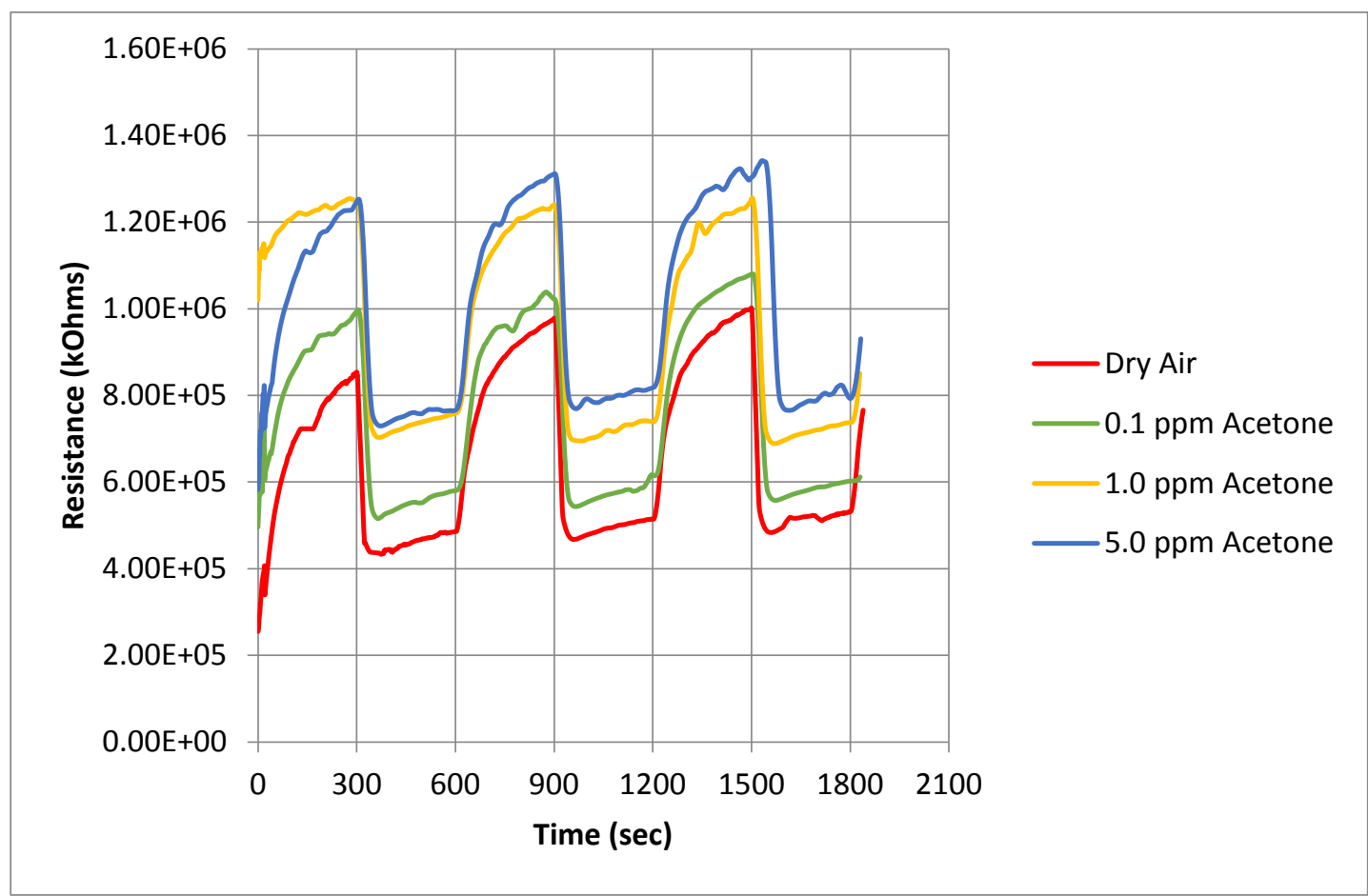

Figure 37: Chip 2A (MATT 57 moles: 0.049 grams Gold) Acetone Resistance

Chip 2A for acetone shows good changes in resistance between each concentration as it increases. The excellent changes in resistance are similar to chip 1C for use of detection of acetone. The ethanol tests in Figure 38 show decent results, except for the $0.1 \mathrm{ppm}$ resistances that move below the dry air sample. This could be due to residual VOCs or the 2A factor levels do not detect ethanol as well as other VOCs. The acetone-ethanol mix resistances show a strong increase as concentration increases. Chip $2 \mathrm{~A}$ could be very helpful in determining if an unknown sample is just acetone or acetone-ethanol mix. Both have strong, but different signal values in Figure 40. Chip 2A has great selectivity for acetone and the mixture. 


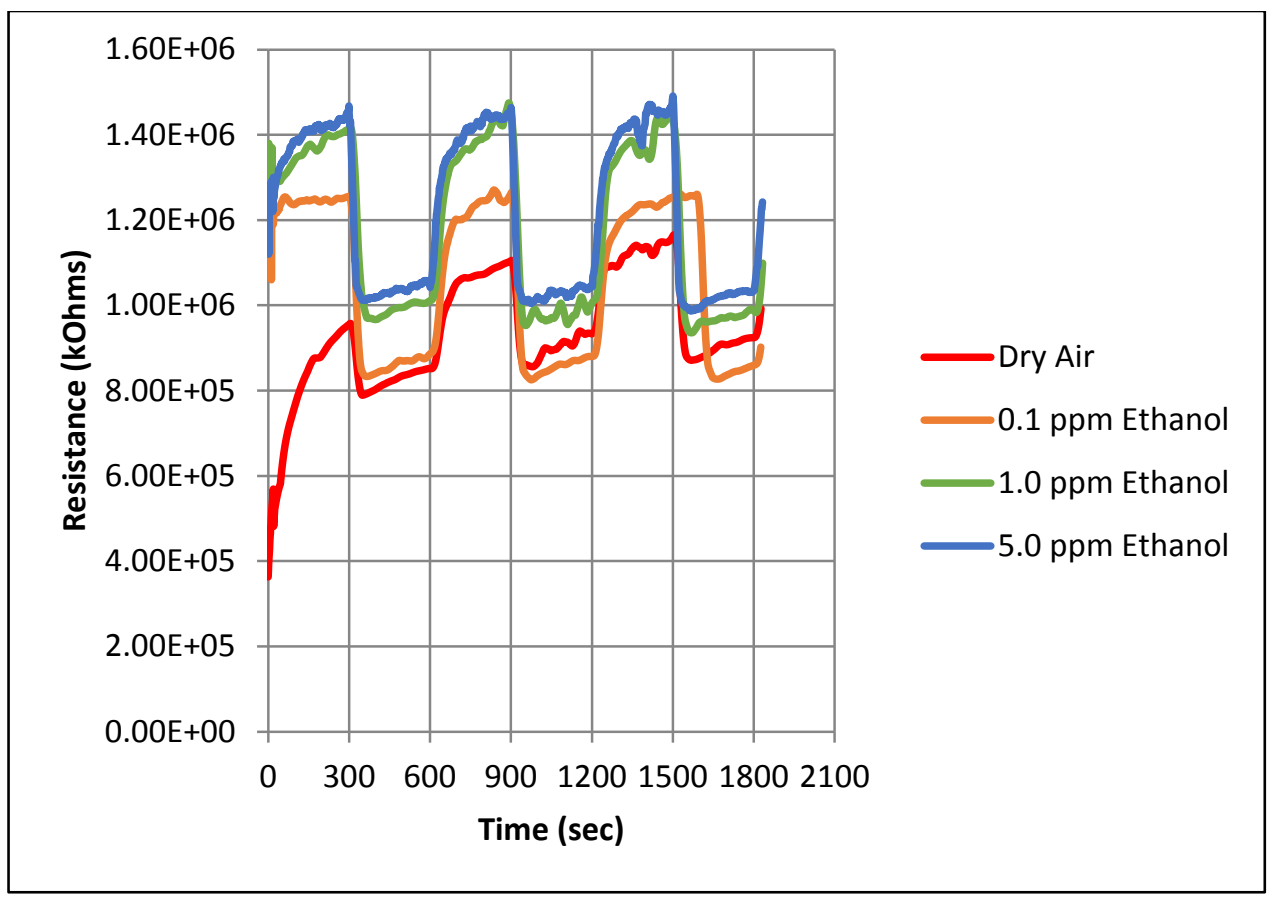

Figure 38: Chip 2A (MATT 57 mmoles: 0.049 grams Gold) Ethanol Resistance

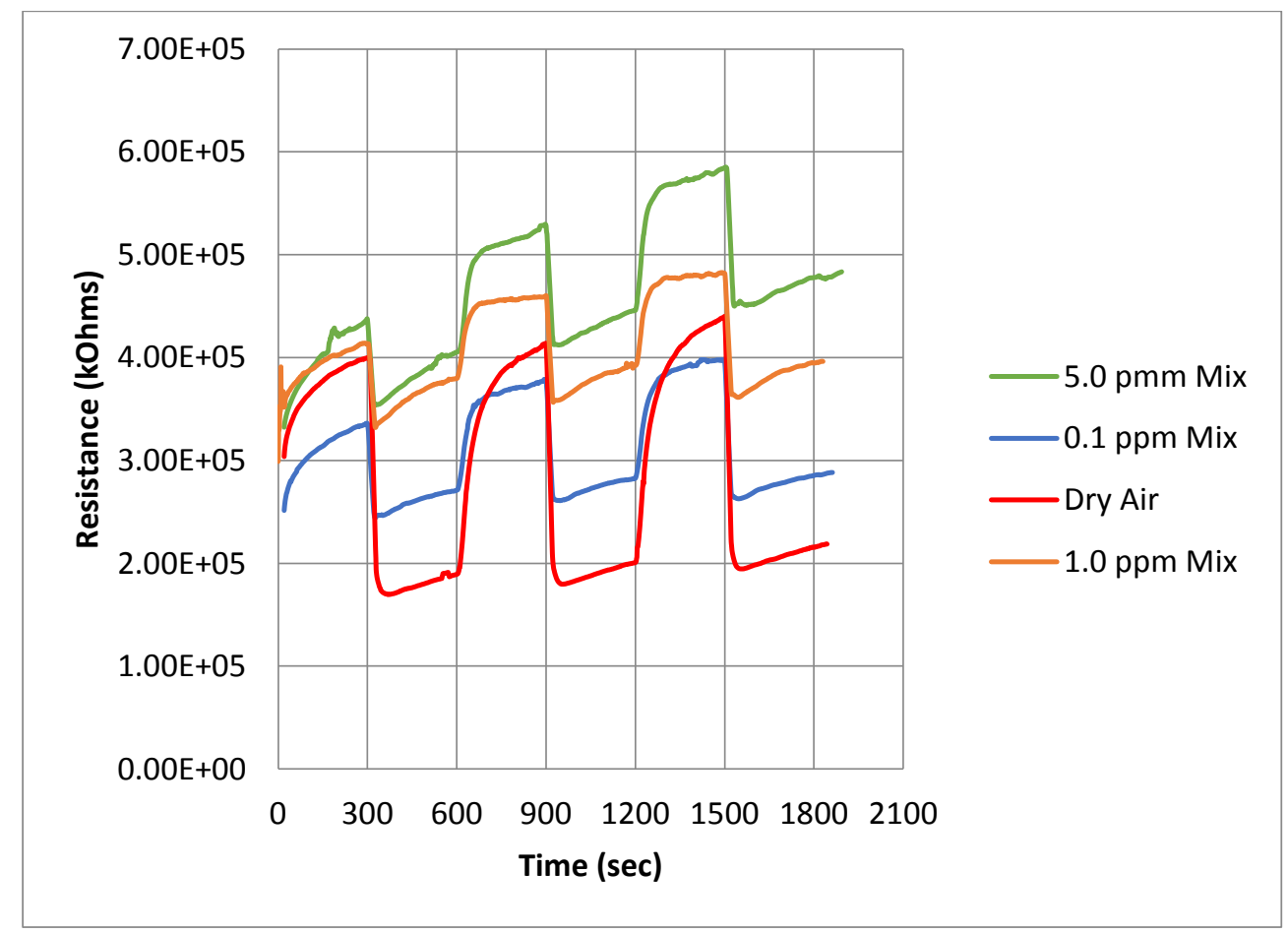

Figure 39: Chip 2A (MATT 57 moles: 0.049 grams Gold) Acetone-Ethanol Mix Resistance 


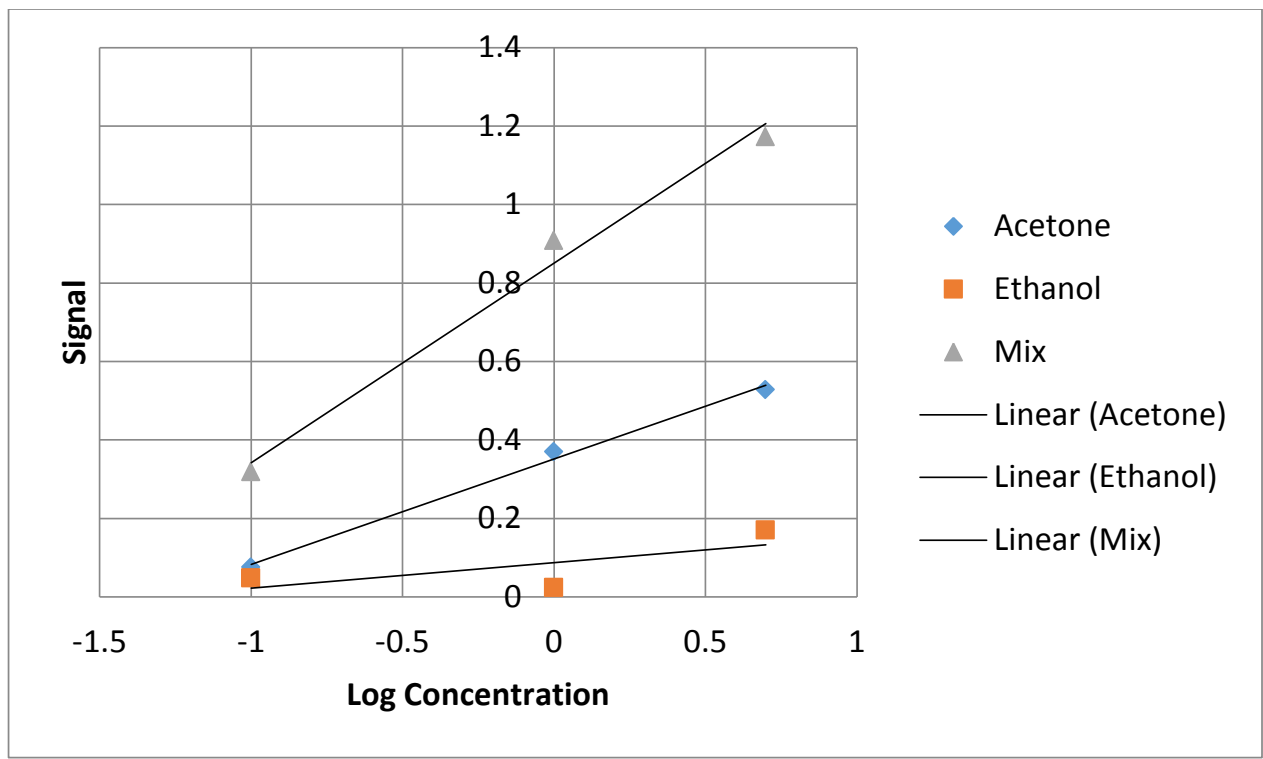

Figure 40: Chip 2A Signal

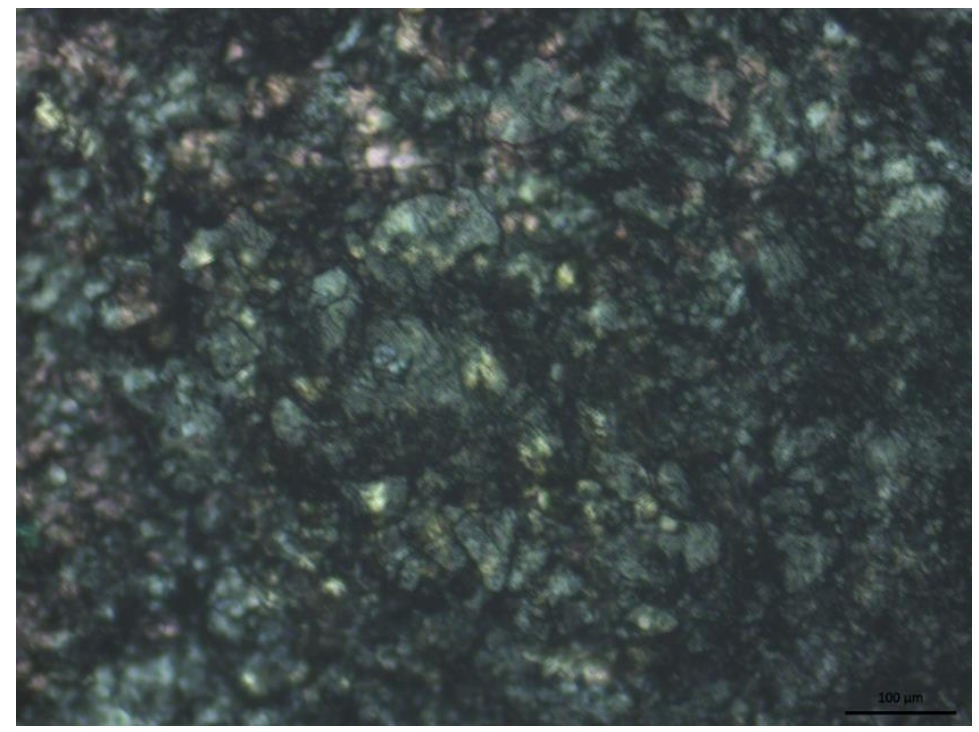

Figure 41: Chip 2A Gold Nanoparticles under 50x Magnification 


\subsubsection{Chip 2B (MATT and $114 \mu$ moles) Results}

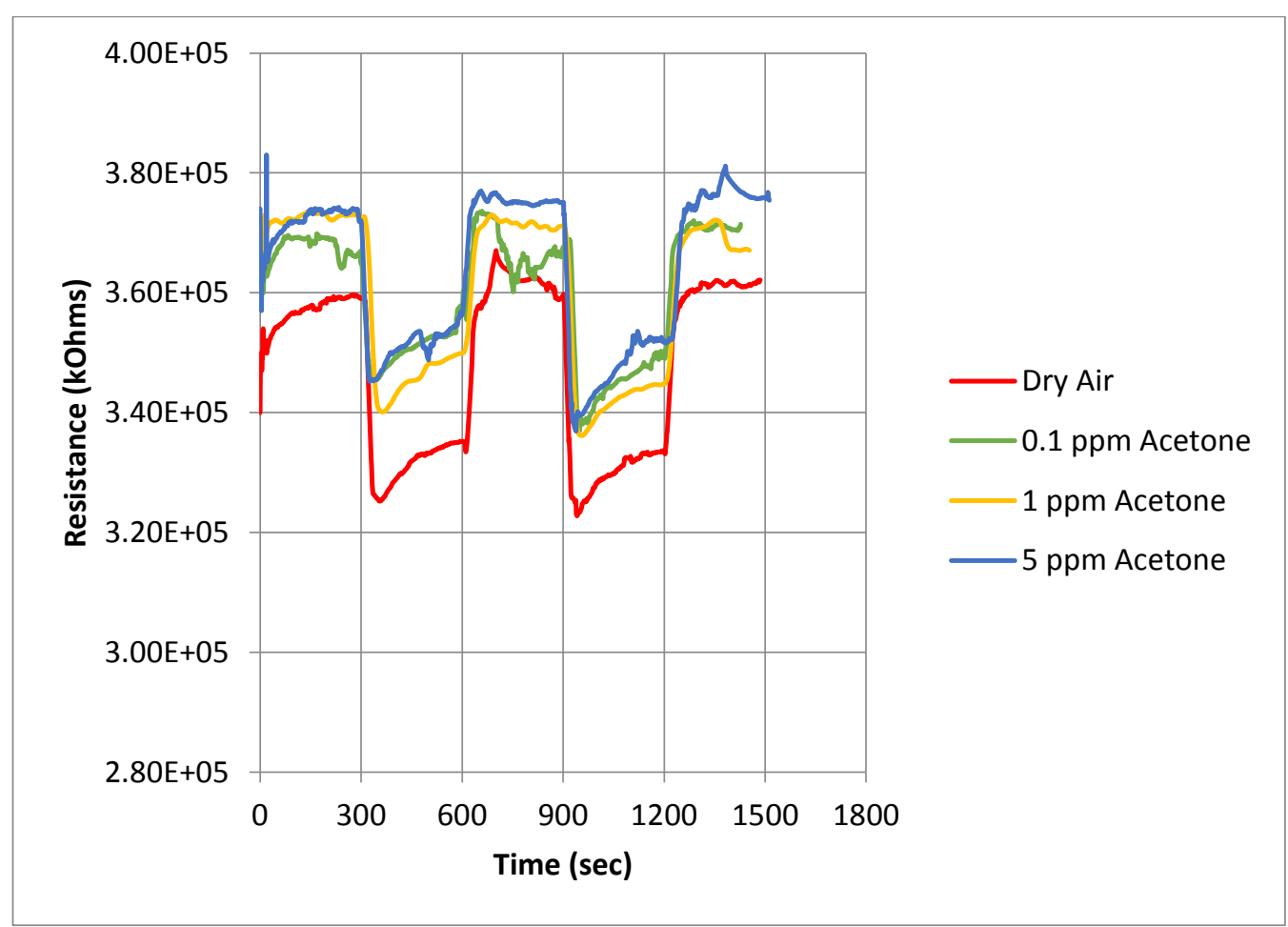

Figure 42: Chip 2B (MATT 114 umoles: 0.049 grams Gold) Acetone Resistance

Chip 2B of acetone shows a very small change in resistances with increasing concentration. Therefore the factor levels of $2 \mathrm{~B}$ are not as good as previous chips to detect acetone. 


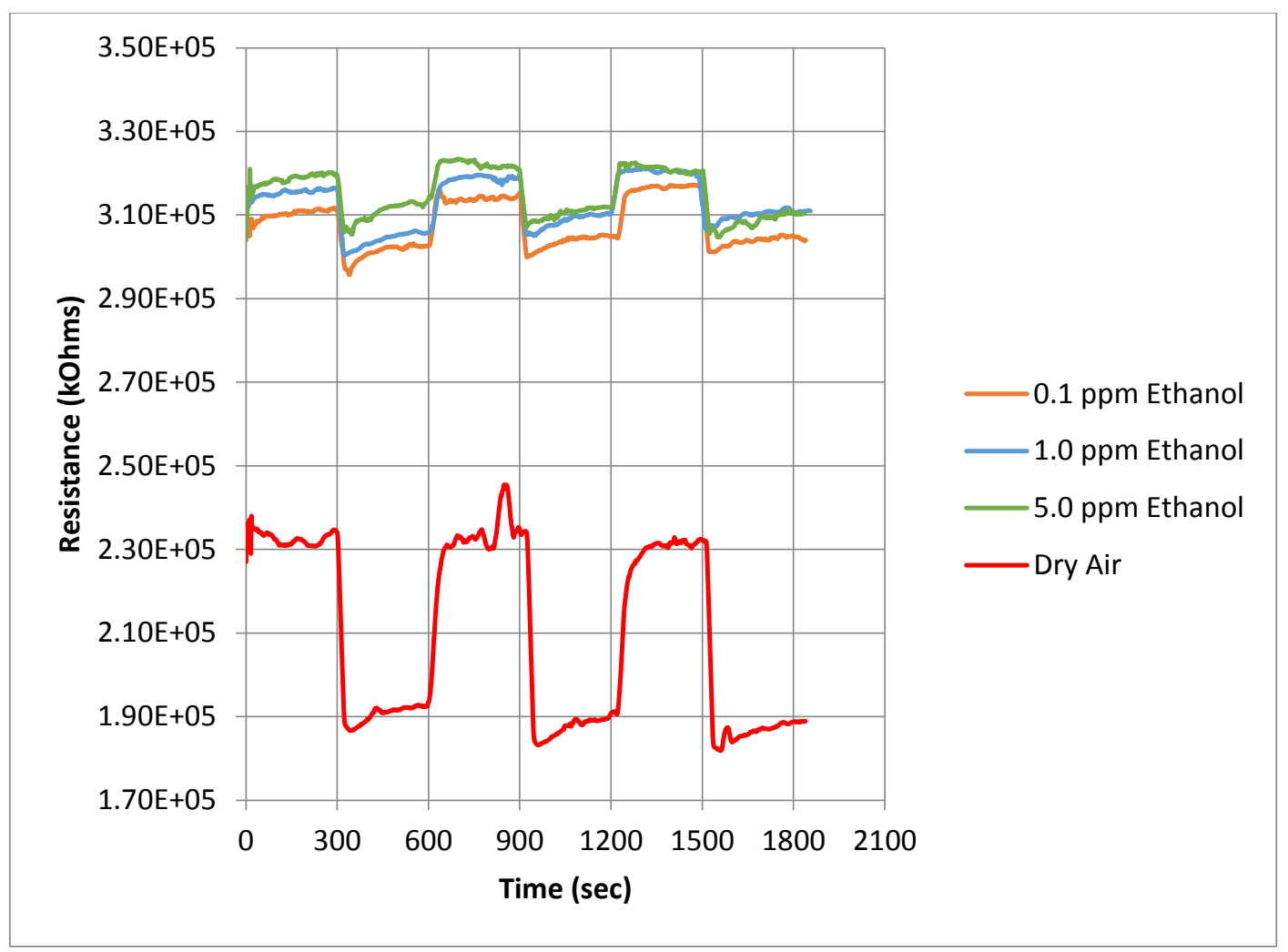

Figure 43: Chip 2B (MATT 114 umoles: 0.049 grams Gold) Ethanol Resistance

The ethanol results do not have a strong detection trend because the average resistances are very close. The ethanol results show a huge shift in resistance from dry air; which could be caused by poor desorption between tests. Chip 2B does not have good acetone or ethanol detection. The same trend appears in the acetone-ethanol mix in Figure 44. In Figure 45, the signal plot shows the low slope of each test results; which means it would be hard to determine an unknown concentration with chip $2 \mathrm{~B}$. 


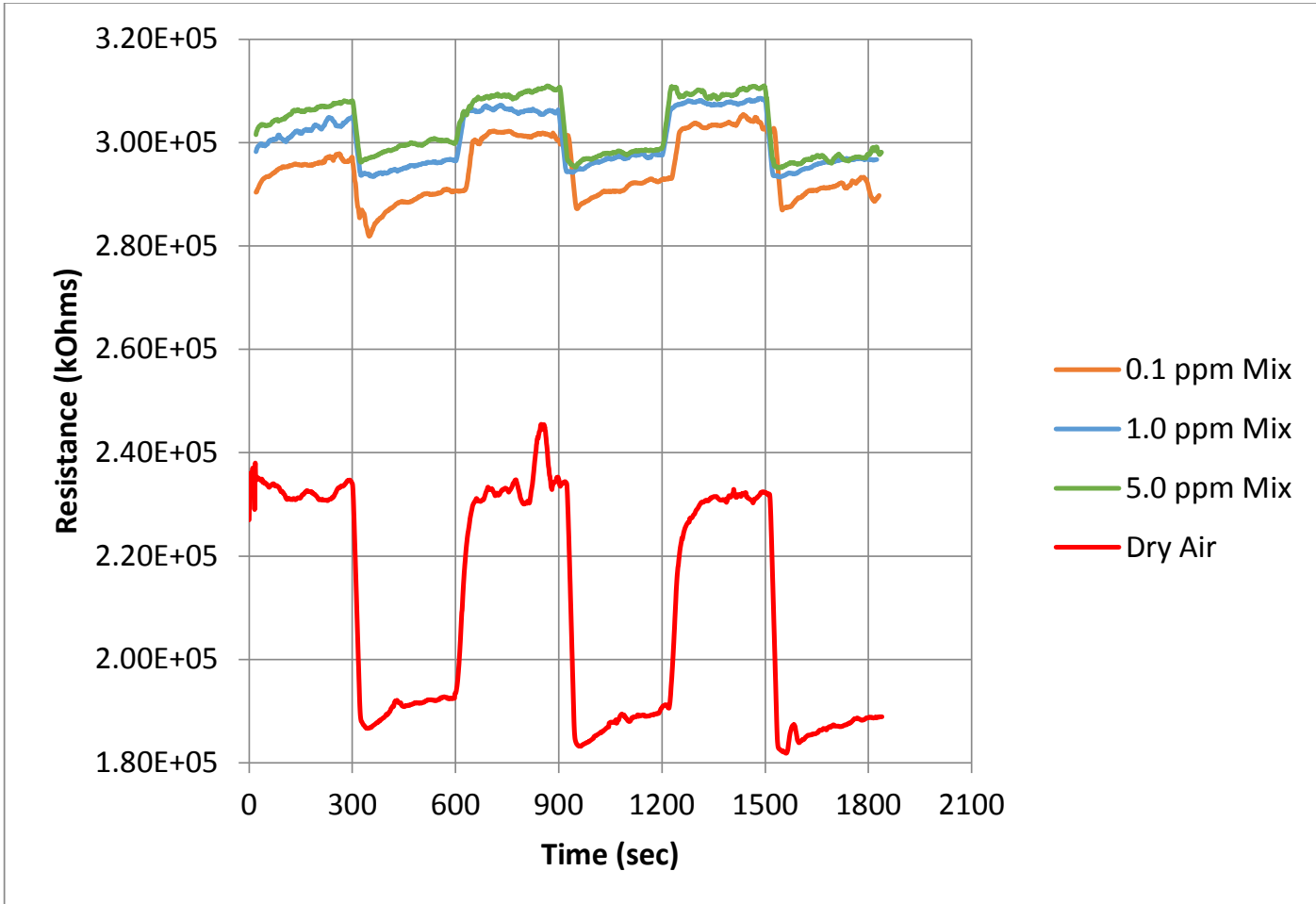

Figure 44: Chip 2B (MATT 114 umoles: 0.049 grams Gold) Acetone-Ethanol Mix Resistance

For chip 2B the issues of dry air resistance being very different than the samples is an interesting issue, like $1 \mathrm{C}$ ethanol and acetone-ethanol mix. For the ethanol test the dry air was run before testing the samples and the large resistance trend occurred. The further work section can investigate if re-running the ethanol and mixture trials can better show the selectivity of the sensor. The cause of this could be running the trials on separate days and therefore adding in the potential for different VOCs to not be completely desorbed by decreasing the pressure of the system. Chip 2B has low linear slopes for all VOCs. 


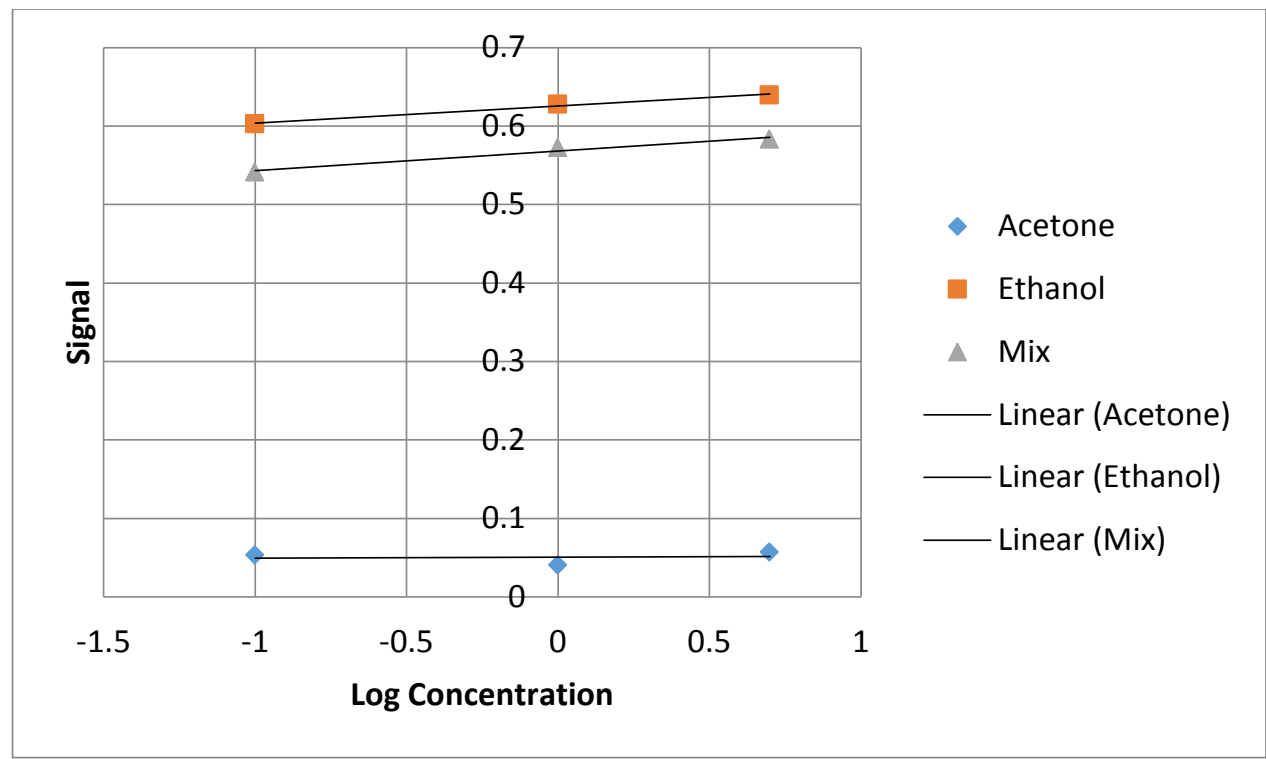

Figure 45: Chip 2B Signal

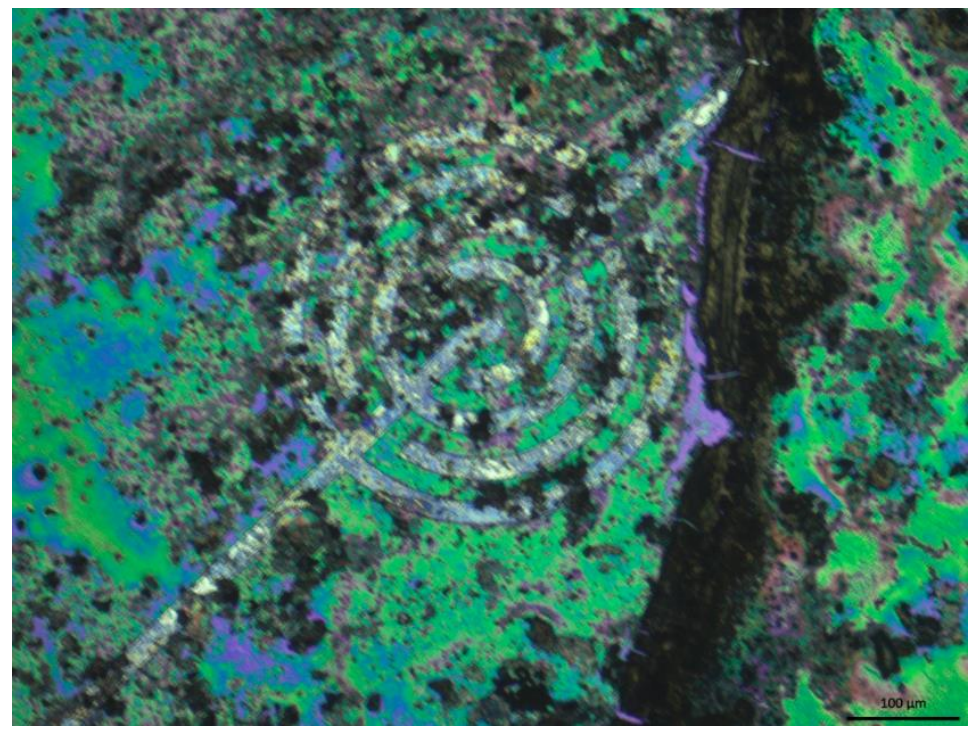

Figure 46: Chip 2B Gold Nanoparticles under 50x Magnification 


\subsubsection{Chip 2C (MATT and 228 rmoles) Results}

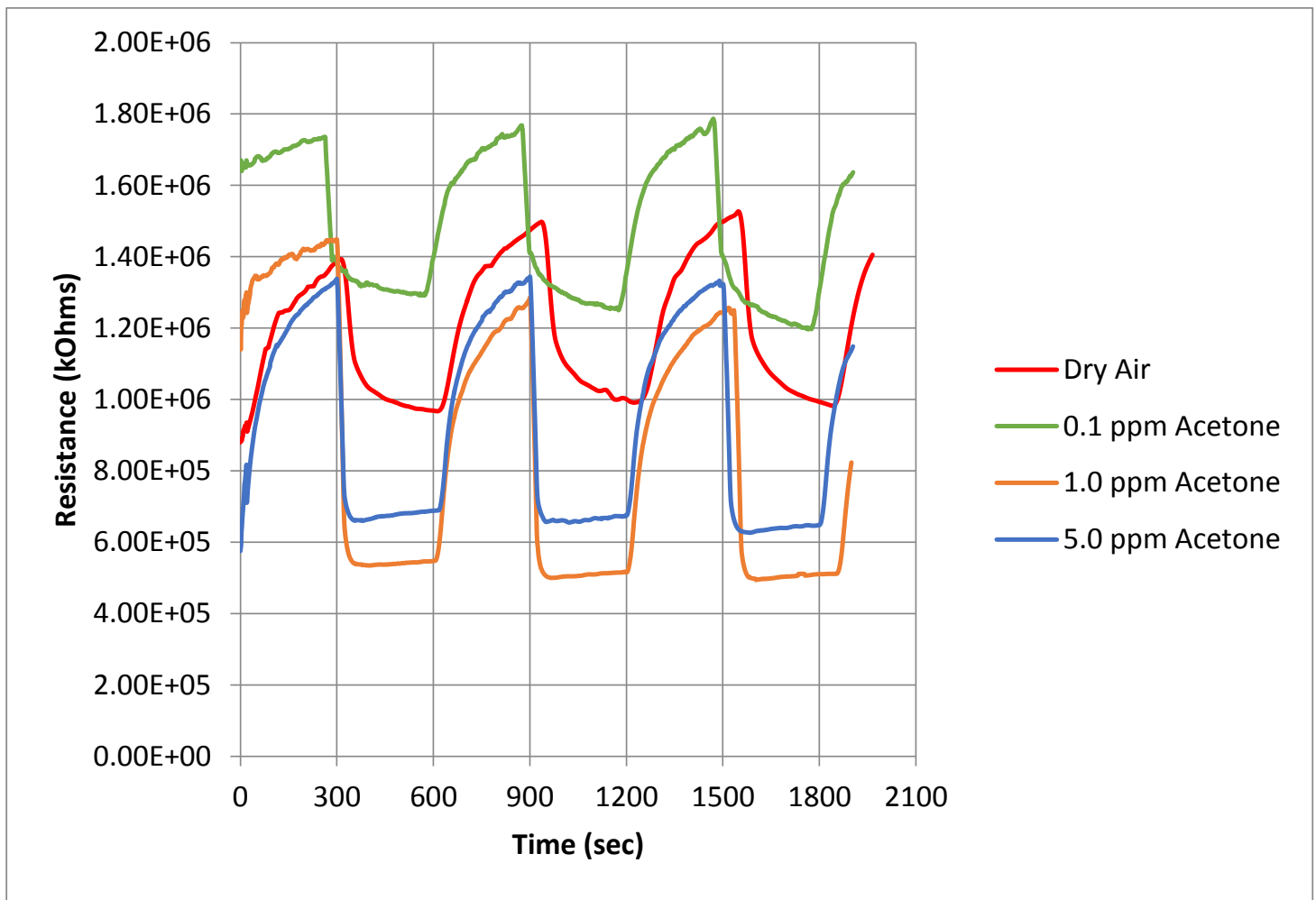

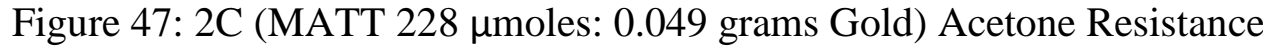

The results of the acetone resistance for chip $2 \mathrm{C}$ do not follow the trend of increasing resistance with increasing VOC concentration. There is a large difference between each concentration which is good however it is a poor fit because of the inconsistent trend. 


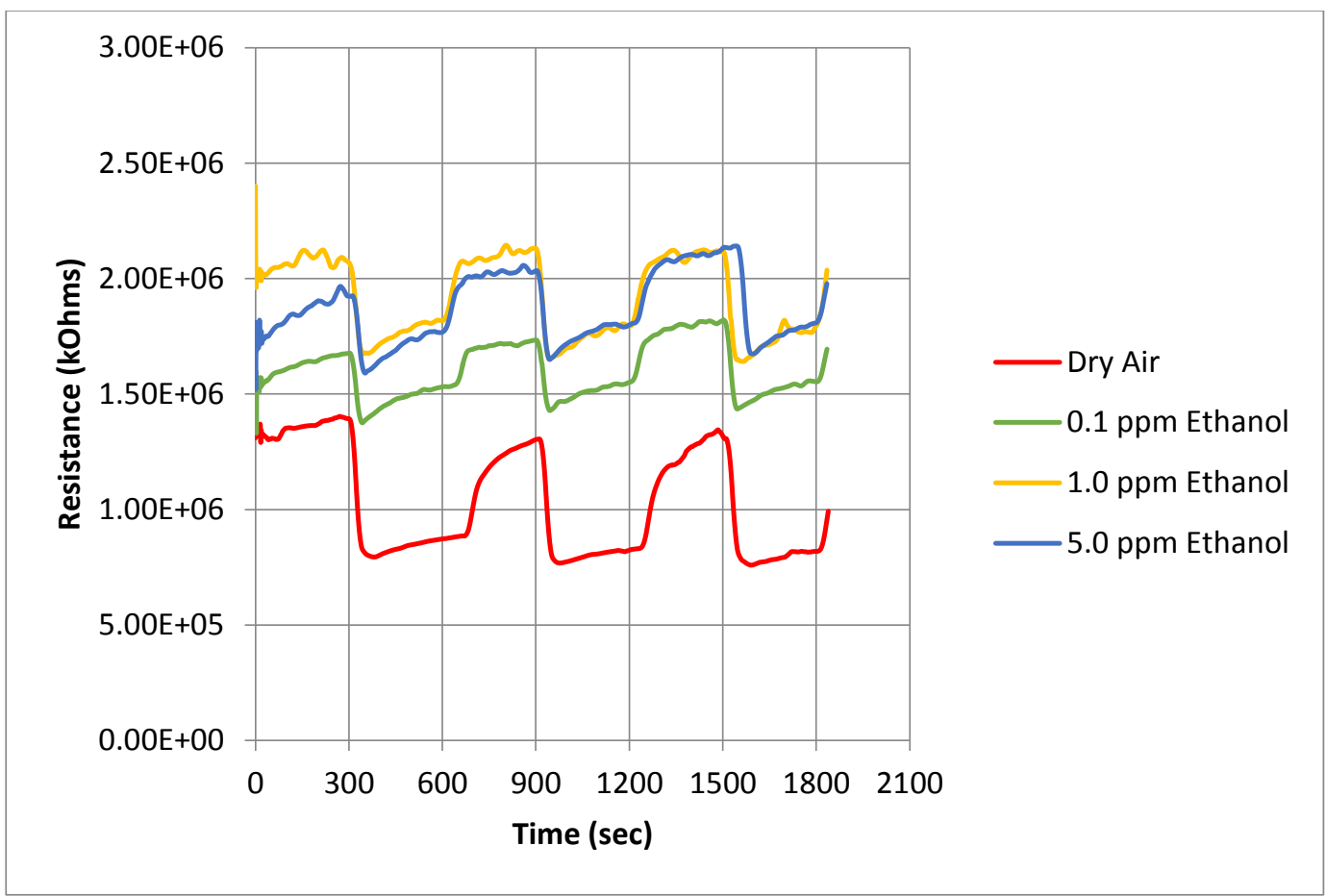

Figure 48: Chip 2C (MATT 228 moles: 0.049 grams Gold) Ethanol Resistance

The ethanol results have a good trend of increasing concentration with increasing resistance.

The 1.0 and $5.0 \mathrm{ppm}$ results are very close; the 0.1 is significantly lower therefore the overall results are strong. Ethanol is the strongest trend of the VOCs for chip $2 \mathrm{C}$. 


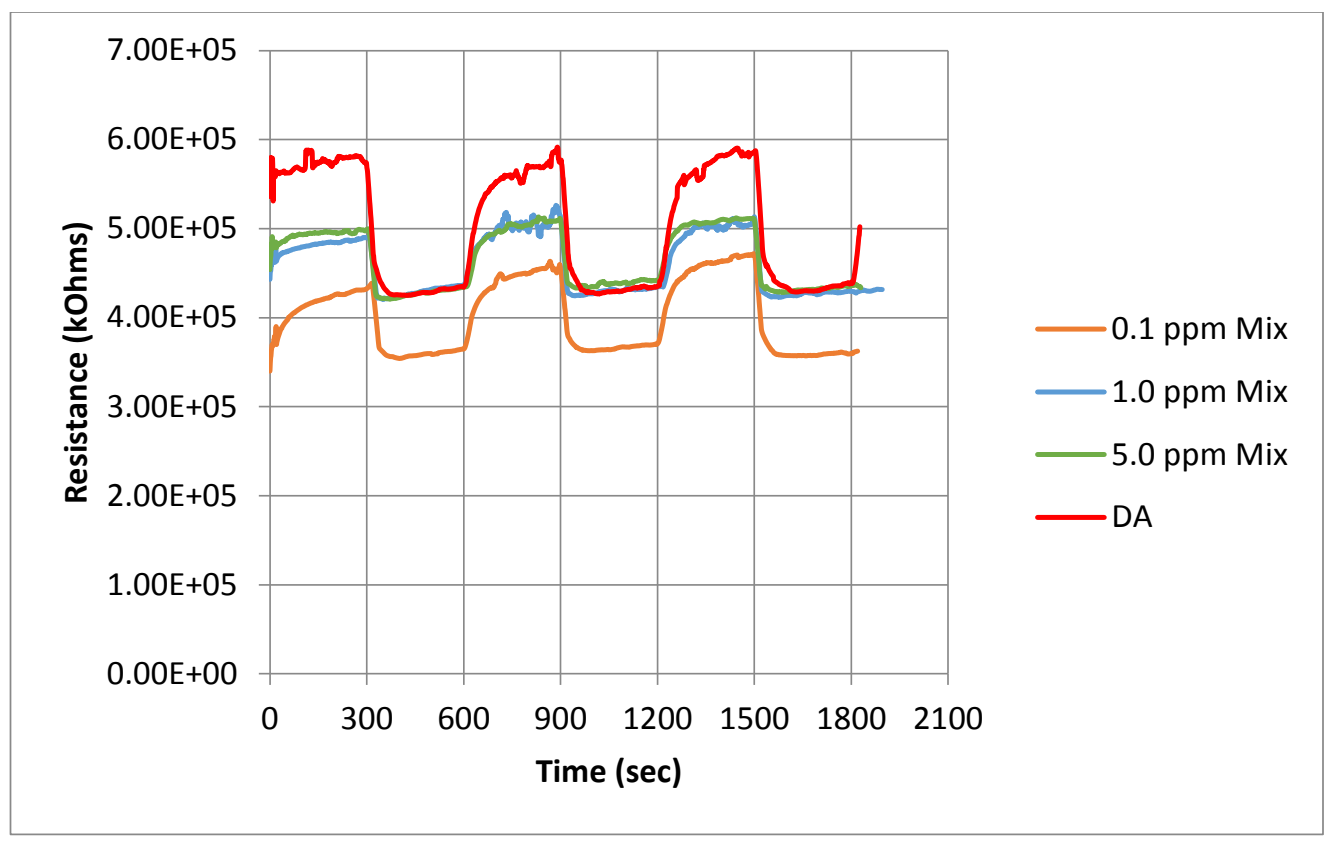

Figure 49: Chip 2C (MATT 228 umoles: 0.049 grams Gold) Acetone-Ethanol Mix Resistance

The acetone-ethanol mix results are weak like the acetone. The dry air resistances are very similar to the 1.0 and $5.0 \mathrm{ppm}$ tests. In Figure 50 the log plot shows the poor detection ability for the acetone-ethanol mix. The ethanol is the strongest results for chip $2 \mathrm{C}$.

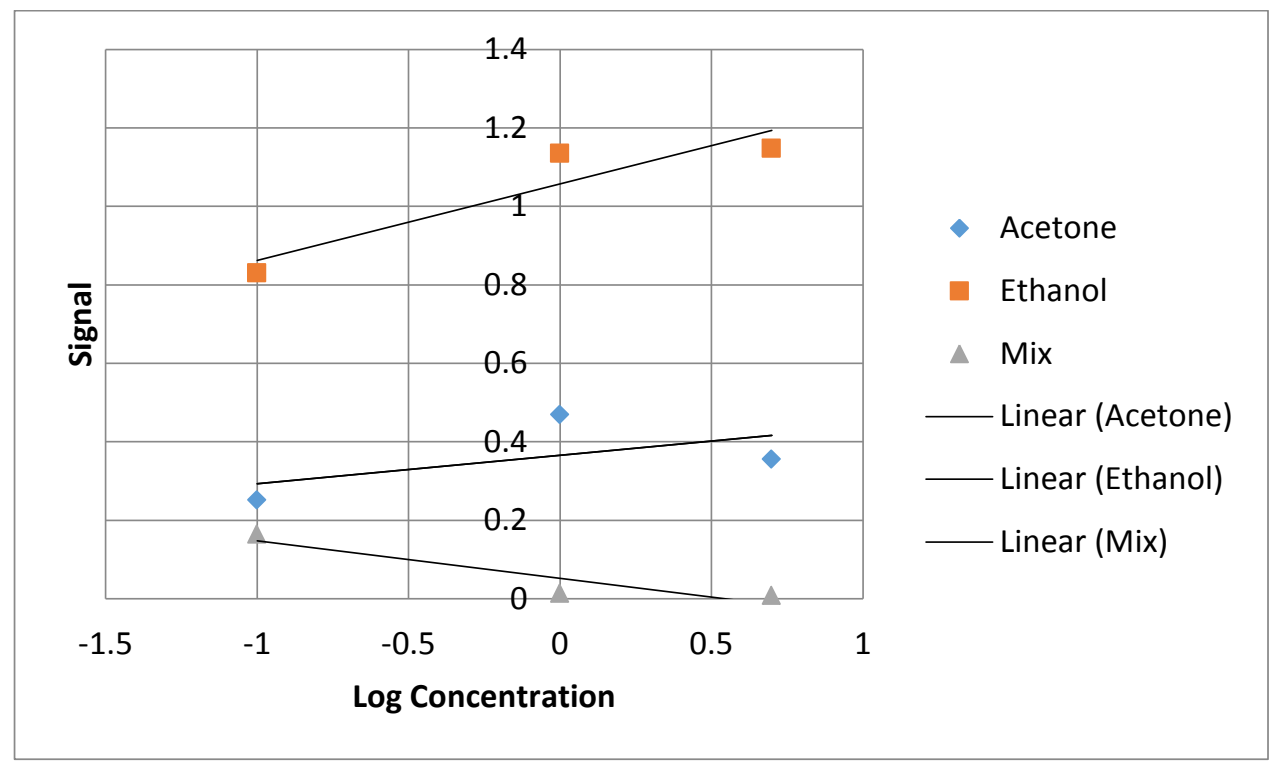

Figure 50: Chip 2C Signal 


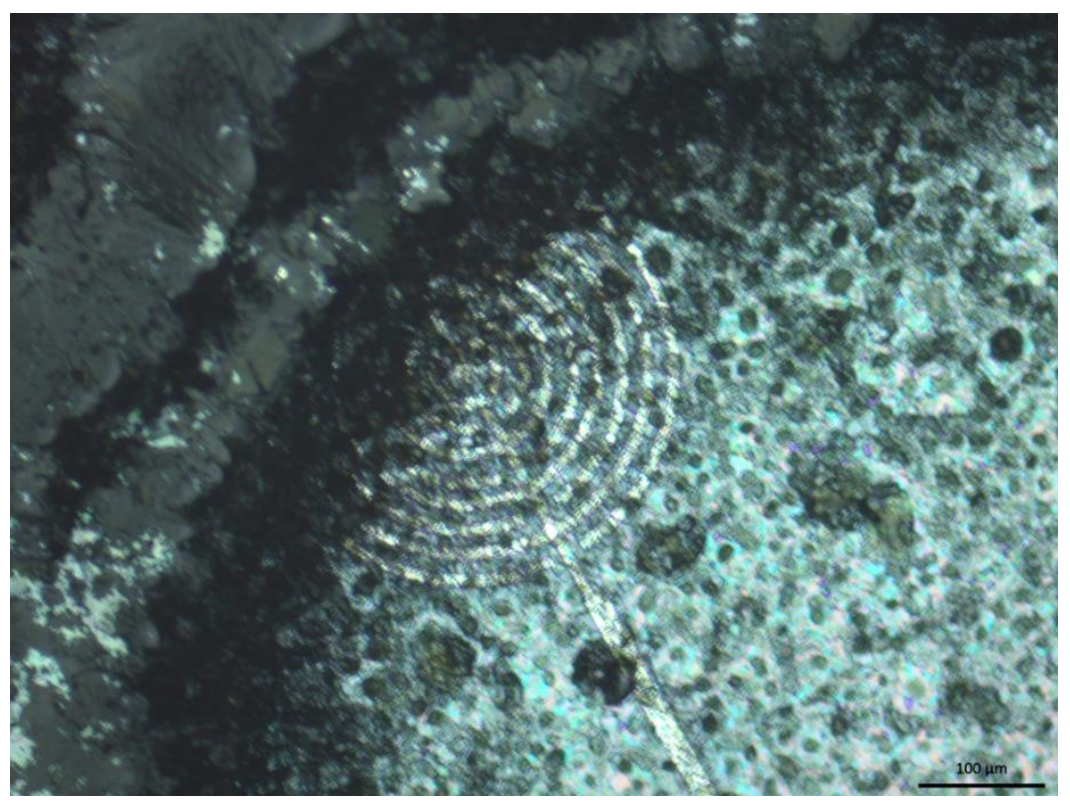

Figure 51: Chip 2C Gold Nanoparticles under 50x Magnification 


\subsection{Statistical Analysis}

Minitab statistical software is used to perform an analysis of variance (ANOVA) general linear model. The ANOVA will show statistically if there is a significant difference between the signal (resistance) values by changing the factor levels.

TABLE III

ANOVA Minitab Results

\begin{tabular}{|c|c|}
\hline Source & $\mathrm{B}$ \\
\hline Thiol & 0.000 \\
\hline Loading & 0.000 \\
\hline VOC & 0.000 \\
\hline Concentration (ppm) & 0.000 \\
\hline Thiol ${ }^{\star}$ Loading & 0.000 \\
\hline Thiol»VOC & 0.000 \\
\hline Thiol`Concentration (ppm) & 0.000 \\
\hline Loading ${ }^{\star}$ VOC & 0.000 \\
\hline Loading ${ }^{\star}$ Concentration (ppm) & 0.000 \\
\hline VoC ${ }^{\star}$ Concentration (ppm) & 0.062 \\
\hline Thiol*Loading*VoC & 0.000 \\
\hline Thiol`Loading Concentration (ppm) & 0.000 \\
\hline Thiol ${ }^{\star} \mathrm{VOC}^{\star}$ Concentration (ppm) & 0.171 \\
\hline Loading ${ }^{\star} \mathrm{VOC}^{\star}$ Concentration (ppm) & 0.000 \\
\hline Thiol ${ }^{\star}$ Loading ${ }^{\star}$ VoC $^{\star}$ & 0.00 \\
\hline Concentration (ppm) & \\
\hline tor & \\
\hline בה & \\
\hline
\end{tabular}

$\mathrm{S}=0.188605 \quad \mathrm{R}-\mathrm{Sq}=99.498 \quad \mathrm{R}-\mathrm{Sq}(\mathrm{adj})=99.238$

Table III shows all the individual factors (thiol, loading, VOC, and concentration) are statistically significant because the $\mathrm{P}$ values are zero; which is less than alpha (0.05). Alpha of 0.05 is a standard value for statistical analysis. The ANOVA R-squared value is excellent at $99.49 \%$. The ANOVA also checks significant interactions between the factors. The interactions are statistically significant, except $\mathrm{VOC} *$ Concentration and 
Thiol*VOC*Concentration because the $\mathrm{P}$ values are larger than 0.05 . The individual factor levels are statistically significantly in impacting the resistance of a sensor. For example Chip $2 \mathrm{~A}$ is the 0.5 loading and uses MATT and yields strong results for detecting acetone and the mixture of acetone and ethanol. The thiol interacting with the loading is a significant factor.

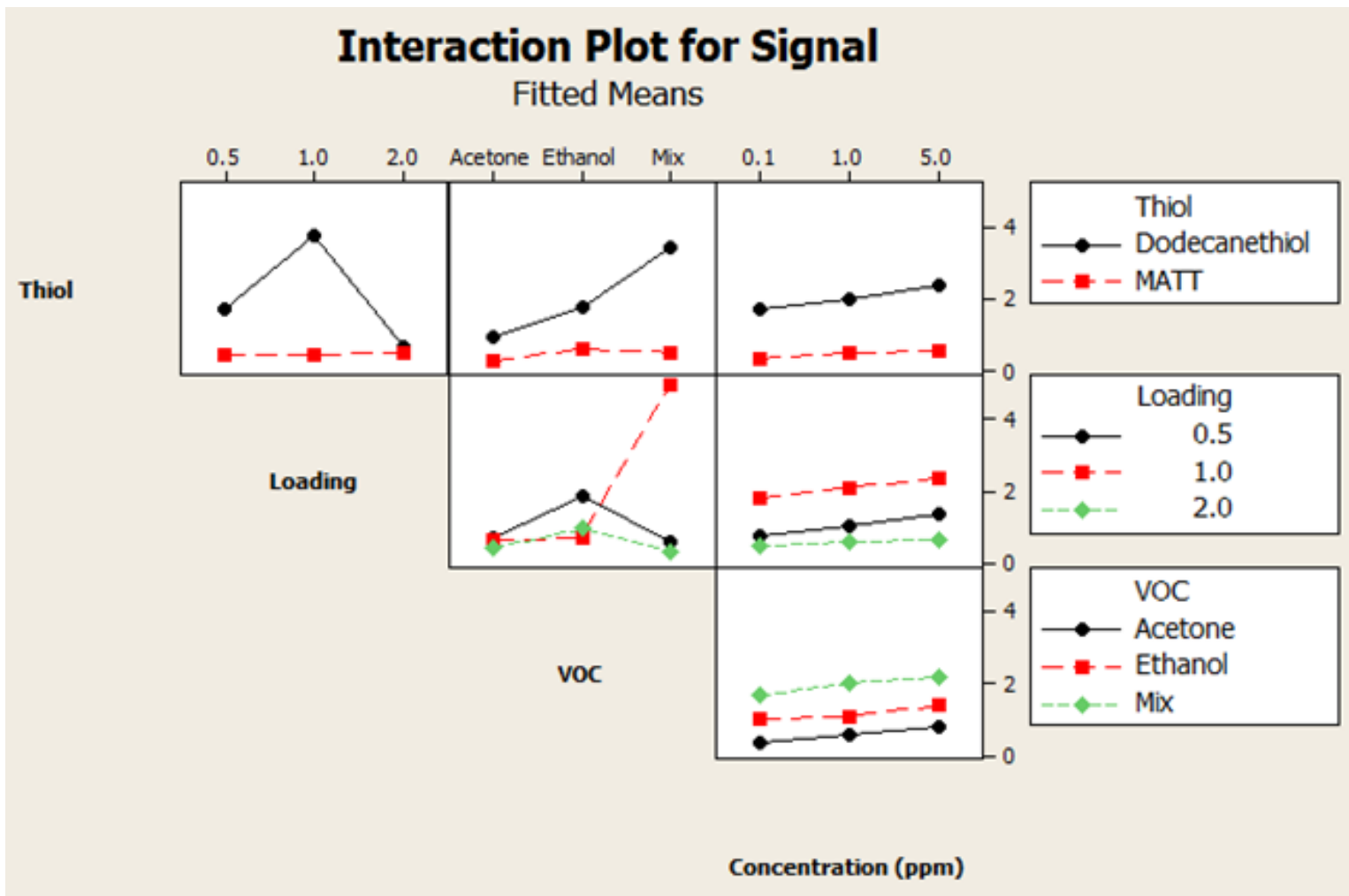

Figure 52: Minitab Interaction Plots for Signal Response

Figure 52 is an interaction plot of the factor levels tested. The y-axis is the average signal value. Each plot shows how the signal values change by the interaction of two factors. The plots help visualize the response of each sensor with respect to the factor interactions. For example the Thiol*Concentration interaction shows increasing concentration of the VOC increases the signal response. The VOC*Concentration plot is not statistically significant 
and therefore not an important interaction plot. The statistical analysis helps confirm the results by showing the statistical significance of the experimental factors.

\subsection{Predicting Unknown Concentrations}

For chips $1 \mathrm{C}, 2 \mathrm{~A}$, and $2 \mathrm{C}$ the signal linear trend lines can be used to determine an unknown concentration of a VOC based on the signal values calculated from the resistance data. Equation 23 is the general form of the trend line with $\mathrm{m}$ is the slope and $\mathrm{b}$ is the $\mathrm{y}$ intercept:

$$
\text { Concentration }=10^{\left(\frac{\text { Signal-b }}{m}\right)}
$$

For chip $1 \mathrm{C}$ acetone

$$
\text { Concentration }=10\left(\frac{\text { Signal-0.49 }}{0.34}\right)
$$

For chip 2A acetone

$$
\text { Concentration }=10\left(\frac{\text { Signal-0.35 }}{0.27}\right)
$$

For chip 2A mixture

$$
\text { Concentration }=10\left(\frac{\text { Signal-0.85 }}{0.51}\right)
$$

For chip 2C ethanol

$$
\text { Concentration }=10\left(\frac{\text { Signal-1.06 }}{0.19}\right)
$$

For $1 \mathrm{C}$ ethanol

$$
\text { Concentration }=10\left(\frac{\text { Signal-0.17 }}{0.12}\right)
$$




\section{CONCLUSIONS}

The log signal plots and the statistical analysis of the response data show strong evidence for thiol derivatized gold nanoparticle sensors to detect VOCs, especially acetone. The thiol derivatized gold nanoparticles are synthesized by a similar process to Brust's method and show successful preparation for the experiment.

The factor of thiol loading level does significantly change the response of the sensors. Both thiols, 1-Dodecanethiol and MATT, have high VOC selectivity sensors. Different loadings have better selectivity for different VOCs. The selectivity is based on the log plot slope and how the signal response is different for each concentration level. A large slope is desired. Chip 1C (142 $\mu$ moles of 1-Dodecanethiol to 0.049 g Gold) has very strong selectivity for acetone. Chip 2A (57 $\mu$ moles of MATT to $0.049 \mathrm{~g}$ Gold) has strong results for acetone and the acetone - ethanol mix. Chip 1A (35 $\mu$ moles of 1-Dodecanethiol to $0.049 \mathrm{~g}$ Gold) and Chip 2C (228 $\mu$ moles of MATT to $0.049 \mathrm{~g}$ Gold $)$ have good ethanol selectivity. The thiol and thiol molar volume loading are statistically different and optimize detection of VOCs.

The resistance of the vacuum portion is expected to stay relatively consistent across each gas sample. Most of the resistance tests do show this behavior; however some results have shifts in vacuum resistances. This could be a result of all the tests not being run on the same day and dry air not being run directly before one or two VOC samples. Also, the 
vacuum pump might not fully desorb the sensor between each sample because of the pump efficiency. The signal log graphs show the trend of increasing VOC concentration increases the signal response. The trend agrees with adsorption mechanics because there are more VOC molecules to adsorb to the chip to alter the resistance even more. 


\section{RECOMMENDATIONS AND FURTHER WORK}

The successful results of testing the thiol derivatized gold nanoparticles for VOCs under several factor levels opened up many new points of discussion and further consideration. The first recommendation is to synthesis gold nanoparticles with additional thiols, such as 2-propanethiol. Additional thiol sensors can be used to observe the effect of carbon chain length in the thiol derivatized gold nanoparticle sensors on the signal response. Next, test additional VOCs such as toluene and benzene for the current sensors to show the ability of the sensors to detect a larger variety of VOCs. Research group member, Zhenzhen Xie, is testing benzene and toluene for sensors already. A key recommendation is to look at the dry air resistance shifting issues seen in chips $1 \mathrm{~B}, 1 \mathrm{C}$, and $2 \mathrm{~B}$. The sensors can be retested for dry air and needed VOCs to investigate the large resistance differences between dry air and the samples. The vacuum pump efficiency could be a cause of the shifting in resistance. Also, test the sensors with human breath or unknown VOC concentrations. Exhaled breath samples can be used to test the trendline equations developed in Chapter 4.5 for three sensors which have the best selectivity results. 


\section{REFERENCES}

1. Brust, Mathias, Merryl Walker, Donald Bethell, David J. Schiffrin, and Robin Whyman. "Synthesis of Thiol-derivatised Gold Nanoparticles in a Two-phase Liquid-Liquid System." Journal of the Chemical Society, Chemical Communications 7 (1994): 801. Print.

2. Faraday, Michael. "Experimental Relations of Gold (and Other Metals) to Light." (1857): Print.

3. Gerfen, Kurt. 2012. Detection of Acetone in Air Using Silver Ion Exchanged ZSM-5 and Zinc Oxide Sensing Films. Master of Science thesis, University of Louisville.

4. Jian, Rih-Sheng, Rui-Xuan Huang, and Chia-Jung Lu. "A Micro GC Detector Array Based on Chemiresistors Employing Various Surface Functionalized Monolayer-protected Gold Nanoparticles." Elsevier (2011). Print.

5. Jung, Linda S., and Charles. T. Campbell. "Sticking Probabilities in Adsorption of Alkanethiols from Liquid Ethanol Solution onto Gold." The Journal of Physical Chemistry B 104.47 (2000): 11168-1178. Print.

6. Knight, Andrew. "Gas Adsorption." University of Florida, 15 Nov. 1996. Web. 5 Dec. 2013.

7. Kutuzov, S., J. He, R. Tangirala, T. Emrick, T. P. Russell, and A. Böker. "On the Kinetics of Nanoparticle Self-assembly at Liquid/liquid Interfaces." Physical Chemistry Chemical Physics 9.48 (2007): 6351. Print.

8. Lower, Stephen. "Free Energy: The Gibbs Function" 2010. Web. 2 Dec. 2013.

9. Milev, Stoyan. "Isothermal Titration Calorimetry: Principles and Experimental

Design." General Electric, 9 Jan. 2013. Web. 5 Dec. 2013.

10. Myers, Alan L. "Thermodynamics of Adsorption." 2004. Print.

11. Peng, G., M. Hakim, Y. Y. Broza, S. Billan, R. Abdah-Borynyak, A. Kuten, U. Tisch, and H. Haick. "Detection of Lung, Breast, Colorectal, Prostate Cancers from Exhaled Breath Using a Single Array of Nanosensors." British Journal of Cancer (2010): 542-51. Print. 12. Peng, Gang, Ulrike Tisch, Orna Adams, Meggie Hakim, Nisrean Shehada, Yoav Y. Broza, Salem Billan, Roxolyana Abdah-Bortnyak, Abraham Kuten, 
and Hossam Haick. "Diagnosing Lung Cancer in Exhaled Breath Using Gold Nanoparticles." Nature Nanotechnology 4.10 (2009): 66973. Print.

13. Prausnitz, J. M., Ruediger N. Lichtenthaler, and Edmundo Gomes De Azevedo. Molecular Thermodynamics of Fluid-phase Equilibria. Upper Saddle River, NJ: Prentice Hall PTR, 1999. Print.

14. Ravi, Venkataramanan, Jason M. Binz, and Rober M. Rioux. "Thermodynamic Profiles at the Solvated Inorganic-Organic Interface: The Case of Gold-Thiolate Monolayers." NANO Letters (2013). Print.

15. Schwamberger, Valentin, and Ferdinand P. Schmidt. "Estimating the Heat Capacity of the Adsorbate-Adsorbent System from Adsorption Equilibria Regarding Thermodynamic Consistency." Industrial \& Engineering Chemistry Research (2013). Print.

16. "Thermodynamics of Redox Reactions." Boundless. Creative Commons Attribution ShareAlike, Web. 2 Dec. 2013.

17. "Thermodynamics: Gibbs Free Energy." Texas A\&M University, Web. 1 Dec. 2013.

18. Tissue, Brian M. "More About Spontaneous Reactions." CHP. Virginia Tech University, 2000. Web. 5 Dec. 2013.

19. Tykodi, Ralph J. "Thermodynamics of Adsorption." The Journal of Chemical Physics (1953). Print.

20. Vörös, Nikoletta Molnár, Rita Patakfalvi, and Imre Dékány. "Alkylthiolfunctionalized Gold Nanoparticles for Sensing Organic Vapours: The Connection between the Adsorption Isotherm and the Sensor Resistance." Colloids and Surfaces A: Physicochemical and Engineering Aspects 329.3 (2008): 205-10. Print.

21. Walton, Krista S., and M. Douglas LeVan. "Adsorbed-Phase Heat Capacities: Thermodynamically Consistent Values Determined from Temperature-Dependent Equilibrium Models." Industrial \& Engineering Chemistry Research 44.1 (2005): 178-82. Print.

22. Wang, Jiaxu, and Joslyn Wood. "Standard Reduction Potential." UC DAVIS CHEMWIKI. UC DAVIS, Web. 2 Dec. 2013.

23. Wang, L., et al. "An Acetone Nanosensor For Non-Invasive Diabetes Detection." AIP Conference Proceedings 1137.1 (2009): 206208. Academic Search Premier. Print.

24. Wohltjen, Hank, and Arthur W. Snow. "Colloidal Metal-Insulator-Metal Ensemble Chemiresistor Sensor." Analytical Chemistry (1998). Print.

25. Zamborini, F. "Distance-dependent Electron Hopping Conductivity and Nanoscale Lithography of Chemically-linked Gold Monolayer 
Protected Cluster Films." Analytica Chimica Acta 496.1-2 (2003): 316. Print.

26. Zhang, H. L., and S. D. Evans. "Vapour Sensing Using Surface Functionalized Gold Nanoparticles." Nanotechnology (2002). Print. 


\section{CURRICULUM VITAE}

NAME:

ADDRESS:

DOB:

EDUCATION:

WORK EXPERIENCE:
Jared Stuart Stephens

6414 Quailwood Dr.

Floyds Knobs, IN 47119

June 7, 1990

B.S., Chemical Engineering University of Louisville 2009-2013

M.Eng., Chemical Engineering University of Louisville 2013-2014

SABIC Innovative Plastics

Engineering Co-op

2011-2012

University of Louisville

Research Assistant

2012-2014 